\title{
FABIANA CORDEIRO DE ARAUJO
}

\section{Doença de Wilson:}

\section{a experiência de seis décadas no HC-FMUSP}

\author{
Dissertação apresentada à Faculdade de Medicina \\ da Universidade de São Paulo para obtenção do \\ título de Mestre em Ciências \\ Programa de Ciências em Gastroenterologia \\ Orientador: Prof. Dr. Eduardo Luiz Rachid Cançado
}

São Paulo

2012 
Dados Internacionais de Catalogação na Publicação (CIP)

Preparada pela Biblioteca da

Faculdade de Medicina da Universidade de São Paulo

Creprodução autorizada pelo autor

Araujo, Fabiana Cordeiro

Doença de Wilson : a experiência de seis décadas no HC-FMUSP / Fabiana

Cordeiro de Araujo. -- São Paulo, 2012.

Dissertação(mestrado)--Faculdade de Medicina da Universidade de São Paulo.

Programa de Ciências em Gastroenterologia.

Orientador: Eduardo Luiz Rachid Cançado.

Descritores: 1.Doença de Wilson 2.Diagnóstico 3.Tratamento 4.Evolução clínica

USP/FM/DBD-288/12 
A todos pacientes portadores da doença de Wilson e a seus familiares 


\section{AGRADECIMENTOS}

Ao analisar a minha caminhada nesses três anos de pós-graduação, surpreendo-me ao lembrar-me da transformação que se fez em tão pouco tempo, não porque já saiba o necessário, penso que ainda estou distante disso, mas por ter despertado para pesquisa científica. Neste processo de construção muitos foram fundamentais e dedico a estes a minha sincera gratidão:

\section{A Deus...sempre}

Aos meus pais Francisco de Araujo Tomé e Maria Cordeiro de Lima, pela minha vida e por proporcionar estrutura necessária para o início da caminhada acadêmica

Aos meus irmãos e sobrinhos, pelo apoio e carinho

A Dra Marta Mitiko Deguti, sinônimo e espelho de profissionalismo, por seu constante estímulo à pesquisa, primando pela excelência aliada à integridade e a verdade científica. Pelo acolhimento ao chegar a esta universidade, e por toda inestimável ajuda na confecção desse trabalho e enfim pela sua amizade Ao Professor Dr Eduardo Luiz Rachid Cançado, minha imensurável gratidão pelo acolhimento e viabilização desse trabalho, pelo exemplo impar de dedicação a todos os pacientes e pesquisador, e pelo pioneirismo no estudo da doença de Wilson na Hepatologia do HC-FMUSP Ao Professor Dr Egberto Reis Barbosa e Dr Alexandre Aluízio Costa Machado por brilhantemente prosseguirem no estudo dessa doença, incentivando e apoiando os novos pesquisadores 
Aos meus queridos companheiros de ambulatório e laboratório Andréia Evangelista da Silva, Clarice Lemos Abrantes, Débora Raquel Benedita Terrabuio, Fabrício Guimarães, Kátia Oliveira, Maria Cristina Nackle, Michele Harriz e Thiago Ferreira de Araújo, pela amizade e apoio

A secretária Fabiana Soares, pelo suporte e carinho concedidos aos pósgraduandos

Aos professores da graduação do curso de Medicina da Universidade Federal do Rio Grande do Norte, início de tudo

Aos funcionários do SAME, particularmente a senhora Mercês de Fátima Fonseca Silva, pelo dinamismo e atenção dedicados ao seu trabalho Aos funcionários da biblioteca da FMUSP pelo compromisso e profissionalismo A todos os médicos assim como todos os demais profissionais que atenderam os pacientes com doença de Wilson nos serviços de Hepatologia, Hepatologia pediátrica, Neurologia e Transplante do fígado do HC-FMUSP 


\section{LISTA DE ABREVIATURAS E SÍMBOLOS}

ATP: Adenosina trifosfato

AST: Aspartato aminotransferase

ALT: Alanina aminotransferase

BAL: British anti-lewisite

CAPPesq: Comissão para Análise de Projetos de Pesquisa

Cp: Ceruloplasmina

Cu: Cobre

d: Dia

$\mathrm{dL}$ : Decilitro

DPA: d- Penicilamina

Dr: Doutor

DW: Doença de Wilson

EDTA: Ácido etileno diamina tetra acético

ELISA: Enzyme Linked Immunosorbent Assay

et al: e outros

FAN: Fator anti-nuclear

$\mu \mathrm{g}$ : Micrograma

$\mathrm{g}$ : Grama

$\gamma$ GT: Gama glutamil transferase

GSH: Glutationa

h: Hora

Hb: Hemoglobina

HC-FMUSP: Hospital das Clínicas da Faculdade de Medicina da Universidade de São Paulo

hCTR1: Human copper transporter1

$\mathrm{Ht}$ : Hematócrito

ID: Idade

INR: International Normalized Ratio

$\mathrm{kg}$ : Quilograma

LSN: Limite superior de normalidade 
mg: Miligrama

$\mathrm{mm}$ : Milímetros

MT: Metalotioneína

MTHFR: Metilenotetrahidrofolato redutase

TC: Tomografia computadorizada

RNM: Ressonância nuclear magnética

TAP: Tempo de atividade da protrombina

XLSN: Número de vezes acima do limite superior de normalidade

$\%$ : Porcentagem

>: Maior que

$<$ : Menor que

$=$ : Igual 
SUMÁRIO 


\section{SUMÁRIO}

LISTA DE ABREVIATURAS E SÍMBOLOS

LISTA DE TABELA

RESUMO

SUMMARY

1

INTRODUÇÃO

1.1 Aspectos Gerais

2

$1.2 \quad$ Histórico 3

1.3 Homeostase do cobre e ATP7B

5

$\begin{array}{lll}1.4 & \text { Patogenia } & 8\end{array}$

1.5 Diagnóstico 12

$\begin{array}{lll}1.6 & \text { Tratamento } & 20\end{array}$

$\begin{array}{lll}1.7 & \text { Justificativas } & 24\end{array}$

2 Objetivos gerais $\quad 29$

$\begin{array}{lll}2.1 & \text { Objetivos específicos }\end{array}$

$3 \quad$ CASUÍSTICA E MÉTODOS 31

$\begin{array}{lll}3.1 & \text { Casuística } & 31\end{array}$

3.1.2 Tamanho da amostra 31

$\begin{array}{lll}\text { 3.1.3 Aspectos éticos } & 31\end{array}$

$3.2 \quad$ Métodos 32

3.2.1 Critérios de inclusão e exclusão 32 
3.2.1.2 Critérios de exclusão

3.2.2 Obtenção dos dados

3.2.2.1 Dados Demográficos

3.2.2.2 Dados clínicos

3.2.2.2.1 Formas clínicas de apresentação

3.2.2.2.2 Outros órgãos envolvidos

3.2.2.3 Dados laboratoriais

3.2.2.4 Estudo anátomo-patológico hepático

3.2.2.5 Estudos de imagens

3.2.2.6 Genotipagem do ATP7B 40

3.2.2.7 Avaliação do tratamento e seguimento 40

$\begin{array}{lll}\text { 3.2.3 Análise estatística } & 41\end{array}$

$4 \quad$ RESULTADOS 44

$\begin{array}{lll}4.1 & \text { Casuística } & 44\end{array}$

$\begin{array}{lll}4.2 & \text { Aspectos demográficos } & 45\end{array}$

4.3 Aspectos clínicos, laboratoriais e estudos de imagens 48

$\begin{array}{lll}\text { 4.3.1 } & \text { Aspectos clínicos } & 48\end{array}$

$\begin{array}{lll}\text { 4.3.2 } & \text { Aspectos laboratoriais } & 53\end{array}$

$\begin{array}{lll}\text { 4.3.3 } & \text { Estudos de imagens } & 58\end{array}$ 
4.4 Estudo anatomopatológico hepático 59

$\begin{array}{lll}4.5 & \text { Genotipagem ATP7B } & 60\end{array}$

$\begin{array}{lll}4.6 & \text { Tratamento e seguimento }\end{array}$

$\begin{array}{lll}5 & \text { DISCUSSÃO } & 73\end{array}$

6 CONCLUSÕES/ CONSTATAÇÕES MAIS RELEVANTES 103

$\begin{array}{lll}7 & \text { ANEXOS } & 106\end{array}$

$8 \quad$ REFERÊNCIAS BIBLIOGRÁFICAS 128 


\section{LISTA DE TABELAS}

Tabela 1 Sumário das séries descritas de DW 24

Tabela 4.1 Distribuição por décadas, idade e tempo de 45

atraso no diagnóstico dos 258 pacientes com

DW

Tabela 4.3 Manifestações clínicas iniciais de 259

pacientes

com doença de Wilson

Tabela 4.3.1 Parâmetros diagnósticos das principais

formas de apresentação clínica dos

portadores de doença de Wilson

Tabela 4.4 Aspectos cínicos e laboratoriais dos cinco 62

pacientes com DW e insuficiência hepática

aguda grave

Tabela 4.6.1 Farmacoterapia utilizada, padrões de

65

resposta terapêutica e efeitos adversos em

226 pacientes com DW

Tabela 4.6.2- Padrões de resposta à farmacoterapia ao 67

final do segmento, conforme as formas de apresentação clínica nos portadores de DW com boa aderência terapêutica

Tabela 4.6.3 Formas clínicas predominantes e causas de 71 morte em 82 pacientes com doença de Wilson 


\section{LISTAS DE FIGURAS}

Figura 1.1 Samuel Alexander Kinnier Wilson 2

Figura 1.2 Metabolismo normal do cobre, a esquerda. A ATP7B atua 7 na excreção biliar do cobre e na sua secreção celular associada a ceruloplasmina. Na doença de Wilson, figura direita, há diminuição ou ausência dessas atividades levando ao acúmulo tóxico do metal.

GSH: glutationa; MT: metalotioneína; Cu: cobre; (holo) $\mathrm{Cp}$ : holoceruloplasmina; (Apo) $\mathrm{Cp}$ : apoceruloplasmina

Figura 1.3 Etapas da lesão hepatocelular. A: Início do processo com 12 tumefação mitocondrial. $\mathrm{B}$ : esteatose macro $\mathrm{e}$ microvesicular. C: fase intermedária com início de fibrose D: cirrose hepática, com evidente pigmentação de rodanina

$\begin{array}{lll}\text { Figura 1.4 Anel de Kayser- Fleischer em paciente da casuística } & 15\end{array}$

$\begin{array}{lll}\text { Figura 1.5 Cristais de ceruloplasmina } & 16\end{array}$

Figura 1.6 RNM encefálica mostrando"sinal do urso panda" em 20 paciente da casuística

Figura 4.2 Distribuição nacional dos estados de origem em 112 famílias de portadores de doença de Wilson

Figura 4.3 Representação das idades de início do quadro clínico, idade e atraso diagnóstico, em anos, com as formas clínicas da DW.

A: assintomática; Hem: hemólise; $\mathrm{H}$ : hepática; $\mathrm{N}$ : neurológica; P: psiquiátrica 


\section{NORMALIZAÇÃO ADOTADA}

Essa dissertação está de acordo com as seguintes normas, em vigor no momento desta publicação:

Referências: adaptado do International Committee of Medical Journals Editors (Vancouver).

Universidade de São Paulo. Faculdade de Medicina. Divisão de Biblioteca e Documentação. Guia de Apresentação de dissertações e teses e monografias. Elaborado por Anneliese Carneiro da Cunha, Maria Julia de A. L. Freddi, Maria F. Cresiana, Marinalva de Souza Aragão, Suely Campos Cardoso, Valéria Vilhena. 3a ed. São Paulo. Divisão de Biblioteca e Documentação; 2011.

Abreviaturas dos títulos dos periódicos de acordo com o List of Journals Indexed in Index Medicus. 


\section{RESUMO}

Araujo FC. Doença de Wilson: a experiência de seis décadas no HC-FMUSP [dissertação]. São Paulo: Faculdade de Medicina, Universidade de São Paulo; 2012.

INTRODUÇÃO: A doença de Wilson é um distúrbio autossômico recessivo, decorrente de mutações no gene $A T P 7 B$, resultando em acúmulo tóxico de cobre no organismo. Devido a sua raridade, séries com grande casuística e longo seguimento são escassas na literatura. Nesse estudo relatamos a experiência do Hospital das Clínicas da Faculdade de Medicina da Universidade de São Paulo (HC-FMUSP) com os pacientes diagnosticados com doença de Wilson entre o período de 1946 a 2010. MÉTODOS: Realizamos análise retrospectiva de 262 casos, descrevendo as formas de apresentação clínica, os achados dos exames diagnósticos, os padrões de resposta terapêutica e a evolução clínica da doença. RESULTADOS: A idade média do início dos sintomas foi 17,4 anos (7-49 anos). Os pacientes foram acompanhados em média 9,6 anos (0-45 anos). As apresentações clínicas mais frequentes foram hepática $(36,3 \%)$, neurológica $(34,7 \%)$, assintomática $(16,8 \%)$, neuro-psiquiátrica $(8,3 \%)$ e hematológica $(1,9 \%)$. Outras formas menos comuns foram renal, neuro-hepática, e osteoarticular. Disartria e manifestações clínicas de cirrose hepática descompensada foram as principais características neurológicas e hepáticas, respectivamente. Os parâmetros diagnósticos observados foram anéis de Kayser-Fleisher 78,3\%, reduzidos níveis séricos de ceruloplasmina $98,3 \%$, níveis elevados de cuprúria basal de 24 horas 73,0\%, teste da D-penicilamina positivo em 54,0\% e comprometimento nos dois alelos do gene ATP7B 84,4\%. O exame de ressonância magnética encefálica mostrou alterações nos núcleos da base em $77,7 \%$ dos examinados. D-penicilamina foi prescrita inicialmente em $93,6 \%$ dos 245 casos tratados, e 53\% relataram efeitos adversos. Houve necessidade de substituição em 50 indivíduos. Outras medicações utilizadas foram os sais de zinco e trientina. Não evidenciamos diferença significativa entre os resultados terapêuticos dessas três drogas $(p=0,2)$. Os casos de má aderência à terapia evoluiram com pior desfecho quando comparados aos usuários regulares ( $p$ 
$<0,0001$ ). Nove pacientes realizaram transplante hepático. Durante o seguimento 82 casos faleceram. As principais causas dos óbitos foram descompensação hepática 41,5\% (hemorragia digestiva, peritonite bacteriana espontânea, encefalopatia) e pneumonia 20,7\%. Três pacientes cometeram suicídio. CONCLUSÕES: Não existe um exame padrão ouro ou achado patognomônico da doença. Todo paciente jovem com manifestações hepáticas, neurológicas, neuropsiquiátricas, hematológicas, renais ou osteoarticulares de causa indefinida deverá ser investigado para doença de Wilson. Além da farmacoterapia específica é necessária a avaliação psiquiátrica para detectar precocemente sintomas depressivos.

Descritores: Doença de Wilson; Diagnóstico; Tratamento; Evolução clínica. 


\section{SUMMARY/ABSTRACT}

Araujo FC. Wilson's disease: the experience of six decades in the Hospital das Clínicas of Sao Paulo University School of Medicine [dissertation]. São Paulo: "Faculdade de Medicina, Universidade de São Paulo"; 2012.

INTRODUCTION: Wilson's disease is an autosomal recessive disorder, caused by mutations in the gene $A T P 7 B$, leading to toxic copper accumulation in the body. Because it is a rare disease, large series with long-term follow-up are limited in literature. We reported the experience of Hospital das Clínicas of Sao Paulo University School of Medicine (HC-FMUSP) with Wilson's disease patients diagnosed between 1946 and 2010. METHODS: A retrospective analysis of 262 cases was performed describing the clinical presentation, the results of diagnostic tests, the patterns of treatment response and outcome. RESULTS: The mean age at the onset of symptoms was 17.4 years (7- 49 years). Patients were followed for a mean of 9.6 years (0-45 years). The most frequent clinical presentations were hepatic (36.3\%), neurological $(34.7 \%)$, asymptomatic (16.8\%), neuro-psychiatric (8.3\%) and hematologic (1.9\%). Other less common forms were renal, neurological-hepatic, and musculoskeletal. Dysarthria and clinical manifestations of decompensated liver cirrhosis were the main neurological and liver features, respectively. The diagnostic parameters observed in this cohort of patients were Kayser-Fleischer rings in $78.3 \%$, low serum ceruloplasmin in $98.3 \%$, high 24 -h urinary excretion of copper in $73.0 \%$, positive challenge test with d-pencillamine in $54.0 \%$ and detection of two mutations of $A T P 7 B$ gene in $84.4 \%$. The magnetic resonance of brain showed abnormalities in the basal ganglia in $77.7 \%$ of those examined. D-penicillamine was prescribed in $93.6 \%$ of 245 cases as the first drug, and $53 \%$ reported 
adverse effects. It was need to replace it in 50 individuals. Other drugs used were salts of zinc and trientine. There was no significant difference between the therapeutic results of these three drugs $(p=0.2)$. The cases with poor adherence to therapy evolved with a worse outcome when compared to regular users $(p<0.0001)$. Nine patients underwent liver transplantation. During the follow-up 82 patients died. The main causes of death were hepatic decompensation $41.5 \%$ (variceal hemorrhage, spontaneous bacterial peritonitis, encephalopathy) and pneumonia $20.7 \%$. Three patients committed suicide. CONCLUSIONS: There is no gold standard or pathognomonic test for diagnosing this disease. Any young patient with hepatic, neurological, neuropsychiatric, hematologic, renal, or osteoarticular manifestations of unknown cause should be investigated for Wilson's disease. In addition to the classical pharmacotherapy, specific psychiatric evaluation is necessary to detect early symptoms of depression.

Descriptores: Wilson's disease; Diagnosis; Treatment; Outcomes. 


\section{INTRODUÇÃO}

\subsection{ASPECTOS GERAIS}

A doença de Wilson (DW) é um distúrbio autossômico recessivo, decorrente de mutações no gene $A T P 7 B$, resultando em acúmulo tóxico de cobre no organismo. Estima-se que a DW ocorra na proporção de um para cada 30.000 a 100.000 indivíduos com variações geográficas relacionadas à taxa de consangüinidade (Ala; Shilsky, 2004; Ala et al., 2007).

O nome da doença é atribuído ao neurologista Samuel Alexander Kinnier Wilson (Figura 1.1), que por meio da tese intitulada "Progressive lenticular degeneration: a familial nervous disease associated with cirrhosis of the liver", fez a primeira descrição sistemática da DW, entretanto nesse trabalho mencionou casos também de outros autores tais como Gowers, Ormerod e Homen (Wilson, 1912).

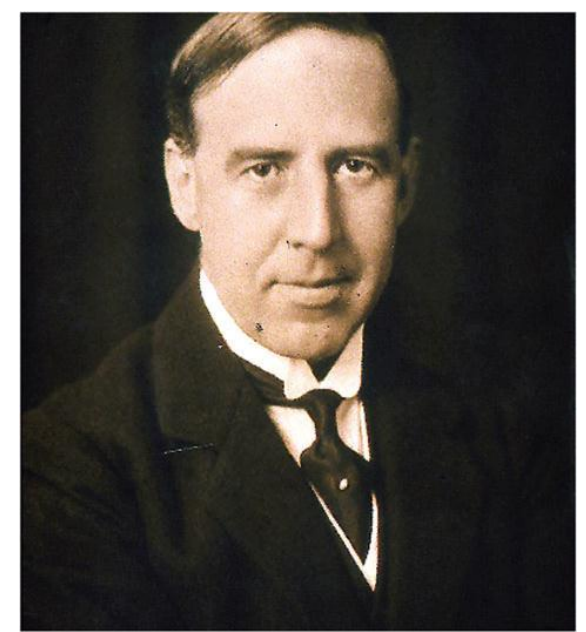

FONTE: Adaptada de Walshe, 2009

Figura 1.1 - Samuel Alexander Kinnier Wilson 


\subsection{HISTÓRICO}

Anteriormente à tese de Samuel Alexander Kinnier Wilson já existiam relatos de semelhante enfermidade, tais como os de Morgagni* apud Walshe (2006) que em 1761 publicou uma coletânea de casos com manifestação neurológica e doença hepática. Frerichs** (1860) descreve um quadro que para Wilson (1912) deveria tratar-se de degeneração lenticular progressiva.

Segundo Suvarna (2008), dois oftalmologistas alemães Bernhard Kayser em 1902 e Bruno Fleischer em 1903 descreveram, independentemente, a presença de estruturas anelares nas córneas de paciente com diagnóstico de esclerose múltipla. Em 1912 Fleischer as reconheceu em um paciente com DW. Essas estruturas foram denominadas de anéis de Kayser-Fleischer (KF).

Rumpel (1913) observou cobre no fígado de indivíduo falecido com a DW. Cumings (1948) também noticiou incremento do metal no fígado e cérebro de paciente com DW e citando Mandelbrote***(1948), que detectou aumento de cuprúria com uso de BAL (British anti-lewisite), propôs essa droga para tratamento da DW. Três anos após surgiram as primeiras publicações, com relatos de estabilização clínica dessa condição anteriormente fatal (Brown; Porter, 1951; Cumings, 1951).

*Morgagni GB. De sedibus et causis morborum. London: Trans B Alexander; 1761.

${ }^{* *}$ Frerichs FT. A clinical treatise on diseases of the liver. Vol. 1. London:

Trans Murchison C New Sydenham Soc; 1860.

${ }^{* * *}$ Mandelbrote, B. M., Stanier, M. W., Thompson, R. H. S., and Thruston, M. N. Brain, 71, 212, 1948. 
Posteriormente, estudos revelaram associação da DW com anormalidades bioquímicas do metabolismo do cobre (Porter, 1951; Cartrwight et al., 1954; Frommer, 1974) e com reduzidos níveis séricos de ceruloplasmina (Scheinberg; Gitlin, 1952).

Devido ao incômodo da administração parenteral e efeitos colaterais produzidos pelo BAL, a busca de uma nova droga era imprescindível, e em 1956 Walshe anuncia a d-penicilamina (DPA) como a primeira medicação realmente efetiva e de uso oral para tratamento da doença de Wilson (Walshe, 1956). Em seguida, surgiram outras opções terapêuticas, tais como zinco, trientina, tetratiomolibdato de amônio (ainda em fase experimental) e transplante hepático (Walshe, 1969; Dubois et al., 1971; Starzl et al., 1971; Hoogenraad et al., 1978; Walshe 1996).

$\mathrm{Na}$ década de 90, três grupos distintos realizaram a identificação, no cromossomo 13q14.1, do gene ATP7B (Bull et al., 1993; Tanzi et al.; 1993, Yamaguchi et al., 1993). Ele codifica uma proteína transportadora de cobre do tipo ATPase, com 1465 aminoácidos, seis domínios de ligação de cobre, oito porções transmembrana, um domínio de transdução que converte a energia da hidrólise do ATP para o transporte do metal, um canal transmembrana para o cátion e um domínio de fosforilação (Petrukhin et al., 1994). Essa ATPase foi designada ATP7B.

No Hospital das Clínicas da Faculdade de Medicina da Universidade de São Paulo (HC-FMUSP), o primeiro caso de DW foi identificado em 1946, na ocasião o diagnóstico foi realizado mediante manifestações neurológicas e hepáticas, além dos anéis de Kayser-Fleischer (Barbosa et al., 2009). Na 
década de 60 iniciou-se, no serviço, a investigação com estudo do cobre e ceruloplasmina (Canelas et al., 1962; Canelas et al., 1963a;b Canelas et al., 1964). Posteriormente, nos anos 80 , houve a incorporação de exames de imagens, ecografia e tomografia computadorizada à investigação dessa doença (Barbosa et al., 1986; Cançado et al., 1987). A análise molecular do gene ATP7B começou a ser realizada no início da década passada, com análise de pacientes provenientes do serviço, assim como de outras instituições (Deguti et al., 2004; Machado et al., 2008).

\subsection{HOMEOSTASE DO COBRE e a ATP7B}

Aproximadamente $60 \%$ do cobre oriundo da dieta (cerca de 1-2 mg/dia) é absorvido no estômago e intestino delgado, essa quantidade é suficiente para as necessidades do indivíduo, entretanto interferem nesse processo sexo, idade, uso de contraceptivos e a alimentação (Tao; Gitlin, 2003; van den Berghe; Klomp, 2009; Huster 2010). Contudo, um estudo mostra que na faixa etária de 20 a 59 anos, a absorção foi maior no sexo feminino, porém não houve diferença em relação à idade (Johnson et al., 1992).

No processo de absorção do cátion, é necessária a ação da metalo redutase que atua no pólo apical da célula, antes do seu ingresso. O transporte transmembrana é realizado via proteínas hCTR1 e DMT1. A ATP7A, expressa no trato gastro-intestinal exporta o metal à circulação porta, onde associado à albumina ou histidina, é transportado a vários tecidos principalmente ao fígado, principal órgão de armazenamento. No hepatócito desliga-se das transportadoras, sendo introduzido via proteína transportadora CTR1, situada 
no pólo sinusoidal da célula (Figura 1.2). No citoplasma é ligado a proteínas citoprotetoras (metalotioneína, glutationa) e a chaperona Atox 1 que o direciona até a ATP7B, localizada na rede trans-Golgi dos hepatócitos (Tao; Gitlin, 2003; Roberts; Sarkar, 2008).

A ATP7B participa do metabolismo do cobre por dois mecanismos: a) incorporando-o à apoceruloplasmina, originando a holoceruloplasmina, mais estável, com meia-vida de 4 a 5 dias que será secretada para o plasma, contendo 95\% do cobre circulante; b) redistribuição do metal para o endossomo e lisossomo até a sua excreção biliar. Nesse último processo a proteína MURR1 interage com a ATPase, para excreção biliar do metal. Outra via de eliminação é a renal, porém esse modo representa menos de $5 \%$ do cobre eliminado (Schaefer et al., 1999; Harris, 2000; Shim; Harris, 2003; Ala; Schilsky, 2004 Ala et al., 2007). 


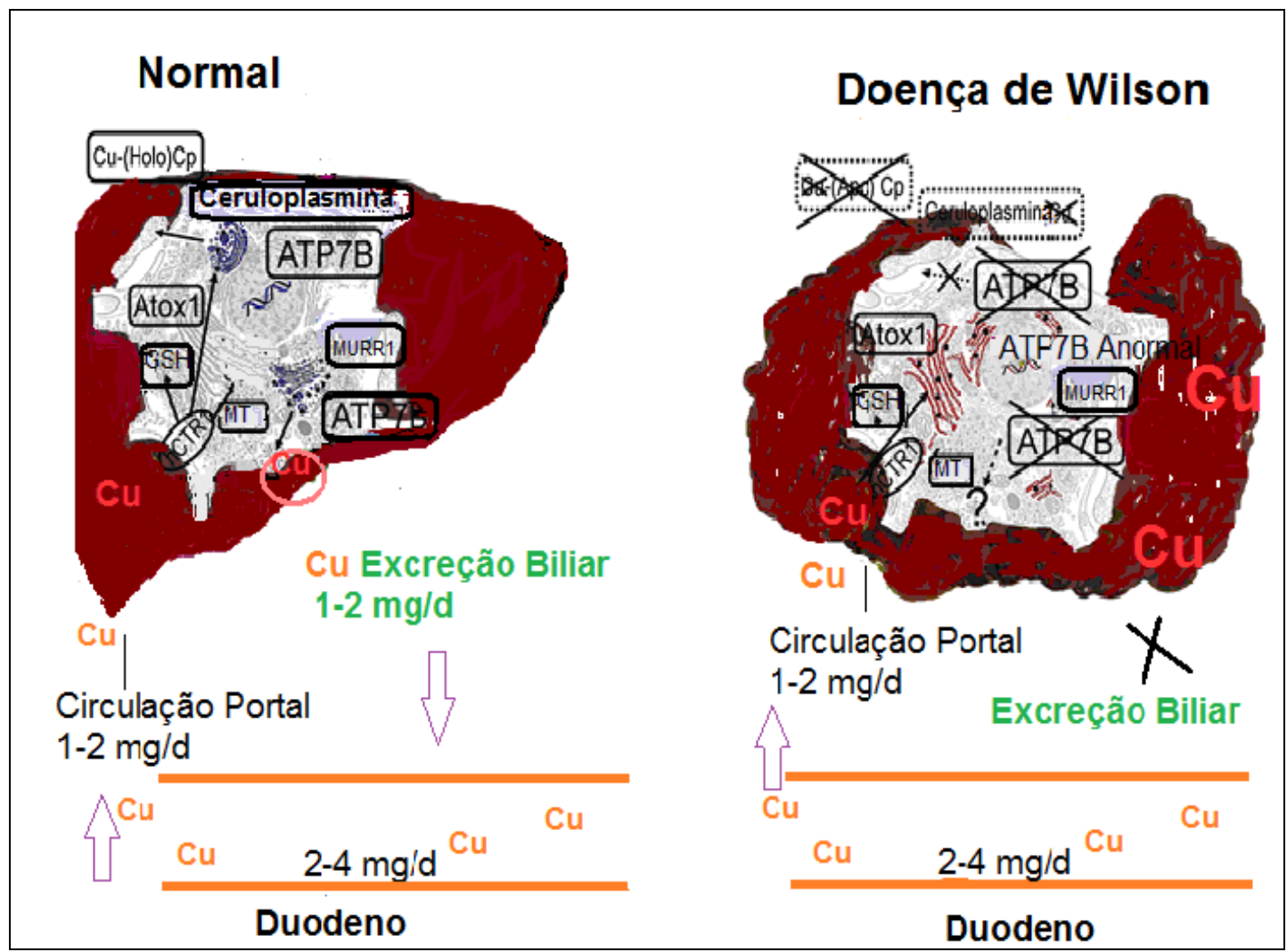

FONTE: Adaptado de Huster, 2010

Figura 1.2 - Metabolismo normal do cobre, a esquerda. A ATP7B atua na excreção biliar do cobre e na sua secreção celular associada a ceruloplasmina. $\mathrm{Na}$ doença de Wilson, figura direita, há diminuição e/ou ausência dessas atividades levando ao acúmulo tóxico do metal.

GSH: glutationa; MT: metalotioneína; Cu: cobre; (holo) Cp: holoceruloplasmina; (Apo) Cp: apoceruloplasmina

A ATP7B também é expressa em outros tecidos tais como cérebro, coração, rins, pulmões e placenta, entretanto um estudo em experimental, em murinos, sugeriu que ocorrendo excesso de cobre no intestino, o metal é 
compartimentado em forma de vesículas por essa proteína, contribuindo para homeostase do metal também no enterócito (Weiss et al., 2008).

\subsection{PATOGENIA}

A patogênese da DW está associada à produção deficiente da proteína ATP7B. Estudo realizado em rato "knouckout" (gene ATP7B -/-) demonstrou alterações bioquímicas e anátomo-patológicas, devido à sobrecarga do cobre no fígado, semelhante às observadas nos portadores de DW (Huster et al., 2006).

Os primeiros relatos de mutações no gene foram da década de 90 (Figus et al.; 1995, Thomas et al., 1995; Shah et al., 1997 Curtis et al., 1999). Até o presente momento, foram identificadas mais de 500 mutações, em diversas populações do mundo (http://www.medicalgenetics.med.ualberta.ca/wilson/index.php; Bennett; Hahn, 2011). Acredita-se que essa diversidade dificulte o esclarecimento da patogênese na DW, entretanto sabe-se que na presença de algumas mutações tais como H1069Q, G591D e G85V, a proteína ATP7B encontra-se no retículo endoplasmático, ao invés de estar localizada no complexo de Golgi, resultando em sua degradação proteossomal mais precoce. $\mathrm{Na} \mathrm{H1069Q}$ a disfunção pode ser corrigida com baixas temperaturas, fato não observado na G591D e G85V. Nessas há aumento na interação da proteína defeituosa com a COMMD1 (MURR1), sugerindo que isso interfira na estabilidade e proteólise da ATP7B anômala (Payne et al.,1998; de Bie et al., 2007). 
Alguns trabalhos demonstram correlação genotípica e fenotípica (Panagiotakaki et al., 2004; Stapelbroek et al., 2004; Lee et al., 2011 ), mas outros não a observaram (Shah et al., 1997; Vrabelova et al., 2005; Gupta et al., 2007), possivelmente existam outros agentes modificadores da variabilidade fenotípica.

Um estudo em pacientes com DW que apresentavam os polimorfismos C677T e A1298C no gene da 5,10-metilenotetrahidrofolato redutase (MTHFR), enzima relacionada ao metabolismo da homocisteína, evidenciou alteração na forma de apresentação clínica em relação aos que não os possuiam. 0 polimorfismo C677T está mais frequentemente associado à apresentação hepática e início mais precoce dos sintomas. Especula-se que a ação da homocisteína promovendo estresse oxidativo, resulte em toxicidade hepática e neurológica (Gromadzka et al., 2011).

A apolipoproteína E (APOE) é expressa principalmente no fígado e cérebro e atua no metabolismo e transporte dos lípides para os tecidos. Possui três polimorfismos principais: APOE2, APOE3 e APOE4, sendo essa última associada à despolimerização microtubular e à inibição do crescimento de axônios e dentritos (Nathan et al., 1995; Verghese et al., 2011). Em trabalho com gene $A P O E$, em pacientes com DW e homozigotos $\mathrm{H} 1069 \mathrm{Q}$, observou-se que o genótipo APOE 3/3 foi associado ao início mais tardio da manifestação clínica em relação ao APOE 3/4, possivelmente essa neuroproteção deve-se a ação antioxidante da APOE 3, (Schiefermeier et al., 2000). Outro estudo observou que os pacientes com os genótipos APOE 3/4 e APOE 4/4 exibiam 
quadro clínico mais precoce em relação ao APOE 3/3 no sexo feminino, porém o mecanismo desse achado ainda precisa ser elucidado (Litwin et al., 2012).

Príons são patógenos infecciosos associados a processos neurodegenerativos em humanos, bovinos e caprinos, que envolvem polimorfismos no gene da proteína príon $(P R P)$, sendo a doença CreutzfeldtJakob a mais notável entre humanos (Prusiner, 1998). Os portadores de DW com polimorfismos no códon 129 (PRP 129) e homozigoto para metionina apresentaram quadro neurológico mais grave, associado a faixa etária mais elevada (Grubenbecher et al., 2006). Outro trabalho mostrou resultado semelhante em relação a idade, porém sem impacto na gravidade clínica (Merle et al., 2006).

Sabe-se que o acúmulo de ferro é hepato e neurotóxico e leva à degeneração celular por estresse oxidativo (Núñez et al., 2012). A associação do distúrbio no metabolismo do ferro, com a DW poderia interferir na variabilidade clínica da doença. Todavia, em relato de associação da mutação do gene HFE em paciente portador de DW, não houve desenvolvimento de hemocromatose (Walshe; Cox, 1998). Outro trabalho sobre a influência de polimorfismos do gene HFE na DW, não demonstrou diferença na freqüência em relação à registrada na população em geral, porém os pacientes do sexo masculino e com menores níveis de ceruloplasmina, apresentavam altos níveis de ferritina (Pfeiffenberger et al., 2012).

Apesar da patogênese na DW não estar completamente esclarecida, sabe-se que a ATP7B codificada pelo gene mutante não consegue excretar o cobre do hepatócito (Figura 1.2), produzindo desequilíbrio no balanço e 
acúmulo tóxico do metal, que inicialmente se distribui no citosol, levando posteriormente à formação de radicais livres, deposição de glicogênio nuclear, disfunção mitocondrial, alteração da oxidação lipídica (gerando esteatose), e ao estresse oxidativo que resulta em dano celular, inflamação, fibrogênese e cirrose (Figura 1.3). Esse estresse também provoca resposta adaptativa celular com expressão de vários genes, alguns relacionados à degradação proteassomal e outros que possibilitam a sobrevivência celular (Gu et al., 2000; Ferenci, 2004, Rosencrantz; Muller et al., 2007; Schilsky, 2011).

O cobre atua direta ou indiretamente (produzindo radicais livres) na esfingomielinase ácida liberando ceramida, que está implicada no processo de apoptose em hepatócitos e eritrócitos nos indivíduos com DW (Lang et al., 2007). Outro mecanismo descrito é que o excesso do metal resulta em mudança na conformação e degradação mais precoce da proteína relacionada à inibição da apoptose (XIPA), que atua na supressão da caspase-3, o que leva a maior suscetibilidade ao processo de morte celular (Mufti et al., 2006). 


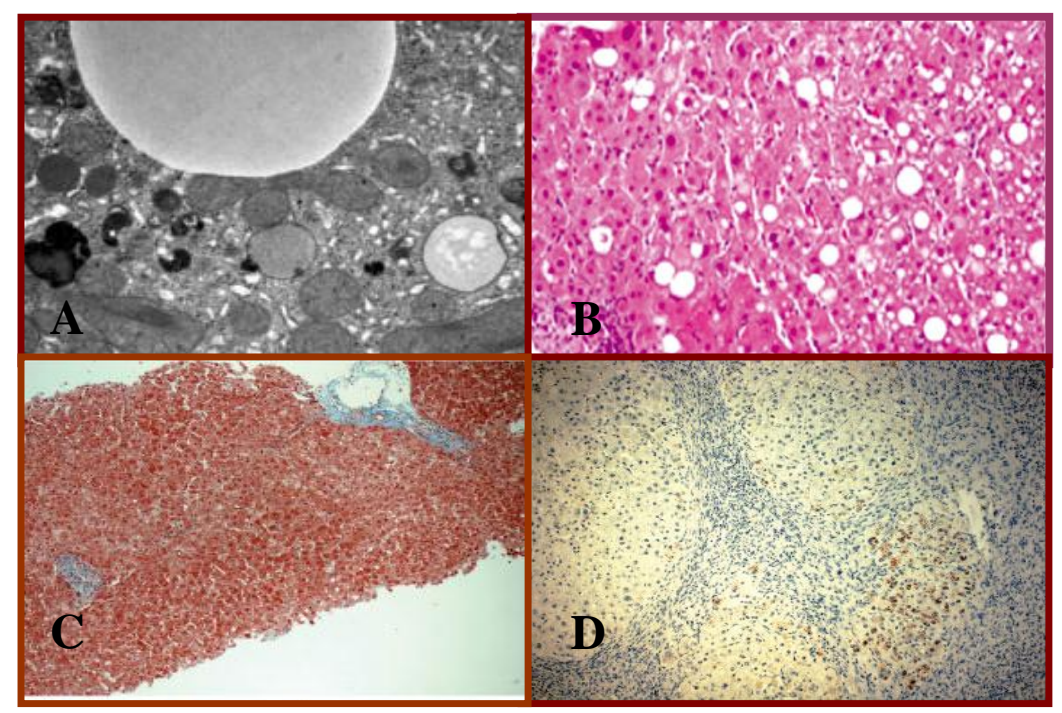

FONTE: Adaptado de Johncilla e Mitchell, 2010.

Figura 1.3 - Etapas da lesão hepatocelular. A: Início do processo com tumefação mitocondrial. B: esteatose macro e microvesicular. C: fase intermedária com início de fibrose D: cirrose hepática, com evidente pigmentação de rodanina.

Quando a capacidade de armazenamento hepático do cobre se esgota, há liberação desse metal na circulação, onde será distribuído e depositado em outros tecidos. No cérebro, ainda não está bem esclarecido como esse acúmulo é lesivo, porém a sua interação com proteínas forma complexos bioinorgânicos, com propriedade oxidante ou antioxidante, que poderiam alterar a função neuronal ou desencadear processo neurodegenerativo (Ferenci, 2004).

\subsection{DIAGNÓSTICO}

O início do quadro clínico dá-se mais frequentemente na infância, adolescência e juventude, porém existe descrição em septuagenários (Ala et al., 2005; Członkowska et al., 2008). A doença acomete ambos os sexos, 
contudo um estudo, com a maior casuística registrada na literatura, demonstrou predominância no sexo masculino (Litwin et al., 2012).

O cobre acumula-se em diversos tecidos, principalmente no fígado e cérebro, levando a manifestações hepáticas, neurológicas, hematológicas, oftalmológicas, renais, osteomusculares e neuropsiquiátricas, porém alguns casos são assintomáticos (Quadro 1).

Nem sempre é simples estabelecer o diagnóstico da DW, dada a sua variedade de manifestações clínicas e raridade. $\mathrm{Na}$ tentativa de padronização diagnóstica Scheinberg e Sternlieb (1984) estabeleceram critérios baseados nos achados clínicos associados à presença dos anéis de KF, aos níveis de ceruloplasmina sérica menor que $20 \mathrm{mg} / \mathrm{dL}$, à concentração de cobre hepático maior que $250 \mu \mathrm{g} / \mathrm{g}$ de tecido seco, à cuprúria basal de $24 \mathrm{~h}$ maior que 100 $\mu \mathrm{g} /$ dia e ao teste com cobre radioativo. Para o estabelecimento diagnóstico seriam necessários pelo menos dois desses parâmetros. Entretanto, os pacientes com quadro neurológico e sem os anéis de KF seriam excluídos para DW. 
Quadro 1 - Manifestações Clínicas na DW

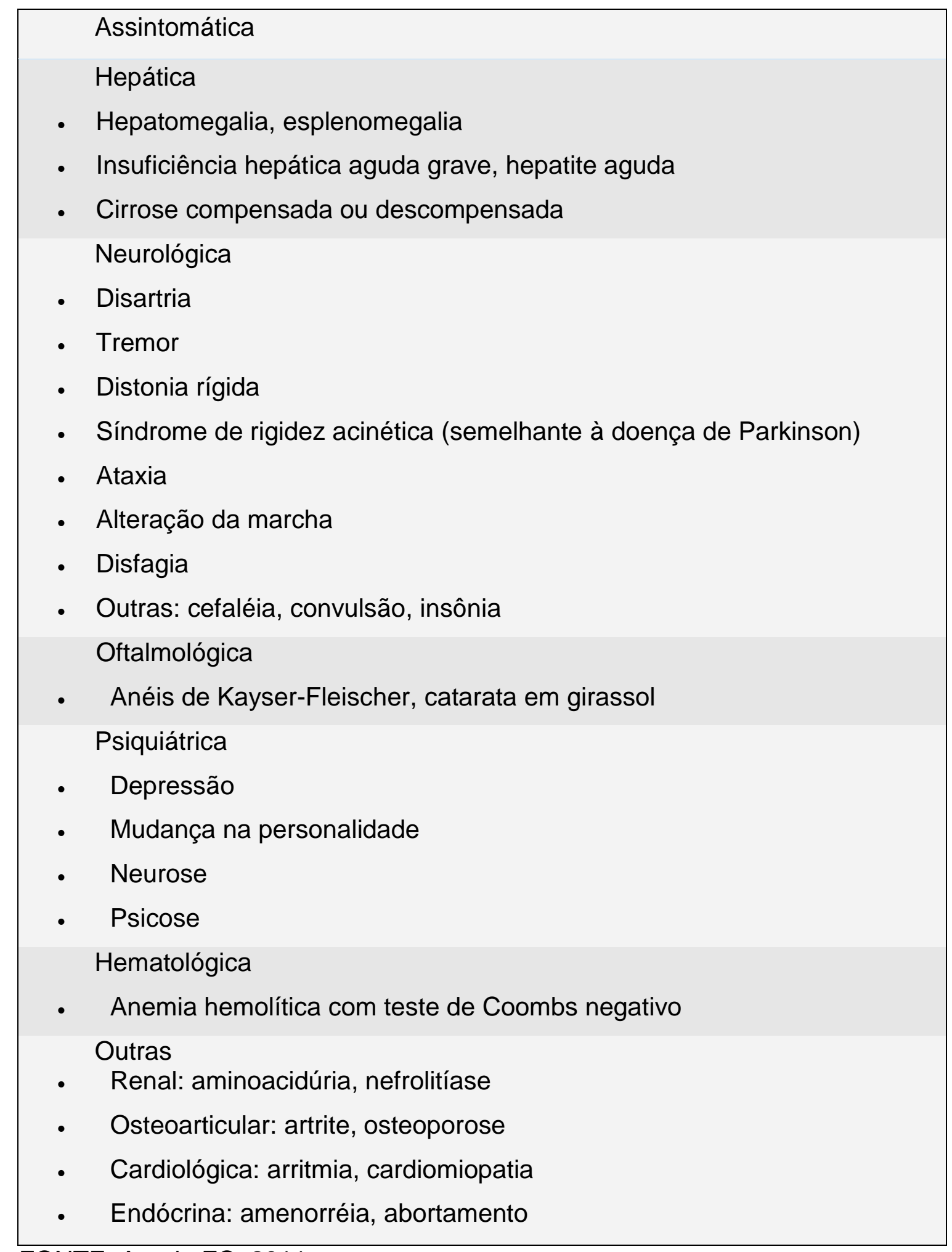

FONTE: Araujo FC, 2011. 
Os parâmetros diagnósticos utilizados na doença de Wilson são os seguintes:

a) Anéis de Kayser-Fleischer

Deverão ser pesquisados por lâmpada de fenda (Figura 1.4). São observados na DW, principalmente na forma neurológica, contudo podem ser encontrados em outras afecções, tais como colestase de longa duração tais como na colestase extra-hepática, na cirrose biliar primária (Scheinberg; Sternlieb, 1984; Roberts; Schilsky, 2008). Nessas situações, os níveis de ceruloplasmina são normais ou mesmo elevados. Crianças assintomáticas com DW raramente apresentam essas estruturas (Nicastro et al., 2010).

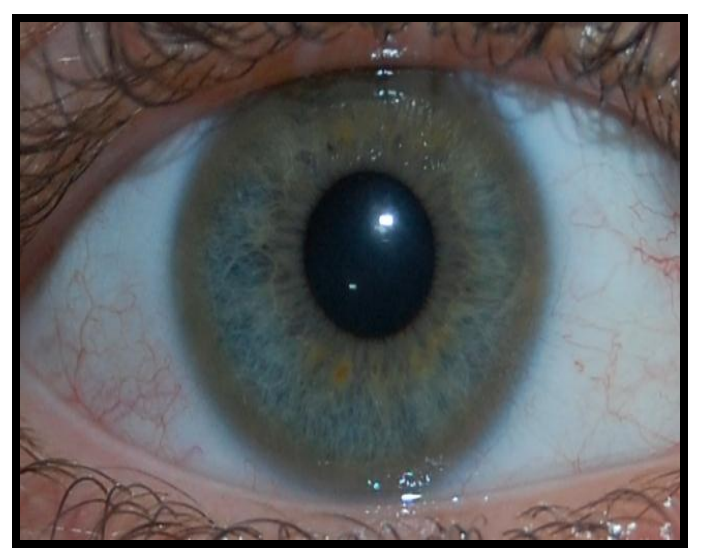

Figura 1.4 - Anel de Kayser-Fleischer

em paciente da casuística

b) Ceruloplasmina

A ceruloplasmina é uma a2-globulina azul (Figura 1.5), com atividades de ferroxidase e transporte de cobre sérico. É detectada no soro pelos métodos de imunonefelometria, que mensura a apoceruloplasmina e holoceruloplasmina, 
ou atividade de oxidase (Walshe, 2003). Seus níveis elevam-se em processos inflamatórios, gestação, uso de contraceptivos, hepatite aguda e em neoplasias. Por outro lado está reduzida nos casos de doença de Wilson, desnutrição grave, cirrose descompensada, falência hepática aguda, aceruloplasminemia, enteropatia ou nefropatia perdedora de proteínas, síndrome de Menkes e em aproximadamente $20 \%$ dos indivíduos heterozigotos para o gene $A T P 7 B$ (Scheinberg; Sternlieb, 1984; Brewer; Yuzbasiyan-Gurkan, 1994; Ala; Schilsky, 2004).

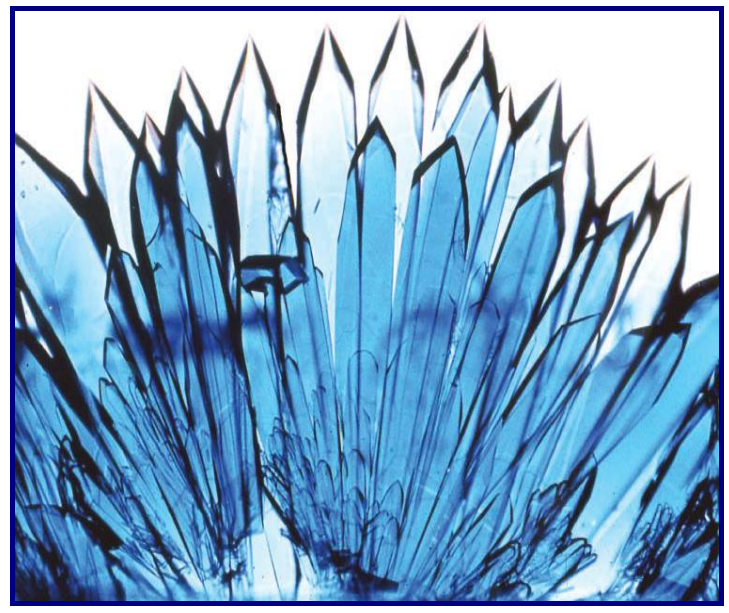

FONTE: Adaptado de Walshe, 2009

Figura 1.5 - Cristais de Ceruloplasmina

Walshe (2005) observou que outras condições neurológicas também cursam com reduzidos valores de ceruloplasmina doença de Huntington, esclerose múltipla, aceruloplasminemia, panencefalite esclerosante subaguda e síndrome de Hallervorden Spatz. 
Mak et al. (2008) encontraram níveis séricos de ceruloplasmina menores que $20 \mathrm{mg} / \mathrm{dL}$ em 5,8\% indivíduos saudáveis, entretanto nenhum apresentava níveis menores de $14 \mathrm{mg} / \mathrm{dL}$, a análise desse valor mostrou sensibilidade e especificidade no diagnóstico da DW de $93 \%$ e $100 \%$ respectivamente, com valor preditivo positivo de $100 \%$ e negativo de $97,1 \%$.

Trabalhos de screening em massa, inclusive com recém-nascidos, têm demonstrado que a dosagem de ceruloplasmina sérica, utilizando a técnica sandwich ELISA, mostrou-se eficaz como marcador diagnóstico da DW (Ohura et al., 1999; Hahn et al., 2002; Kroll et al., 2006). A mensuração de holoceruloplasmina urinária também parece ser uma promissora alternativa para triagem em massa e diagnóstico precoce da DW (Owada et al., 2002).

c) Cobre urinário

A concentração normal do cobre urinário é menor que $40 \mu \mathrm{g} / 24 \mathrm{~h}$, entretanto valores maiores que $100 \mu \mathrm{g} / 24 \mathrm{~h}$ são encontrados em pacientes sintomáticos com DW, cirrose biliar primária, colangite esclerosante e hepatite autoimune. Indivíduos heterozigotos e assintomáticos com DW podem apresentar valores intermediários (Medici et al., 2007; Roberts; Schilsky, 2008).

O cobre urinário, assim como a ceruloplasmina, pode ter níveis séricos normais na infância (Werlin et al., 1978; Nazer et al., 1986). Para aumentar a acurácia diagnóstica dessa população, foi proposto o teste da DPA, na qual 500 mg de penicilamina são administrados com intervalo de 12 horas, com coleta de urina por $24 \mathrm{~h}$, a partir da primeira dose. Níveis maiores que $1600 \mu \mathrm{g} / 24 \mathrm{~h}$, apresentaram sensibilidade e especificidade, para o diagnóstico, de $88 \%$ e 
98,2\%, respectivamente (Costa et al., 1992), entretanto quando esse teste foi reproduzido em crianças sintomáticas a sensibilidade observada foi $92 \%$, enquanto a do grupo assintomático 46\% (Muller et al., 2007). Outro estudo demonstrou sensibilidade, nessa população, de apenas 12\%, mas ao utilizar cuprúria basal maior que $40 \mu \mathrm{g} / 24$ h observou sensibilidade e especificidade de $78,9 \%$ e $87,9 \%$, respectivamente, sugerindo que em crianças assintomáticas com DW, esse seja o limite adotado (Nicastro et al., 2010).

Foruny et al. (2008) realizaram o teste da DPA em adultos. O valor discriminante encontrado, para diferenciar os portadores de DW de outras hepatopatias, foi $1057 \mu \mathrm{g} / 24 \mathrm{~h}$, com sensibilidade e especificidade de $100 \%$ e $82,3 \%$, respectivamente. Todos os pacientes com valor de cuprúria maior que $1400 \mu \mathrm{g} / 24 \mathrm{~h}$, após teste, tinham DW.

d) Quantificação do cobre hepático

A quantificação do cobre hepático maior do que $250 \mu \mathrm{g} / \mathrm{g}$ de tecido seco, é considerada o melhor teste diagnóstico para DW. Os indivíduos sadios geralmente apresentam valores menores do que $50 \mu \mathrm{g} / \mathrm{g}$ (Roberts; Schilsky, 2008).

Em estudo de Ferenci et al. (2005) foram encontrados níveis menores do que $250 \mu \mathrm{g} / \mathrm{g}$ em $17 \%$ dos pacientes. A sensibilidade e especificidade observadas foi $83,3 \%$ e $98,6 \%$, respectivamente, e ao reduzir o limite de 250 para $75 \mu \mathrm{g} / \mathrm{g}$, aumentou-se a sensibilidade do exame para $96,5 \%$ com leve queda na especificidade.

Além da DW, colestases, cirrose infantil da Índia e outras hepatopatias também elevam cobre hepático (Roberts; Schilsky, 2008). 
e) Cobre radioativo

Esse teste utiliza o principio da incorporação do cobre marcado (radiativo) à ceruloplasmina, como nos pacientes com degeneração hepatocelular esse processo está prejudicado, haverá déficit na detecção. Atualmente este exame está em desuso (Roberts; Schilsky, 2008).

Após a elaboração dos critérios de Scheinberg e Sternlieb, surgiram outros exames que foram utilizados como recursos diagnósticos na DW, tais como os exames de imagem encefálica e a análise de mutações do gene ATP7B.

f) Estudos de imagem encefálica

Os achados mais freqüentes da DW nos estudos de imagem encefálica são as alterações nos gânglios da base, tálamo e tronco cerebral, placa tectal visualizadas na tomografia de crânio (TC) como hiperdensidade e na ressonância nuclear magnética (RNM) encefálica como hiperintensidade do sinal em T2. Outras alterações são a atrofia cortical e subcortical. Uma imagem característica da doença é o sinal do urso panda (Figura 1.6), encontrado na ponte ou mesencéfalo (Roberts; Schilsky, 2008; Prashanth et al., 2010). 


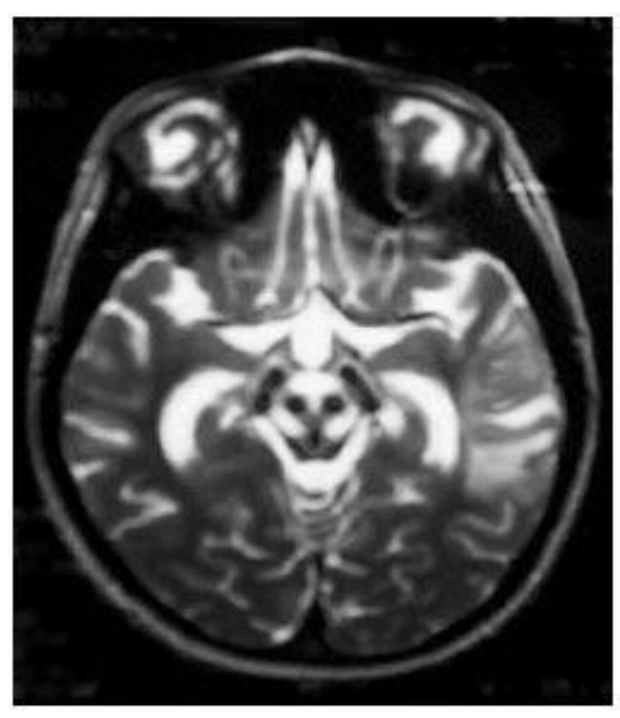

Figura 1.6 - RNM encefálica mostrando

"sinal do urso panda" em paciente da

casuística

f) Teste genético para o gene $A T P 7 B$

A análise de mutações $A T P 7 B$ é realizada com técnicas de seqüenciamento de todo o gene ou pesquisa de alelos específicos. Recomenda-se o estudo genético naqueles pacientes em que o diagnóstico não pôde ser estabelecido mediante os achados do quadro clínico e exames laboratoriais e nos indivíduos assintomáticos com irmão portador de DW (Ferenci et al., 2003; Roberts; Schilsky, 2008, Huster, 2010; EASL, 2012).

\subsection{TRATAMENTO}

O tratamento inicial, de todos os casos sintomáticos, deverá incluir agentes queladores do cobre como DPA e trientina (Roberts; Schilsky, 2008; EASL, 2012), entretanto naqueles com a forma hepática a DPA parece ser mais 
eficaz, enquanto nos assintomáticos e com quadro neurológico os sais de zinco tiveram melhor tolerância (Wiggelinkhuizen et al., 2009). As diretrizes da EASL (2012) sugerem que os sais de zinco possam ser a primeira escolha na apresentação neurológica, mas para a manutenção qualquer uma dessas drogas. Nos assintomáticos tanto os agentes quelantes quanto o zinco poderiam ser utilizados como tratamento inicial.

a) d-Penicilamina:

A DPA promove a excreção urinária do cobre e induz a síntese de metalotioneína. é usada na dose inicial de 250 a $500 \mathrm{mg} / \mathrm{dia}$, aumentando-se $250 \mathrm{mg}$ a cada sete dias, até atingir 1 a $1,5 \mathrm{~g} / \mathrm{dia}$, dividida em duas a quatro tomadas. Administra-se uma hora antes das refeições. A dose de manutenção é 750-1000 mg/dia. Entre os efeitos adversos mais freqüentes estão hipersensibilidade, piora neurológica que ocorre em $10 \%$ a $50 \%$ dos casos, síndrome nefrótica e mielotoxicidade. Faz-se suplementação com piridoxina 25 mg/dia. Em geral doses prolongadas acima de 1,0g/dia estão associadas a lesões dermatológicas do tipo elastose serpiginosa perfurante.

O controle terapêutico faz-se com cuprúria de 24 h que deverá estar entre 200-500 $\mu \mathrm{g} / 24 \mathrm{~h}$ e com o cobre sérico livre entre 5-15 $\mu \mathrm{g} / \mathrm{dL}$. Esse exame tem valor estimado, obtido com a subtração do cobre sérico pelo resultado do produto ceruloplasmina x 3 (Roberts; Schilsky, 2008; EASL, 2012).

b) Trientina:

Atua aumentando a excreção renal do cobre e ferro. Pode causar deterioração neurológica, mas em menor frequência que a DPA, outros efeitos são anemia sideroblástica, plaquetopenia e gastrite. A dose inicial é de 750- 
$1500 \mathrm{mg} / \mathrm{dia}$ e a de manutenção de 750-1000 mg/dia, dividida em duas a três tomadas, uma hora antes das refeições (Roberts; Schilsky, 2008; EASL, 2012). O controle terapêutico é da mesma forma que para a DPA.

c) Sais de zinco:

Bloqueiam a absorção intestinal do cobre e estimula a síntese de metalotioneína intestinal e hepática. A formulação dos sais poderá ser em acetato ou gluconato. Para o sulfato de zinco a dose deve ser de 220 mg, três vezes ao dia e para o acetato de zinco $170 \mathrm{mg} / \mathrm{dia}$, que corresponde a $150 \mathrm{mg}$ de zinco elementar por dia, dividida em 3 tomadas, também 1 hora antes das refeições (Roberts; Schilsky, 2008; Huster, 2010; EASL, 2012).

d) Tetratiomolibdato de amônia:

É um potente quelante de cobre, porém não causa deterioração neurológica. Ainda não está disponível comercialmente (Roberts; Schilsky, 2008; EASL, 2012).

e) Dieta

Alimentos com alto teor de cobre como feijão, castanha, nozes, cogumelos, vísceras e chocolates deverão ser desencorajados, ao menos no primeiro ano de tratamento. Em pacientes que não utilizam agentes quelantes, a dieta deve ser mais rigorosa (Roberts; Schilsky, 2008; EASL, 2012).

f) Transplante Hepático

É procedimento reservado para os casos de insuficiência hepática aguda grave mesmo sem tentativa de tratamento ou de cirrose hepática descompensada, que não melhoraram com tratamento clínico. 
$\mathrm{Na}$ forma hepática da DW é considerado tratamento curativo, ao contrário da neurológica que não está indicado, uma vez que o tratamento clínico é preferível. (Roberts; Schilsky, 2008; Catana; Medice, 2012; EASL, 2012).

g) Outros:

Uso de antioxidantes, principalmente vitamina E, pode proteger a célula contra o estresse oxidativo gerado pelo excesso de cobre (Roberts; Schilsky, 2008; Huster, 2010; EASL, 2012). O tratamento farmacológico com as chaperonas curcumina e 4-fenilbutirato em mutações missense, in vitro, aumentaram a expressão da proteína mutante e o transporte do metal, contudo maiores estudos são necessários a respeito dessas possíveis alternativas terapêuticas (van den Berghe et al., 2009).

Transplante de hepatócitos, já foi utilizado em outros erros do metabolismo, e a terapia gênica é uma perspectiva futura (Catana; Medice, 2012). 


\subsection{JUSTIFICATIVAS PARA O ESTUDO}

$\mathrm{Na}$ Tabela 1 observa-se heterogeneidade na forma clínica predominante, na presença dos anéis de KF e discrepantes taxas de óbitos.

Tabela 1 - Sumário das séries descritas de DW

\begin{tabular}{|c|c|c|c|}
\hline Autor, ano & País, etnia & $\mathbf{N}$ & Comentários \\
\hline Lau, 1990 & $\begin{array}{l}\text { China } \\
(1953-1988)\end{array}$ & 37 & $\begin{array}{l}\text { Sem consanguinidade; ID*: } 19 \text { a; } \\
\text { perda } 10,8 \% \text {; óbitos } 8,1 \% \text { dos } \\
\text { casos }\end{array}$ \\
\hline Gow, 2000 & $\begin{array}{l}\text { Austrália } \\
(1971-1998)\end{array}$ & 30 & $\begin{array}{l}\text { ID: } 21 \text { a; } 10 \% \text { forma neurológica; } \\
\text { óbitos } 20 \%\end{array}$ \\
\hline Vrabelova, 2005 & $\begin{array}{l}\text { República Theca } \\
\text { (2005) }\end{array}$ & 227 & $\begin{array}{l}\text { ID 15,2 a; mutação presente em } \\
80,3 \% \text {; sem correlação } \\
\text { fenotípica e genotípica; forma } \\
\text { hepática } 63,4 \%\end{array}$ \\
\hline Merle, 2007 & $\begin{array}{l}\text { Alemanha } \\
(2000-2005)\end{array}$ & 163 & $\begin{array}{l}\text { ID 20,4 a; } 60,1 \% \text {; f forma } \\
\text { hepática } 58,9 \% \text {; óbitos } 1,8 \%\end{array}$ \\
\hline Taly, 2007 & $\begin{array}{l}\text { Índia } \\
(1970-2000)\end{array}$ & 282 & $\begin{array}{l}\text { ID 15,9 a; Consanguinidade } \\
54 \% \text {; đ } 69 \% \text {; forma hepática } \\
\text { 14,9\%; óbito } 8,1 \%\end{array}$ \\
\hline Bruha, 2010 & $\begin{array}{l}\text { República Theca } \\
(1965-2008)\end{array}$ & 117 & $\begin{array}{l}\text { ID } 38,5 \text { a; } ð \text { 50,4\%; forma } \\
\text { neurológica } 47 \% \text {; anel KF } 71 \% \\
\text { da forma neurológica; mutação } \\
\text { presente em } 80 \% \text {; óbito } 3 \%\end{array}$ \\
\hline Barbosa, 1985 & $\begin{array}{l}\text { Brasil } \\
(1946-1985)\end{array}$ & 95 & $\begin{array}{l}\text { forma neurológica } 54,4 \% \text { e } \\
\text { psiquiátrica } 14,4 \% \text {; anel } \mathrm{KF} \\
91,3 \% \text {; cuprúria elevada } 78,2 \%\end{array}$ \\
\hline
\end{tabular}

*ID: idade à época do diagnóstico 
Essas séries refletem o comportamento da doença nas diversas populações do mundo. (Lau et al., 1990; Gow et al., 2000; Vrabelova et al., 2005; Merle et al., 2007; Taly et al., 2007; Bruha et al., 2010; Bem et al., 2011).

Os pacientes com a forma hepática e os assintomáticos têm mais dificuldade para o diagnóstico, pois frequentemente não apresentam os parâmetros clássicos da doença. Steindl et al. (1997) encontraram reduzidos níveis séricos de ceruloplasmina, cuprúria maior que $100 \mu \mathrm{g} / \mathrm{dL}$ e anéis de KF em $65 \%$, $88 \%$ e $47 \%$, respectivamente, dos pacientes com quadro de hepatopatia crônica, afirmando que os resultados desses exames são insuficientes para excluir o diagnóstico na investigação de hepatopatia.

A introdução na propedêutica desses exames, associada à falta de padronização das formas clínicas e dos critérios diagnósticos, fez com que os especialistas reunidos no Oitavo Encontro Internacional Sobre Doença de Wilson e de Menkes em Leipzig, Alemanha, em 2001, propusessem que o diagnóstico da DW deveria ser baseado na combinação de sintomas clínicos, testes laboratoriais, exame histológico (pesquisa de rodanina no hepatócito), quantificação do cobre hepático, ressonância encefálica e análise de mutações no gene $A T P 7 B$, sendo essa última merecedora de expressiva pontuação num sistema de escore (Ferenci et al., 2003;).

Em 2003, Roberts e Schilsky publicaram o primeiro guia de orientações da DW e em 2008 voltaram a publicar diretrizes para esta doença, com maior ênfase na utilização do teste genético (Roberts; Schilsky, 2003, Roberts; Schilsky, 2008). 
Gheorghe et al. (2004) analisaram fatores preditivos para diagnóstico da DW, sugerindo que outros critérios tais como idade maior que 18 anos, exclusiva da forma hepática e cuprúria maior que $100 \mu \mathrm{g} / 24 \mathrm{~h}$ deveriam ser considerados em indivíduos sem os achados clássicos da doença.

Recentemente, a associação européia para estudo do fígado publicou outro guia de orientações (EASL, 2012), em que não se recomenda o uso do teste da DPA em adulto, sugere o estudo genético como exame primordial para triagem familiar em parentes de primeiro grau, e propôs uso de zinco como primeira escolha na forma neurológica.

Os autores atribuem a complexidade do diagnóstico à diversidade clínica, à raridade (tendo escassos trabalhos com grande casuística), à ausência de exame $100 \%$ preciso. A análise das mutações ainda não mostrou relação óbvia entre fenótipo e genótipo. A associação de todos esses fatores resulta, frequentemente, em atraso no diagnóstico e no tratamento.

Os trabalhos a respeito da farmacoterapia são escassos e sem randomização, e as drogas utilizadas parecem não apresentar a mesma eficácia para todas as formas da doença, assim como o transplante hepático que não resolve o quadro neurológico. Agravado a isso as opções terapêuticas são mínimas, fazendo-se necessário diagnóstico preciso dessa condição fatal.

Em recente série brasileira de 36 pacientes procedentes de região com importante imigração europeia (Bem et al., 2011), os anéis de KF estavam presentes em apenas 55,6\% da casuística e a sobrevida registrada em 39 anos de seguimento foi $90,1 \%$. Contudo num país com forte miscigenação e 
considerando a diversidade de mutações da DW, talvez os achados desse trabalho não reflitam o comportamento da doença no Brasil.

Considerando que o HC-FMUSP é um centro de referência no tratamento e na pesquisa da DW, com séries clínicas previamente publicadas (Barbosa et al., 1985; Canelas, 1987) e mais de duas centenas de pacientes cadastrados, faz-se mister um estudo unicêntrico dessa doença sob a ótica dos recentes avanços diagnósticos e terapêuticos e com análise mais detalhada do comprometimento hepático. 


\section{OBJETIVOS GERAIS}

- Relatar a experiência do HC-FMUSP com os casos de DW diagnosticados nas últimas seis décadas.

\subsection{OBJETIVOS ESPECÍFICOS}

- Descrever as formas de apresentação clínica

- Descrever os achados dos exames diagnósticos

- Avaliar padrões de resposta terapêutica

- Analisar evolução clínica 


\section{CASUÍSTICA E MÉTODOS}

\subsection{CASUÍSTICA}

\subsubsection{Seleção da Casuística}

A casuística foi selecionada a partir do registro de 280 indivíduos cadastrados com o diagnóstico ou como casos suspeitos de DW, matriculados nos Serviços de Gastroenterologia Clínica, de Neurologia, de Cirurgia do Fígado e Transplante Hepático, bem como do Serviço de Hepatologia Pediátrica do Instituto da Criança, do HC-FMUSP, no período de janeiro de 1946 a dezembro de 2010.

Após a aplicação dos critérios de inclusão e exclusão (item 2.2.1) a casuística foi composta de 262 casos com o diagnóstico de DW.

\subsubsection{Tamanho da Amostra}

Por se tratar de enfermidade rara, não se aplicaram cálculos estatísticos para determinação do número de casos (n), buscando-se a inclusão da totalidade da casuística deste centro de referência.

\subsubsection{Aspectos Éticos}

O presente estudo foi aprovado pela Comissão de Ética para Análise de Projetos de Pesquisa (CapPesq) do HC-FMUSP sob o número 667/09 (Anexo A). 


\subsection{MÉTODOS}

Os dados foram compilados por meio de análise retrospectiva de prontuários e os exames complementares também foram obtidos do sistema HC-NET (arquivo eletrônico com dados de exames complementares dos pacientes atendidos no HC-FMUSP). Quando possível e necessário, foi realizada a confirmação das informações com os pacientes ou seus familiares. O levantamento foi realizado por um único médico clínico (o pesquisador principal, FCA).

\subsubsection{Critérios de Inclusão e Exclusão}

\subsubsection{Critérios de Inclusão}

Foram incluídos os pacientes cujo diagnóstico de DW foi estabelecido mediante achados clínicos, laboratoriais e de exames complementares, de acordo com os critérios de Wilson (1912), Scheinberg e Sternlieb (1984), Ferenci et al. (2003), Roberts e Schilsky (2008), a saber:

- Alterações hepáticas clínicas, bioquímicas, anatomopatológicas ou ultrassonográficas;

- Doença neurológica com alteração distonica, extra-piramidal, cerebelar ou convulsões, com ou sem manifestações psiquiátricas associadas;

- Presença de anéis corneanos de Kayser-Fleischer;

- Ceruloplasmina sérica $<20 \mathrm{mg} / \mathrm{dL}$

- Cuprúria > $100 \mu \mathrm{g} / 24$ h, ou após estímulo com 1,0 g de penicilamina por via oral > $1600 \mu \mathrm{g} / 24 \mathrm{~h}$ em crianças ou > $1400 \mu \mathrm{g} / 24 \mathrm{~h}$ em adultos;

- Cobre hepático > $250 \mu / g$ tecido seco; 
- Biópsia hepática com achados como glicogênio nucleolar, esteatose hepática, fibrose, hepatite crônica ou cirrose, reatividade para coloração de rodanina;

- Ressonância magnética de encéfalo com evidências de deposição de cobre em gânglios da base.

\subsubsection{Critérios de Exclusão}

Foram critérios de exclusão:

- casos cujos prontuários não tenham sido localizados, ou apresentassem dados incompletos ou ilegíveis;

- casos cuja revisão de prontuário não tenha confirmado diagnóstico de DW;

- casos em que tenha ocorrido recusa do paciente em fornecer dados para fins de estudo ou pesquisa.

\subsubsection{Obtenção dos Dados}

Foram obtidos dados demográficos, clínicos, bioquímicos, anatomopatológicos, exames de imagem e genotipagem ATP7B.

\subsubsection{Dados Demográficos}

Obtiveram-se os seguintes dados demográficos:

- gênero: masculino ou feminino;

- naturalidade e procedência;

- origem étnica e ou geográfica familiar: caucasiana, africana, asiática, indígena, miscigenado.

No anexo B constam os dados de identificação dos casos, número de 
ordem na casuística, iniciais dos nomes, número de registro, gênero, naturalidade, origem e procedência.

\subsubsection{Dados Clínicos}

Os dados clínicos obtidos estão especificados a seguir:

- caso-índice: sim ou não. Considerou-se caso-índice o primeiro paciente da família com diagnóstico de DW caracterizado e registrado na presente casuística, ainda que houvesse casos suspeitos ou confirmados em outros serviços;

- história familiar: sim ou não. Em caso afirmativo, menção ao grau de parentesco com os afetados;

- consangüinidade entre os pais: em caso afirmativo, registrou-se o grau de parentesco;

- manifestação inicial: vide item 3.2.2.2.1;

- forma da doença (ou quadro clínico principal): vide item 3.2.2.2.1;

- outras manifestações à época do diagnóstico: vide item 3.2.2.2.2;

- pesquisa do anel de Kayser-Fleischer: presente, ausente;

- idade de início dos sintomas;

- idade no momento do diagnóstico.

\subsection{Formas Clínicas de Apresentação}

As formas clínicas foram definidas conforme as manifestações iniciais da doença, sendo categorizadas nas seguintes apresentações:

- Assintomática: ausência de sinais e sintomas. Nesse grupo, os pacientes 
vieram encaminhados por triagem familiar ou por achado incidental de alterações hepáticas em exames de rotina. Os casos assintomáticos foram subclassificados em: sem hepatopatia, hepatite crônica ou cirrose hepática. A hepatite crônica foi definida mediante achado anatomopatológico demonstrando agressão à placa limitante e fibrose portal sem destruição da arquitetura lobular, e ou por alterações de enzimas hepáticas e ou da ecotextura hepática. Os pacientes foram subcategorizados em cirrose hepática quando se identificou alteração da arquitetura hepática com transformação nodular, e ou detectaram-se calibre de veia porta $>1,4 \mathrm{~cm}$, circulação colateral em leito esplâncnico, varizes esofagogástricas;

- Neurológica:

As manifestações neurológicas foram categorizadas em: bradicinesia, rigidez, instabilidade postural, tremor, distonia, riso sardônico, coréia, atetose, distúrbios cerebelares (ataxia apendicular, disdiadococinesia e hipotonia), disartria, disfagia, alteração da marcha e outras menos comuns, tais como sinais de disfunção piramidal, epilepsia e alterações oculomotoras.

Quanto às síndromes neurológicas as mais frequentemente encontradas são o quadro distônico, parkinsoniano e cerebelar. Em grande parte dos pacientes há sobreposição, mas em outros é possível a classificação em formas neurológicas clássicas tais como a de Wilson com predomínio de quadro distônico ou a de Westphal-Strumpell caracterizada pelas manifestações 
cerebelares e presença do típico tremor postural em bater de asas.

O grau de comprometimento motor para cuidados pessoais, de higiene e alimentação foi categorizado em ausente, leve (tem anormalidade na execução, mas o paciente se mantém independente), moderada (dependência ocasional) e grave (dependência permanente);

- Hepática: foram considerados os casos com achados de icterícia, ginecomastia, telangiectasias, hepatoesplenomegalia, hemorragia digestiva, encefalopatia, ascite, anasarca. Identificaram-se quatro formas de apresentação hepática:

- Hepatite aguda: icterícia em indivíduo previamente hígido, náusea, desconforto abdominal, fadiga, com ou sem hemólise Coombs negativo, com resolução espontânea em 1 a 2 semanas;

- Insuficiência hepática aguda grave: pacientes com início súbito de encefalopatia, coagulopatia grave, insuficiência renal aguda e/ou anemia hemolítica Coombs negativo e apresentando relação fosfatase alcalina/ bilirrubina $<4$;

- Cirrose hepática compensada: achados de ginecomastia, telangiectasia, hepatoesplenomegalia, icterícia, eritema palmar. Enfatiza-se que os casos de hepatite crônica e de cirrose cujo diagnóstico ocorreu por meio de exames complementares, na 
ausência de sinais clínicos de hepatopatia, foram categorizados como forma assintomática;

- Cirrose hepática descompensada: paciente sabidamente cirrótico com ascite, anasarca, sangramentos por hipocoagulabilidade, peritonite bacteriana espontânea (PBE), encefalopatia, síndrome hepatorenal, ou hemorragia digestiva causada por rotura de varizes esofágicas.

- Neuro-hepática: na concomitância das características das formas neurológica e hepática.

- Neuro-psiquiátrica: psicoses, neuroses, alterações do humor ou comportamento associadas à forma neurológica.

\subsection{Outros órgãos envolvidos}

Além dos órgãos mencionados no item 3.2.2.2.1, foram também contabilizados o envolvimento:

- oftalmológico: mediante presença de anéis de Kayser-Fleischer à biomicroscopia corneana à lâmpada de fenda, e catarata em girassol.

- renais: nefrocalcinose, acidose tubular renal;

- cardíacas: miocardiopatia, arritmia;

- osteomusculares: artrite, fraturas recorrentes e osteoporose precoce;

- hematológica: anemia hemolítica não imunológica, epistaxe.

\subsubsection{Dados Laboratoriais}

Os exames bioquímicos foram realizados na rotina do Laboratório Central do HCFMUSP. A ceruloplasmina sérica era inicialmente determinada 
pelo método de Houchin (Canelas e De Jorge, 1964) e posteriormente por imunonefelometria, sendo esse o método vigente até o momento. A análise dos níveis de cobre era realizada por meio de espectrofotometria, até a implantação da espectroscopia de absorção atômica (Canelas et al., 1962; Canelas et al., $\left.1963_{a}, 1963_{b}\right)$

Foram obtidos os seguintes dados laboratoriais:

- ceruloplasmina sérica: em mg/ dL;

- cuprúria basal e após administração oral de $1 \mathrm{~g}$ de penicilamina: em $\mu \mathrm{g} /$ $24 \mathrm{~h}$;

- cobre hepático, quando disponível: em $\mu \mathrm{g} / \mathrm{g}$ de tecido seco;

- enzimas hepáticas: número de vezes acima do limite superior de normalidade $(\mathrm{XSSN})$ de alanina amino transferase (ALT), aspartato aminotransferase (AST), fosfatase alcalina e gamaglutamil transpeptidase $(\gamma \mathrm{GT})$;

- bilirrubinas totais, direta e indireta: em mg/dL;

- albuminemia: $\mathrm{g} / \mathrm{dL}$;

- urina I;

- proteinúria de $24 \mathrm{~h}$ : em g/ vol;

- hemograma com plaquetas: em células $/ \mathrm{mm}^{3}, \mathrm{Hb}(\mathrm{g} / \mathrm{dL}), \mathrm{HT} \%$

- Teste de Coombs

- TAP/INR.

\subsubsection{Dados Anatomopatológicos Hepáticos}

Quando os dados foram disponíveis, registrou-se a origem do material, 
isto é, se proveniente de biópsia diagnóstica, de seguimento de tratamento, explante hepático ou autópsia. Além disso, notificou-se a presença ou não dos marcadores diagnósticos: esteatose, glicogênio nuclear, coloração de rodanina. Por fim, cada caso foi classificado em hepatite crônica, cirrose hepática ou fígado reacional.

\subsubsection{Estudos de Imagem}

Admitiram-se as alterações de gânglios da base visibilizadas na ressonância magnética de encéfalo ou na tomografia computadorizada de crânio. Conforme descrição prévia da literatura (Cançado et al., 1987), foram considerados achados ultrassonográficos relevantes: alteração na textura hepática (heterogênea) e da dimensão hepática, aumento da ecogenicidade, presença de nódulos hipo ou hiperecóicos, colelitíase, hipertensão portal e esplenomegalia.

Avaliou-se a presença de sinais sugestivos de hipertensão portal (gastropatia congestiva e varizes esofagogástricas) pelo exame de endoscopia digestiva alta.

\subsubsection{Genotipagem ATP7B}

Foram obtidos os resultados da genotipagem $A T P 7 B$, realizados por seqüenciamento completo dos 21 éxons do gene $A T P 7 B$, já publicados (Deguti et al., 2004; Machado et al., 2008), bem como os resultados ainda não publicados do projeto aprovado pela Comissão de Ética para Análise de Projetos de Pesquisa (CapPesq) do HC-FMUSP sob o número 1111/051 com financiamento FAPESP 06/00499-1. 


\subsubsection{Avaliação do Tratamento e Seguimento}

Registraram-se dados referentes à terapêutica, como droga de escolha, dose inicial e de manutenção, tempo de uso, aderência, negativação dos anéis de KF, resposta terapêutica, efeitos adversos e mudança de tratamento. A aderência à terapia foi classificada conforme as diretrizes de Barbosa et al. (1991), sendo categorizada como boa quando a medicação era raramente interrompida e por período inferior a 7 dias. Irregular nos casos que a interrupção ocorreu apenas eventualmente e durante 7 a 30 dias e ruim quando a suspensão da terapia era frequente ou por período superior a 30 dias. Analisaram-se as demais medicações utilizadas, a realização de transplante hepático e por fim o padrão evolutivo.

Considerou-se como resposta completa ao tratamento, a resolução dos achados clínicos referentes à lesão hepática, a regressão significativa das manifestações neurológicas (salvo seqüelas), normalização bioquímica das aminotransferases, das bilirrubinas, do tempo de atividade da protrombina, dos níveis de albumina, o desaparecimento dos anéis de Kayser-Fleischer, e a estabilização da cuprúria na faixa de 200-500 $\mu \mathrm{g} / 24 \mathrm{~h}$, exceção feita aos pacientes em uso de sais de zinco. Esses dois últimos parâmetros foram reavaliados pelo menos um ano após início do tratamento.

Classificou-se como resposta incompleta a não obtenção de alguns desses parâmetros, porém com estabilidade do quadro clínico, após o mesmo período e resposta ruim como a deterioração clínica, ou importante piora laboratorial na vigência da terapia. Casos que não se encaixaram nesses 
padrões serão especificados. Em relação ao seguimento observou-se também a presença de complicações, perdas e óbitos.

\subsubsection{Análise Estatística}

A avaliação das médias de idades obtidas no início dos sintomas, à época do diagnóstico e do tempo de atraso diagnóstico, dentre as formas clínicas mais freqüentes, foi realizada através do teste t de Student.

Empregaram-se testes estatísticos para estudo do comportamento dos parâmetros diagnósticos com as diversas classificações clínicas, detalhando-se a seguir:

a) Foram utilizados os testes de Fisher e $\chi^{2}$ para análise da presença dos anéis de KF nas principais apresentações clínicas da casuística;

b) Compararam-se, por meio do teste t de Student, os níveis séricos de ceruloplasmina observados nos modos clínicos mais relevantes e utilizou-se o teste $\chi^{2}$ para avaliação das categorias fenotípicas com mensurações inferiores a $20 \mathrm{mg} / \mathrm{dL}$;

c) Empregaram-se os testes de Fisher e $\chi^{2}$ para análise entre os quadros clínicos e níveis de cuprúria superiores a $100 \mu g / 24$ h. Para comparação dos valores do cobre urinário exibidos pelas formas clínicas utilizou-se o teste t de Student;

d) A análise das respostas dos quadros clínicos ao teste de DPA foi efetivada pelo teste de Fisher; 
e) A avaliação da presença de mutações nos dois alelos associada às categorias fenotípicas foi realizada por meio dos testes de Fisher e $\chi^{2}$.

A confrontação da classificação de Child-Pugh antes e após tratamento foi realizada por meio do teste do $\chi^{2}$.

A análise das respostas terapêuticas (completa, incompleta e ruim) ao uso das drogas DPA, sais de zinco e trientina foi efetivada pelo teste do $\chi^{2}$.

Para avaliação dos padrões de resposta ao tratamento (completa, incompleta e ruim), conforme as formas clínicas e drogas utilizadas, foram empregados os testes de Fisher e do $\chi^{2}$. 


\section{RESULTADOS}

\subsection{CASUÍSTICA}

Durante o período de estudo, 262 indivíduos foram diagnosticados com doença de Wilson. Dos 280 casos iniciais 18 foram excluídos, sete porque não tiveram confirmação diagnóstica e 11 pela impossibilidade de resgatar os prontuários. A idade média ao diagnóstico, o tempo de atraso para fazê-lo, assim como o período de inclusão nesse serviço, em cada década, estão ilustrados na Tabela 4.1.

Na casuística o gênero masculino representou 58,8\% ( $N=154)$ dos casos, enquanto o feminino foi $41,2 \%(\mathrm{~N}=108)$.

A idade de abertura do quadro clínico foi em média 17,6 \pm 6,5 anos (649), sendo obtida de 128 homens (média 17,8 anos; 7-49) e 88 mulheres (média 17,4 anos; 6-35). Nessa análise foram incluídos somente os casos sintomáticos.

A média de idade registrada à época do diagnóstico foi $18,7 \pm 7,5$ anos (4-53), em 261 pacientes.

O tempo de atraso no diagnóstico de 260 portadores da DW foi $1,4 \pm$ 2,5 anos (0-22). Evidenciamos um decréscimo nesse retardo, que era em média de seis anos na década de 50, comparado aos oito meses nos dias atuais. A maior demora registrada foi na década de 60.

O rastreamento por parentesco possibilitou a inclusão de 72 pacientes, dos quais 34 eram assintomáticos, mas apenas três não havia sinais de hepatopatia crônica. $O$ atraso no diagnóstico foi em média $1,1 \pm 3,0$ anos (0- 
22), sem distinção significante quando comparado ao retardo global do estudo $(p=0,4)$. O teste t de Student foi utilizado nessa análise. Em dois portadores a investigação familiar não foi adequadamente realizada.

Tabela 4.1- Distribuição por décadas das médias de idade e atraso diagnóstico, em 258 pacientes com DW atendidos no HC-FMUSP- 1946 a 2010

\begin{tabular}{l|c|c|c|c|c}
\hline Décadas & Casos & $\begin{array}{c}\text { Idade } \\
\text { diagnóstico* } \\
\text { (média } \pm \text { DP) }\end{array}$ & $\begin{array}{c}\text { Mediana* } \\
\text { (mínimo } \\
\text { máximo) }\end{array}$ & $\begin{array}{c}\text { Atraso } \\
\text { diagnóstico* } \\
\text { (média } \pm \text { DP) }\end{array}$ & $\begin{array}{c}\text { Mediana* }^{*} \\
\text { (mínimo } \\
\text { máximo) }\end{array}$ \\
\hline 40 & 1 & 20,0 & 20,0 & 2,0 & 2,0 \\
50 & 3 & $25,7 \pm 7,3$ & $23,0(20-34)$ & $6,0 \pm 8,7$ & $1,0(1-16)$ \\
60 & 16 & $25,5 \pm 10$ & $24,0(14-53)$ & $3,6 \pm 5,1$ & $2,0(1-22)$ \\
70 & 59 & $18,3 \pm 6,8$ & $16,0(7-35)$ & $2,0 \pm 2,3$ & $1,0(0-8)$ \\
80 & 36 & $16,6 \pm 6,5$ & $16,0(5-33)$ & $1,0 \pm 1,3$ & $0,5(0-4)$ \\
90 & 62 & $17,5 \pm 6,2$ & $17,0(8-33)$ & $1,0 \pm 2,0$ & $0,0(0-11)$ \\
A partir & 85 & $19,0 \pm 8,0$ & $18,0(4-51)$ & $0,7 \pm 1,2$ & $0,0(0-6)$
\end{tabular}

de 2000

${ }^{*}$ Valores expressos em anos

\subsection{ASPECTOS DEMOGRÁFICOS}

A etnia caucasiana esteve presente em $77,6 \%(\mathrm{~N}=194)$, a mestiça caucasiana e africana $16,8 \%(\mathrm{~N}=42)$, a africana $4,0 \%(\mathrm{~N}=10)$, a asiática $1,6 \%$ $(\mathrm{N}=4)$, e em 12 casos não havia descrição a respeito. Foram registradas 198 famílias distintas, dessas 65 referiam outro parente portador da DW, e em uma 
houve acometimento em três gerações. Consanguinidade foi mencionada em 35,7\% (50/140) casos-índice.

Notificou-se a origem mais remota de 129 famílias, e nove eram oriundas de mais de um estado.

As famílias eram, principalmente, de São Paulo, Minas Gerais e Bahia, entretanto $15 / 129$ relataram descendência italiana, $11 / 129$ portuguesa e 8/129 espanhola. Nove eram indígenas. Algumas famílias procediam de outros países, tais como, três do Japão, três da Alemanha, duas da Holanda, uma da Koréia, uma da China, uma da Áustria, uma do Líbano, uma da Polônia e uma da Yugoslávia.

A distribuição nacional da origem familiar encontra-se ilustrada na Figura 4.2. 


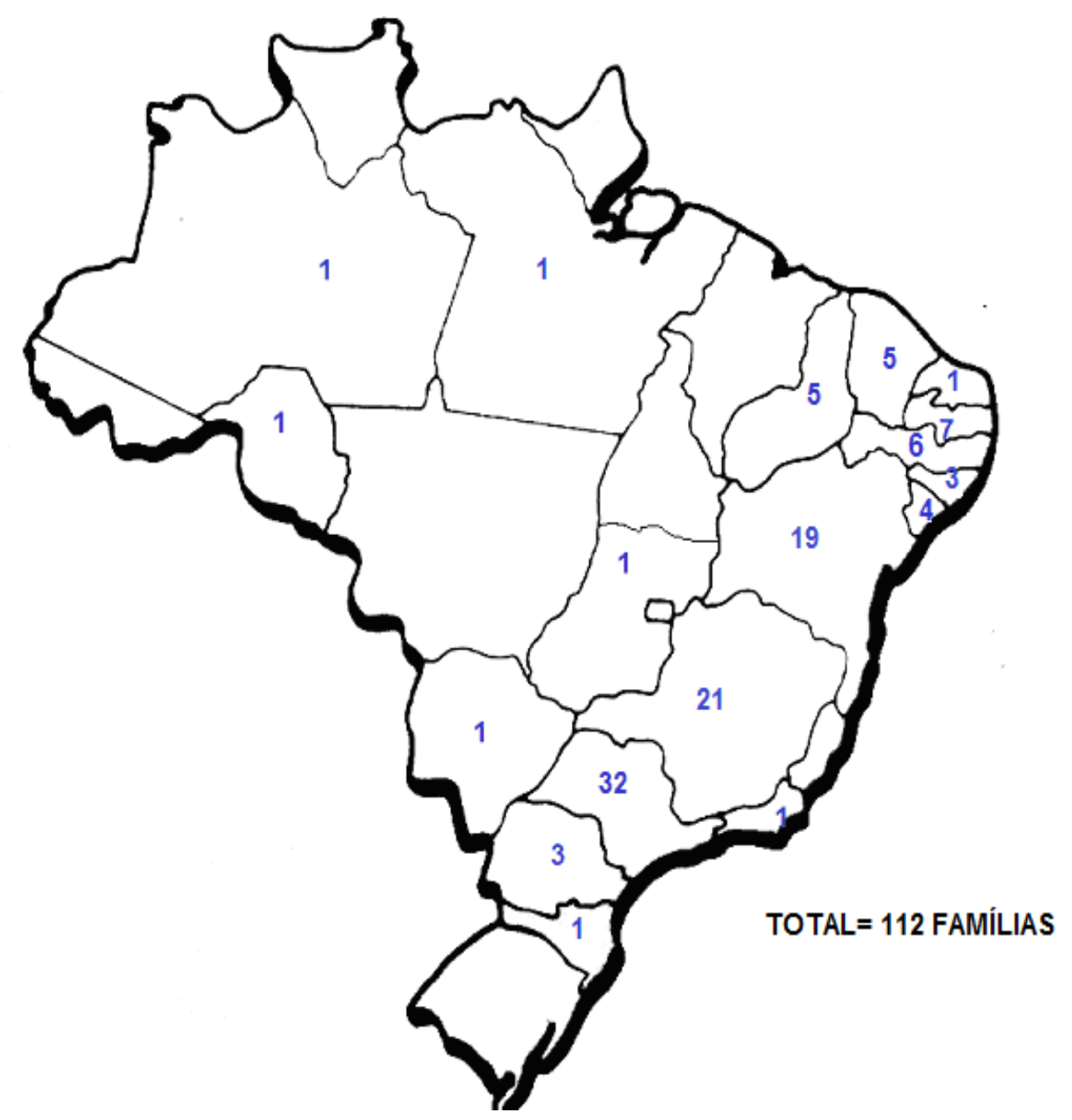

Figura 4.2 Distribuição nacional dos estados de origem em 112 famílias de portadores de doença de Wilson. 


\subsection{ASPECTOS CLÍNICOS, LABORATORIAIS E ESTUDOS DE IMAGENS}

\subsubsection{Aspectos clínicos}

As formas clínicas da DW foram classificadas conforme o órgão em que se observaram as primeiras manifestações da doença. Em 262 pacientes, a forma hepática foi a mais frequente ocorrendo em 95/262 (36,3\%), seguida pela neurológica 91/262 (34,7\%), assintomática 44/260 (16,8\%), neuro-psiquiátrica 22/262 (8,3\%) e hemólise 5/262 (1,9\%).

Outras apresentações menos comuns foram renal e neuro-hepática, com dois pacientes em cada forma, e osteoarticular (um caso).

Observamos que em 72,7\% (32/44) dos pacientes assintomáticos demonstravam hepatite crônica, 20,5\% (9/44) cirrose hepática e 3/44 (6,8\%) não demonstravam sinais de hepatopatia.

Os quadros clínicos predominantes, na ocasião do diagnóstico, foram hepático 38,9\% (102/262), neurológico 24\% (63/262), neuro-hepático 16,4\% (43/262), neuropsiquiátrico 13,4\% (35/262), e 4,2\% (11/262) apresentavam as três formas associadas. Apenas 1,2\% (3/262) eram assintomáticos. Os demais 1,9\% tinham manifestação hepática associada à doença renal ou ortopédica.

Disartria foi a manifestação neurológica mais frequente, ocorrendo em 89\% dos pacientes com essa apresentação. Foram detectados em 155 pacientes da casuística algum grau de comprometimento motor, sendo 33,6\% considerado grave, $45,8 \%$ moderado e $20,6 \%$ leve.

Uma paciente com a forma clínica neuro-psiquiátrica não manifestava sinais neurológicos. 
Em relação às síndromes neurológicas, a forma mista foi evidenciada em 57,1\% (52/91) dos casos com apresentação neurológica, a distônica ou de Wilson em 22\% (20/91), a Westphal-Strumpell em 17,6\% (16/91), a coréica em 2,2\% (2/91) e um caso 1,1\% (1/91) não foi possível definir.

Cirrose hepática descompensada foi registrada em 57,9\% (55/95) dos pacientes com quadro hepático.

Outras alterações observadas foram amenorréia 15 casos, nefrocalcinose 10, artralgia 8 , catarata em girassol 7 , colelitíase 4, aminoacidúria 4, hipotireoidismo 3, traço talassêmico 3, dislipidemia 3, diabetes mellitus 3, hipogonadismo 1, síndrome de Fanconi 1, síndrome de Turner 1, deficiência de $\lg \mathrm{A} 1$, meningocele 1 , doença reumática 1 e arritmia 1.

Os dados com todas as manifestações clínicas e suas respectivas freqüências, estão apresentados na tabela 4.3. 
Tabela 4.3- Manifestações clínicas iniciais de 262 pacientes com doença de Wilson

\begin{tabular}{|c|c|c|}
\hline Forma Clínica (N) & Modo de apresentação & $\begin{array}{l}\text { Pacientes } \\
\text { (N) }\end{array}$ \\
\hline \multirow[t]{3}{*}{ Assintomática (44) } & Hepatite crônica & 32 \\
\hline & Cirrose hepática & 9 \\
\hline & Sem hepatopatia & 3 \\
\hline \multirow[t]{4}{*}{ Hepática (95) } & Cirrose hepática descompensada & 55 \\
\hline & Cirrose hepática compensada & 25 \\
\hline & Hepatite aguda & 10 \\
\hline & Insuficiência hepática aguda grave & 5 \\
\hline \multirow[t]{7}{*}{ Neurológica (91) } & Disartria & 81 \\
\hline & Tremor & 66 \\
\hline & Alteração na marcha & 52 \\
\hline & Distonia & 49 \\
\hline & Rigidez & 45 \\
\hline & Alterações cerebelares & 27 \\
\hline & Epilepsia & 9 \\
\hline \multirow[t]{4}{*}{ Neuro-psiquiátrica (22) } & Alterações não psicóticas & 12 \\
\hline & Depressão & 3 \\
\hline & Esquizofrenia & 5 \\
\hline & Transtorno bipolar & 2 \\
\hline Neuro-hepática (2) & $\begin{array}{l}\text { Cirrose hepática compensada/ } \\
\text { disartria, distonia, rigidez, alteração } \\
\text { na marcha }\end{array}$ & 2 \\
\hline Osteomuscular (1) & Artrite & 1 \\
\hline Hematológica (5) & Anemia Hemolítica & 5 \\
\hline \multirow[t]{2}{*}{ Renal (2) } & Síndrome de Fanconi & 1 \\
\hline & Hematúria & 1 \\
\hline
\end{tabular}


A forma hematológica demonstrou início precoce dos sintomas, com média de 15,8 anos (10-19), contudo essa diferença não foi significante em relação a demais apresentações $(p>0,05)$. A média de idade observada no início da investigação dos assintomáticos foi 15,2 anos (4-51) e comparados com os casos neurológicos e neuro-psiquiátricos em que a abertura da doença ocorreu mais tardiamente, em média 19,3 anos (9-49) e 19,2 anos (6-30) respectivamente, houve diferença significante $(p=0,008$ e $p=0,03$, respectivamente). A forma hepática também manifestou sintomas mais precocemente em relação à neurológica $(p<0,001)$ e neuro-psiquiátrica $(p=$ 0,007), com média de 16,0 anos (7-37). O teste estatístico empregado nessas análises foi o teste $t$ de Student.

Os dados referentes às idades e ao atraso do diagnóstico, em relação às apresentações clínicas, estão ilustrados no gráfico 4.3.

A idade média na ocasião do diagnóstico em 44 pacientes assintomáticos foi 15,4 anos, com variação de 4 a 51 anos, enquanto a observada nas apresentações neurológica e neuro-psiquiátrica foram 21,0 anos (9-53) e 20,3 anos (7-32), respectivamente. Sendo significante a diferença estatística entre esses resultados $(p=0,0002$ e $p=0,03)$, assim como nos pacientes com quadro hepático quando comparados aos neurológicos ( $p=$ 0,0005). Para avaliação dessas variáveis foi utilizado o teste t de Student.

Os casos neurológicos exibiram maior atraso diagnóstico, com média de 1,8 anos, com variação de 0 a 16 anos, enquanto os pacientes assintomáticos demonstraram o menor retardo 0,2 anos (0-4), seguidos dos com a forma hematológica 0,4 anos (0-1), neuro-psiquiátrica 1,1 anos (0-5) e 
hepática 1,6 anos (0-12). A diferença foi significante comparando-se a média da forma assintomática com a hepática, neurológica e neuro-psiquiátrica ( $p=$ 0,0001). Os casos hematológicos exibiram um menor retardo em relação aos hepáticos $(p=0,004)$ e neurológicos $(p<0,001)$. Utilizou-se $o$ teste t de Student para essas análises.

Gráfico 4.3. Representação das idades de início do quadro clínico, idade e atraso diagnóstico, em anos, com as formas clínicas da DW

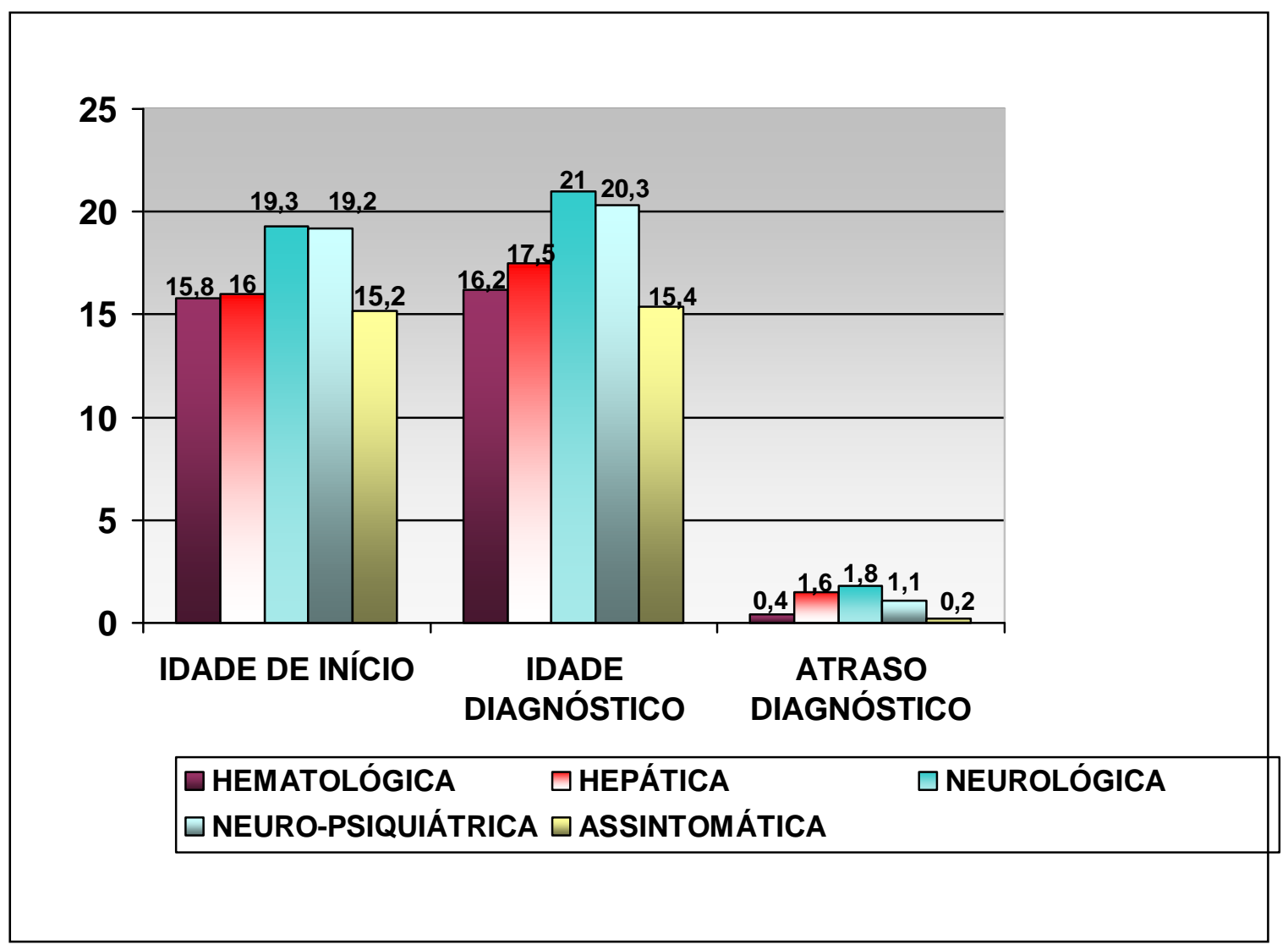

Os anéis de Kayser-Fleischer estavam presentes em 78,3\% (191/244) dos indivíduos pesquisados, todos os casos hematológicos exibiam os anéis. 
Apenas um paciente com quadro neurológico e neuro-psiquiátrico não os apresentaram, em contraste com os da condição hepática em que 71/89 $(79,8 \%)$ dos examinados os registraram. Somente $13,2 \%$ dos casos assintomáticos demonstraram essas estruturas, obtendo-se diferença significante em relação às formas neurológica, neuropsiquiátrica e hepática ( $p=$ $<0,0001$ ), por meio da utilização do teste do $\chi^{2}$. Empregando-se o teste de Fisher na comparação da forma hepática com a condição hematológica, foi observada significância estatística $(p=0,0002)$.

\subsubsection{Aspectos laboratoriais}

Em relação às enzimas hepáticas, observou-se aumento em 45,8\% (98/214) dos pacientes em que os níveis de ALT foram mensurados, com média 1,7 (1-12) vezes acima do limite superior de normalidade (XLSN) e de 1,7 (1-9 XLSN) para a AST, que estava elevada em 53,5\% (114/213) dos casos. A $\gamma$ GT mostrou-se alterada em 59\% (101/171) dos pacientes, com média de 1,7 (1-10) XLSN e a fosfatase alcalina em $40,9 \%$ (74/181) dos casos, aumentando em média 1,4 (1-9) XLSN.

Os níveis de ferritina foram mensurados em 45 casos (27 homens e 18 mulheres) a média registrada foi $317,5 \mathrm{ng} / \mathrm{dL}$ (49-1556), encontrando-se níveis acima de $300 \mathrm{ng} / \mathrm{dL}$ em 14 pacientes do sexo masculino $(31,1 \%)$ e superior a $200 \mathrm{ng} / \mathrm{dL}$ em seis portadoras (13,3\%) de DW.

Em 62 pacientes rastreados para hepatites virais A, B e C, detectou-se cicatriz sorológica para hepatite A em 17 casos e hepatite B em uma portadora. 
Houve uma sorologia reativa para o VHC, todavia o exame de PCR não confirmou a hepatite $\mathrm{C}$.

A pesquisa de autoanticorpos hepáticos foi efetuada em 44 portadores da casuística, observando-se a presença de anticorpo antimúsculo liso com titulação $>1 / 320$ em uma paciente do sexo feminino e $>1 / 160$ em um portador que apresentou padrão VGT (vasos, glomérulos e fibrilas intracelulares das células epiteliais dos túbulos renais).

Sete indivíduos apresentaram reatividade para o fator antinúcleo; houve relato do aspecto pontilhado fino em dois casos, e títulos com variação de 1/40 a $1 / 320$.

Até 1961, o diagnóstico de cinco pacientes foi realizado baseando-se nos achados clínicos característicos, anéis de Kayser-Fleischer, história familiar e exame histopatológico hepático. A partir desse período foram introduzidos os exames de ceruloplasmina e mensuração do cobre nos líquidos orgânicos e tecidos. A Tabela 4.3.1 apresenta a síntese dos parâmetros utilizados para diagnóstico da DW.

A ceruloplasmina sérica foi o teste diagnóstico mais frequentemente alterado no estudo, com níveis inferiores a $20 \mathrm{mg} / \mathrm{dL}$ em 98,7\% (227/230) dos casos examinados. Os níveis séricos da proteína foram em média 4,2 mg/dL (026) e a mensuração obtida após tratamento, em 125 casos, foi em média 5,0 $\mathrm{mg} / \mathrm{dL}$.

Registraram-se valores menores que $5 \mathrm{mg} / \mathrm{dL}$ em 149/230 dos exames (64,8\%). Não houve distinção entre as principais apresentações clínicas que 
demonstraram alteração desse teste $(p=>0,05)$. Para análise estatística empregou-se o teste do $\chi^{2}$.

A forma neuro-psiquiátrica foi a que apresentou menores níveis da proteína, em média 2,9 mg/dL (0-13), seguida da neurológica 3,4 mg/dL (0-26), e hepática 5,2 mg/dL (0-24). A diferença foi significante entre as médias dessas formas (Tabela 4.3.1). Utilizou-se nessa análise o teste de t Student.

A média observada do cobre urinário basal foi 423,2 $\mu \mathrm{g} / 24 \mathrm{~h}$ (10-3870), e $73 \%(119 / 163)$ dos exames exibiram mensuração acima de $100 \mu \mathrm{g} / 24 \mathrm{~h}$. Os valores referentes às principais formas clínicas encontram-se na Tabela 4.3.1 Os pacientes assintomáticos registraram menor cuprúria em relação aos com quadro neurológico e hepático ( $p<0,0001$ e $p=0,01$; respectivamente). A forma hematológica também mostrou valores significantemente inferiores em relação à neurológica $(p=0,04)$. Foi empregado o teste de t Student nessas análises.

Na comparação entre os examinados que demonstraram cuprúria acima de $100 \mu \mathrm{g} / 24 \mathrm{~h}$ (Tabela 4.3.1) houve diferença significante entre os casos da forma assintomática com a neurológica e hepática $(p=0,001$ e $p=0,01$, respectivamente). Foi utilizado o teste do $\chi^{2}$ nesta análise.

O cobre urinário, colhido após administração de um grama de penicilamina (teste da penicilamina), mostrou valores acima de $1600 \mu \mathrm{g} / 24 \mathrm{~h}$, em 50,8\% (32/63) dos examinados, com média 1734,4 $\mu \mathrm{g} / 24$ h (36-6377). Quando utilizado o limite de $1400 \mu \mathrm{g} / 24 \mathrm{~h}$, recomendado para adultos, o teste foi positivo em $54 \%$ (34/63) dos casos examinados. 
Os valores mensurados das principais apresentações clínicas encontram-se na Tabela 4.3.1. Apenas um caso assintomático atingiu cuprúria superior a $1600 \mu \mathrm{g} / 24 \mathrm{~h}$, em contrapartida $65,4 \%$ dos testes da forma neurológica e $62,5 \%$ da hepática obtiveram exame positivo. Houve diferença significante entre os pacientes assintomáticos com os da forma hepática e neurológica ( $p=0,016$ e $p=0,001$, respectivamente), sendo empregado o teste de Fisher, nessa análise.

Dois pacientes que tinham cuprúria basal dentro da normalidade apresentaram positividade ao teste da penicilamina. Utilizando-se o aumento de cinco vezes em relação à excreção urinária basal, cinco exames foram considerados positivos. 17 pacientes com cuprúria basal > $100 \mu \mathrm{g} / 24 \mathrm{~h}$ demonstraram teste negativo. 
Tabela 4.3.1- Parâmetros diagnósticos das principais formas de apresentação clínica em 257 portadores de doença de Wilson

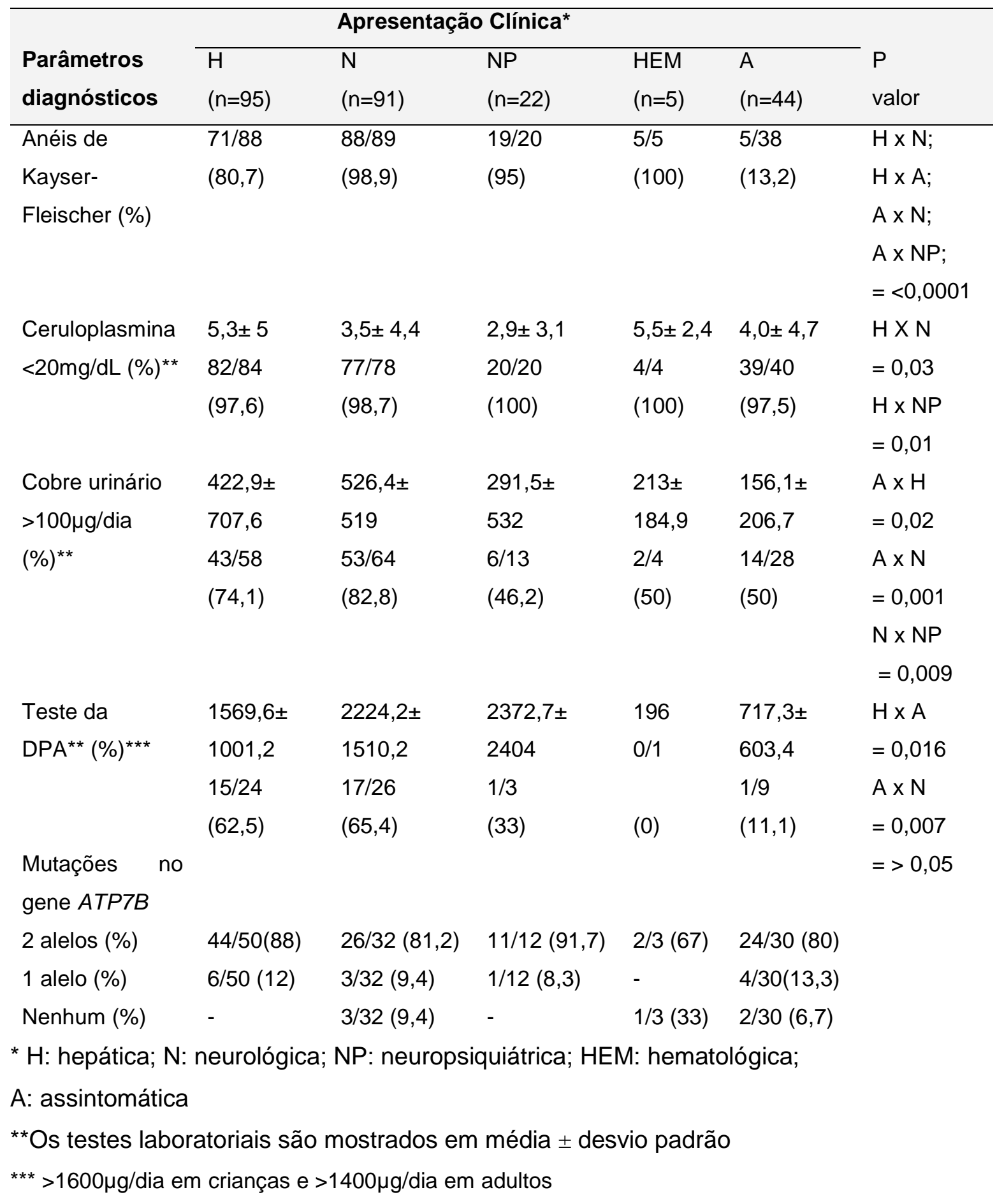


A mensuração estimada do cobre livre sérico foi, em média, de 26,8 $\mu \mathrm{g} / \mathrm{dL}$. Registrou-se aumento em 35,2\% (51/145) dos indivíduos estudados. Contudo 8,3\% (12/145) exibiam níveis inferiores a $5 \mu \mathrm{g} / \mathrm{dL}$. Os demais exames estavam dentro da faixa de normalidade. Os casos que exibiram valores superiores a $25 \mu \mathrm{g} / \mathrm{dL}$ foram 2/19 (10,5\%) dos assintomáticos, 2/13 (15,3\%) neuropsiquiátricos, 20/55 (36,4\%) hepáticos, 24/49 (49\%) neurológicos e 2/4 (50\%) hematológicos.

\subsubsection{Estudos de imagens}

Modificação da ecotextura hepática foi o achado mais observado à ultrassonografia do abdome, ocorrendo em $97 / 136$ exames $(71,3 \%)$, seguido de esplenomegalia 61/136 (44,9\%), hipertensão portal 22/136 (16,2\%), redução do volume hepático 21/136 (15,4\%) e ascite 19/136 (14\%). Alterações sugestivas de hepatopatia crônica foram encontradas em 33 (24,3\%) e cirrose hepática em 67 (49,3\%) das 136 avaliações. Em 17/136 (12,5\%) dos exames foram normais.

$\mathrm{Na}$ avaliação ultrassonográfica de pacientes cirróticos, (diagnosticados por estudo anatomopatológico) foram demonstradas alterações compatíveis com cirrose, tais como: alteração textural, associada à redução da dimensão hepática, hipertensão portal e/ou ascite em 20/36 (56\%) dos exames, entretanto 4/36 (11\%) das análises eram normais.

A tomografia computadorizada do abdome foi realizada em oito pacientes, sendo a esplenomegalia o achado mais comumente encontrado, em cinco exames, hepatomegalia em três, e um exame foi considerado normal.

A respeito dos estudos de imagem encefálica, foram encontradas alterações nos gânglios da base em 9/31 (29\%) e 42/54 (77,7\%), dos pacientes 
submetidos aos exames de TC e RNM, respectivamente. Onze pacientes exibiram sinais sugestivos de atrofia cerebral, na avaliação por TC. Os exames de TC e RNM foram normais em 11/31 (35\%) e 10/54 (18,5\%) dos casos examinados respectivamente. Dos casos com achados normais à RNM, quatro apresentavam manifestações neurológicas, enquanto à tomografia foram dois pacientes. A RNM de um indivíduo com quadro neuro-psiquiátrico demonstrou sinais de mielinólise pontina. Houve 11 registros de RNM em portadores da DW sem abertura de quadro neurológico, não se encontrando anormalidades em $6 / 11(54,5 \%)$ desses exames, os demais exibiam alterações em núcleos da base.

Setenta e dois pacientes foram submetidos à endoscopia digestiva alta. Os achados endoscópicos mais frequentes foram varizes esofagogástricas $34 / 72(47,2 \%)$, gastrites $22 / 72(30,1 \%)$, esofagite $11 / 72(15,3 \%)$, gastropatia hipertensiva $7 / 72(9,7 \%)$, hemorragia digestiva $6 / 72(8,3 \%)$, e 13/72 (18,0\%) dos indivíduos tiveram exame normal.

\subsection{ESTUDO ANATOMOPATOLÓGICO HEPÁTICO}

O estudo anatomopatológico hepático foi realizado em 100 casos, sendo que sete foram explantes, 18 necrópsias e 75 biópsias. Cirrose foi encontrada em $64 \%$ dos exames, esteatose macrogoticular em $33 \%$, glicogênio nuclear em 20\%. A coloração de rodanina foi positiva em 54,5 \% (18/33) dos exames pesquisados. Três pacientes mostravam biópsias sugestivas de hepatite autoimune. Seis apresentaram siderose, um desses após 13 anos de tratamento. 
Em relação ao estudo do metabolismo do cobre, apenas oito pacientes da casuística fizeram quantificação do cobre no fígado, em dois deles o cobre detectado era inferior a $250 \mu \mathrm{g} / \mathrm{g}$ de tecido hepático, contudo duas vezes acima do valor da normalidade. Dois outros casos foram avaliados por necrópsia e apesar de demonstrarem mensurações serem superior a $200 \mu \mathrm{g} / \mathrm{g}$ não atingiram o valor discriminante. A variação noticiada foi 119 a $2264 \mu \mathrm{g} / \mathrm{g}$.

\subsection{GENOTIPAGEM DO ATP7B}

O estudo de genotipagem $A T P 7 B$ foi realizado em 128 pacientes, desses $84,4 \%$ apresentaram mutação nos dois alelos, 10,9\% tinham único alelo afetado e 4,7\% não foi documentada mutação em nenhum dos alelos.

Em 25 pacientes que confirmaram o diagnóstico através da aplicação dos critérios do EUROWILSON (Ferenci et al., 2003) 22 registraram comprometimento nos dois alelos e três análises exibiam apenas um alelo acometido, desses casos 18 eram assintomáticos e sete demonstravam manifestações hepáticas. Os níveis séricos de ceruloplasmina estavam reduzidos em todos os sequenciados. Um caso não mostrava os anéis no início da investigação, mas um mês após transplante hepático iniciou quadro neurológico e essas estruturas foram identificadas. A cuprúria de 24 h estava normal em 10 pacientes, e em cinco casos elevou-se de acima de cinco vezes em relação ao valor normal com o uso de 1,0 g de DPA e os 10 demais não fizeram cuprúria e/ou teste da DPA.

Quando comparados os quadros clínicos com a presença de mutação nos dois alelos não foi observada significância (Tabela 4.3.1). Foi utilizado o 
teste de Fisher para comparar as apresentações neuropsiquiátricas com a hepática e neurológica. O teste do $\chi^{2}$ foi empregado nas demais comparações.

Cincos pacientes abriram o quadro com insuficiência hepática aguda grave. Quatro deles eram do sexo feminino, com idade entre 9 a 18 anos. 0 estudo de genotipagem foi realizado em dois casos. Um desses ainda está em andamento e o outro mostrou heterozigose composta. Houve registro de hemólise em duas crianças do sexo feminino. A Tabela 4.4 apresenta as alterações clínicas e dos testes diagnósticos dos referidos indivíduos. 
Tabela 4.4- Aspectos cínicos e laboratoriais dos cinco pacientes com DW e insuficiência hepática aguda grave

\begin{tabular}{|c|c|c|c|c|c|c|}
\hline Sexo & $\begin{array}{l}\text { Idade } \\
\text { (anos) }\end{array}$ & $\begin{array}{l}\text { Ceruloplasmina } \\
(\mathrm{mg} / \mathrm{dL})\end{array}$ & $\begin{array}{l}\text { Anéis de } \\
\mathrm{KF}\end{array}$ & $\begin{array}{l}\text { Cuprúria } \\
(\mu g / 24 \text { h) }\end{array}$ & $\begin{array}{l}\text { FA/ } \\
\text { bilirrubinas }\end{array}$ & $\begin{array}{l}\text { Biópsia } \\
\text { hepática }\end{array}$ \\
\hline $\mathrm{F}$ & 9 & 10,0 & Presentes & $\begin{array}{l}\text { Sem } \\
\text { dados }\end{array}$ & $<2$ & $\mathrm{CH}^{*}$ \\
\hline $\mathrm{F}$ & 11 & 0,0 & $\begin{array}{l}\text { Sem } \\
\text { dados }\end{array}$ & 555 & $<2$ & $\begin{array}{l}\text { Sem } \\
\text { dados }\end{array}$ \\
\hline $\mathrm{F}$ & 14 & 11,0 & Presentes & 3870 & $<2$ & $\mathrm{CH}^{*}$ \\
\hline$F$ & 18 & 7,0 & $\begin{array}{l}\text { Sem } \\
\text { dados }\end{array}$ & $\begin{array}{l}\text { Sem } \\
\text { dados }\end{array}$ & $<2$ & $\mathrm{CH}^{*}$ \\
\hline M & 14 & Sem dados & Presentes & $\begin{array}{l}\text { Sem } \\
\text { dados }\end{array}$ & $<2$ & $\mathrm{CH}^{*}$ \\
\hline
\end{tabular}

${ }^{*} \mathrm{CH}$ : cirrose hepática

\subsection{TRATAMENTO E SEGUIMENTO}

O tempo de seguimento dos 262 pacientes foi em média 9,6 anos (0-45 anos). O paciente com maior tempo de acompanhamento encontra-se com 72 anos de idade. Houve perda de seguimento de 55 indivíduos, desses 58,2\% residiam em outros estados. Registraram-se 82 óbitos.

Os três primeiros casos desse estudo faleceram em até cinco anos após início dos sintomas, antes da descoberta de tratamento específico. Outros nove pacientes críticos não foram tratados porque morreram durante a investigação diagnóstica. 
Nos 245 casos inicialmente submetidos à farmacoterapia, DPA foi prescrita em 93,5\% ( $n=229)$. A dose foi geralmente $250 \mathrm{mg} / \mathrm{dia}$, com aumentos graduais até 750-1500 mg/dia, em associação à piridoxina 25-50 mg/dia. Em crianças utilizou-se $20 \mathrm{mg} / \mathrm{kg} / \mathrm{dia}$. Trientina foi administrada em quatro pacientes, com similar posologia. Zinco foi introduzido em 10 casos, na dose de $150 \mathrm{mg} / \mathrm{dia}$ (da sua forma elementar). Um paciente fez uso de dimercaprol e outro tomou única dose de ácido etileno diamina tetra acético (EDTA). Todos os indivíduos receberam orientação para evitar ingesta de alimentos com rico teor em cobre.

Durante o seguimento, 79 pacientes modificaram o tratamento. $\mathrm{Na}$ totalidade a DPA foi utilizada por 236 portadores, os sais de zinco em 55 e a trientina em 30 casos.

Efeitos adversos foram registrados em 125 (53,0\%) dos usuários de DPA, 20 (35,7\%) dos sais de zinco, seis da trientina (20,0\%) e um do BAL. Em 50 pacientes foi necessário substituir a DPA por esse motivo, assim como em dois casos submetidos à terapia com sais de zinco. Três pacientes em uso da trientina e sete tratados com DPA realizaram a substituição por falta da medicação. Houve relato de mudança terapêutica devido à má resposta em três pacientes que usavam DPA e dois medicados com sais de zinco.

Foram obtidos dados relacionados à aderência e responsividade à farmacoterapia em 183 casos distintos, dos quais 29 (15,8\%) obtiveram resposta completa, $78(42,6 \%)$ incompleta e $76(41,5 \%)$ ruim. Os 55 doentes que perderam o acompanhamento no serviço não foram incluídos. A aderência foi considerada boa em $112(61,2 \%)$ dos indivíduos, irregular em 37 (20,2\%) e 
ruim em 34 (18,6\%). Quando se analisa apenas os últimos casos, observa-se que nenhum obteve resposta completa, contrapondo-se aos 26/112 (23,2\%) e $3 / 37(8,1 \%)$ em que se considerou como boa e irregular a aderência, respectivamente. Em relação ao desfecho desfavorável, observamos que 29/34 $(85,3 \%)$ e $35 / 112(31,3 \%)$ daqueles categorizados com adesão terapêutica ruim e boa, respectivamente, cursaram com deterioração clínica, sendo essa diferença significante $(p<0,0001)$, quando se utilizou o teste $\chi^{2}$.

Portanto, em decorrência da irregularidade do tratamento interferir nos eventos clínicos, a análise da responsividade de cada droga só foi realizada nos pacientes com boa aderência. Os dados referentes a este evento encontram-se expostos na Tabela 4.6.1. 
Tabela 4.6.1- Farmacoterapia utilizada, padrões de resposta terapêutica e efeitos adversos em 243 pacientes com DW

\section{Terapia farmacológica}

\begin{tabular}{llll} 
Variáveis & Penicilamina & Sais de zinco & Trientina \\
\hline Pacientes (N) início/fim & $229 / 185$ & $10 / 29$ & $4 / 16$ \\
Tempo médio de uso (anos) & $7,6(0,01-44)$ & $3,1(0,02-18)$ & $3,6(0,1-21)$ \\
Modificaram medicação (N) & $69 / 229(30,1 \%)$ & $7 / 10(70 \%)$ & $3 / 4(75 \%)$ \\
Aderência à terapia & & & \\
Boa/irregular/ruim & $78 / 28 / 31$ & $17 / 3 / 2$ & $12 / 2 / 1$ \\
Resposta terapêutica* & & & \\
Completa** (\%) & $16 / 78(20,5 \%)$ & $5 / 17(29,4 \%)$ & $4 / 12(33,3 \%)$ \\
Incompleta** (\%) & $35 / 78(44,9 \%)$ & $7 / 17(41,2 \%)$ & $6 / 12(50,0 \%)$ \\
Ruim (\%) ${ }^{* *}$ & $27 / 78(34,6 \%)$ & $5 / 17(29,4 \%)$ & $2 / 12(16,7 \%)$ \\
Efeitos adversos (N usuários) & & & \\
Proteinúria (\%) & $51 / 236(21,6 \%)$ & - & - \\
Piora neurológica (\%) & $23 / 236(9,7 \%)$ & $4 / 56(7,1 \%)$ & $1 / 30(3,3 \%)$ \\
Transtornos digestivos (\%) & $20 / 236(8,5 \%)$ & $14 / 56(25 \%)$ & $4 / 30(13,3 \%)$ \\
Leucopenia (\%) & $23 / 236(9,7 \%)$ & $1 / 56(1,8 \%)$ & - \\
Hipersensibilidade (\%) & $23 / 236(9,7 \%)$ & - & - \\
Elastosis perforans & $6 / 236(2,5 \%)$ & - & \\
serpiginosa (\%) & & & \\
\hline A diferença dos padoes d & & & \\
\hline & & & \\
\hline
\end{tabular}

${ }^{*}$ A diferença dos padrões de resposta entre as drogas não foi significante $(p=0,2)$

${ }^{* *}$ Avaliação ao final do seguimento dos casos distintos e com boa aderência 
Analisando-se os padrões de resposta terapêutica (completa, incompleta e ruim) em relação ao uso de DPA, sais de zinco ou trientina não se observou diferença significante $(p=0,2)$ entre essas drogas (Tabela 4.6.1). $O$ teste $\chi^{2}$ foi empregado para essa avaliação.

Dez pacientes usaram associação de drogas. Zinco foi utilizado com DPA em sete casos, e com trientina em três. A resposta foi considerada completa em dois pacientes, incompleta em cinco e ruim em dois. Outro doente abandonou o seguimento. As reações adversas relatadas foram dor abdominal e piora neurológica importante, ocorridas em um paciente que estava medicado com sais de zinco e DPA por três meses.

Os efeitos colaterais foram responsáveis pela má resposta terapêutica em 15 indivíduos que usaram DPA e em dois que tomaram sais de zinco.

Nenhum paciente assintomático, com boa aderência ao tratamento, obteve resultado clínico ruim. Foi encontrando diferença estatística significante entre os casos dessa forma que usavam penicilamina com os da forma neurológica $(p=0,012)$ e hepática $(p<0,001)$, entretanto não houve distinção quando comparados ao quadro neuropsiquiátrico $(p=0,1)$. Foi empregado $o$ teste de Fisher para essa análise.

Não se registrou resposta desfavorável entre os portadores da forma hematológica que usaram zinco ou trientina, entretanto não houve distinção estatística significante quando comparados aos modos assintomático, hepático, neurológico e neuropsiquiátrico $(p>0,05)$. Foi utilizado o teste de Fisher para avaliação dessas variáveis. 
Cinco casos da forma hepática que foram tratados com DPA e um com trientina e que cursaram com má resposta estavam há menos de seis meses sob terapia.

Dois portadores de DW com a forma neurológica que não responderam aos sais de zinco, encontravam-se em más condições clínicas e faleceram em menos de um ano após o início do tratamento. Evolução semelhante foi observada em seis casos que usaram DPA, porém faleceram em até cinco meses.

A Tabela 4.6.2 ilustra as respostas terapêuticas obtidas por cada droga ao final do estudo, conforme as principais apresentações clínicas da DW, sendo avaliados apenas os usuários com boa aderência ao tratamento.

Tabela 4.6.2- Padrões de resposta à farmacoterapia ao final do segmento, conforme as formas de apresentação clínica nos portadores de DW com boa aderência terapêutica

\begin{tabular}{|c|c|c|c|c|c|}
\hline \multirow{3}{*}{ Formas clínicas ( $\mathbf{N}$ ) } & \multicolumn{5}{|c|}{ Fármacos e resposta terapêutica } \\
\hline & \multicolumn{3}{|c|}{ (completa/incompleta/ruim) } & \multirow[t]{2}{*}{ Teste } & \multirow[t]{2}{*}{$\mathbf{P}$ valor } \\
\hline & Penicilamina & Zinco & Trientina & & \\
\hline Assintomática (18) & $6 / 8 /-$ & $1 / 1 /-$ & $1 / 1 /-$ & Fisher & 0,69 \\
\hline Hematológica (3) & $-/-/-$ & $1 / 1 /-$ & $1 /-/-$ & Fisher & 0,66 \\
\hline Hepática (42) & $3 / 12 / 15$ & $2 / 3 / 2$ & $1 / 3 / 1$ & $\chi^{2}$ & 0,52 \\
\hline Neurológica (33) & $5 / 12 / 10$ & $1 / 1 / 2$ & $1 / 1 / 1$ & $\chi^{2}$ & 0,93 \\
\hline Neuro-psiquiátrica (9) & $2 / 3 / 2$ & $-/ 1 /-$ & $-/ 1 /-$ & Fisher & 0,99 \\
\hline
\end{tabular}


Nos 132 pacientes com quadro clínico, laboratorial e com estudo de imagem e/ou histopatológico compatível com cirrose hepática, foi realizada a classificação de Child-Turcotte-Pugh, sendo categorizados como A 46,2\% (61/132), B 9,9\% (13/132) e C 43,9\% (58/132). A classificação no final do seguimento foi A $67,4 \%$ (89/132), B 3,8\% (5/132) e C $28,8 \%$ (38/132). Durante o tratamento, houve redução dos casos categorizados como CHILD C e incremento dos classificados como CHILD A sendo essa diferença considerada significante $(p=0,01)$ por meio do teste $\chi^{2}$.

A respeito da resposta clínica hepática foram analisados 110 casos com boa aderência terapêutica, 85 (77,3\%) obtiveram resolução dos sintomas, 22 $(20,0 \%)$ apresentaram piora do quadro e em três $(2,7 \%)$ a melhora foi incompleta.

A análise da bioquímica hepática em 194 pacientes demonstrou normalidade em 77/194 (39,7\%) dos exames, persistência das alterações em $84(43,3 \%)$ e piora em 20/194 (17\%) dos testes.

Quanto à avaliação da resposta neurológica em 111 casos registrou-se resultado satisfatório em $86 / 111 \quad(77,5 \%)$ dos pacientes submetidos à farmacoterapia, 9/111 indivíduos (8,1\%) cursaram com quadro inalterado e 16/111 (14,4\%) dos pacientes evoluiram com deterioração clínica.

Os anéis de KF desapareceram em 29/63 (46,0\%) dos pacientes pesquisados.

A média da cuprúria encontrada foi $570,0 \mu \mathrm{g} / 24$ h (8 a 2280), porém 17/127 dos examinados apresentavam níveis indetectáveis, ou seja, menores 
que $80 \mu \mathrm{g} / 24$ h, não sendo computados para extração dessa média, incluindose aqueles sob uso de zinco. Em relação aos pacientes com boa aderência, os valores estavam dentro da faixa terapêutica recomendável em 30/83 $(36,2 \%)$ dos casos avaliados e 27/83 (32,5\%) apresentaram mensuração acima do limite superior sugerido, os demais 26 registraram níveis abaixo do estipulado $(31,3 \%)$.

O exame do cobre sérico livre foi analisado em 95 exames, entretanto somente 55 casos relatavam boa aderência, entre eles $44(80,0 \%)$ exibiam níveis inferiores a $5 \mu \mathrm{g} / \mathrm{dL}$, oito (14,5\%) estavam na faixa entre $5-15 \mu \mathrm{g} / \mathrm{dL}$ e três $(5,5 \%)$ os valores encontravam-se acima de $15 \mu \mathrm{g} / \mathrm{dL}$.

Dos cinco pacientes que abriram o quadro com insuficiência hepática aguda grave dois sucumbiram antes da disponibilidade do transplante, e os demais foram submetidos a esse tratamento. Seis outros portadores de DW desenvolveram descompensação hepática e necessitaram de transplante, três deles usavam irregularmente as medicações e dois pacientes iniciaram a farmacoterapia poucos dias antes do transplante. Todos pacientes transplantados sobreviveram, exceto um que morreu de insuficiência respiratória, asfixiado por alimento três anos após a realização do transplante.

Os três primeiros casos diagnosticados desse estudo faleceram até cinco anos do início dos sintomas, antes do descobrimento da terapia específica. O tratamento na época foi somente paliativo. Outros nove casos não foram tratados porque sucumbiram durante a investigação. $O$ tempo de sobrevida do início dos sintomas ao óbito foi em média 1,8 anos (0,027-5 anos). 
Óbito com menos de seis meses de tratamento foi notificado em 11 casos submetidos à farmacoterapia com DPA e um com sais de zinco, todos esses indivíduos foram diagnosticados com a doença em fase avançada. Todavia, seis portadores não apresentavam sinais de descompensação clínica, e evoluíram com piora progressiva e faleceram após a admissão.

O retardo para realização do diagnóstico foi em média 2,0 anos (0-22), superior a média de 0,9 anos (0-12 anos) dos 124 pacientes que sobreviveram e não perderam o seguimento. Essa diferença foi significante $(p=0,001)$. $O$ teste t de Student foi empregado para essa análise.

As principais causas de óbitos nos 82 casos com DW, foram por descompensação hepática $(41,5 \%)$ e pneumonia $(20,7 \%)$, todavia foram registradas causas não naturais tais como mortes violentas por acidente de trânsito (3,7\%) e suicídio (3,7\%). A Tabela 4.6 .3 exibe as principais causas de óbito no nosso serviço. 
Tabela 4.6.3- Formas clínicas predominantes e causas de morte em 82 pacientes com doença de Wilson

\begin{tabular}{lll}
\hline Formas Clínicas & Causas & Pacientes (\%) \\
\hline Hepática & PBE $^{*}$, encefalopatia & $25(30,5 \%)$ \\
& Rotura de varizes esofágicas & $9(11 \%)$ \\
& Insuficiência hepática aguda grave & $2(2,4 \%)$ \\
& Pneumonia & $6(7,3 \%)$ \\
Neurológica & Pneumonia, ITU**, sepsis & $11(13,4 \%)$ \\
& Coma, caquexia & $4(4,9 \%)$ \\
& Status epilepticus & $1(1,2 \%)$ \\
Psiquiátrica & Asfixia & $1(1,2 \%)$ \\
Causas Externas & Complicação de neurocirurgia & $1(1,2 \%)$ \\
& Suicídio & $3(3,7 \%)$ \\
Outras & Atropelamente automobilístico & $2(2,4 \%)$ \\
& Hemorragia por úlcera péptica & $1(1,2 \%)$ \\
& Nefropatia por DPA & $1(1,2 \%)$ \\
& Desconhecida & $14(1,2 \%)$ \\
\hline
\end{tabular}

*PBE: peritonite bacteriana espontânea. ${ }^{* *}$ ITU: infecção do trato urinário

Ao longo do tempo houve uma redução no número de mortes devido à DW. Na década de 80 , registrou-se 25 óbitos em 86 pacientes acompanhados (29\%), a partir de 2000 notificaram-se 15 falecimentos em 166 portadores (9\%), contudo neste período registrou-se uma maior perda do seguimento, com 24 abandonos, o dobro do que foi evidenciado nos anos 80 e 90 . 
DISCUSSÃO 


\section{DISCUSSÃO}

A presente casuística é constituida de 262 portadores da doença de Wilson com diagnóstico estabelecido nas últimas seis décadas.

A idade observada à época do diagnóstico compreendeu de 4 a 53 anos, porém há relato na literatura de criança com elevação de enzima hepática desde um ano (Beyersdorff; Findeisen, 2006), assim como a ocorrência da DW em septuagenários (Ala et al., 2005), sugerindo que poderíamos ampliar o screening para essas faixas etárias.

A média de idade obtida na abertura do quadro clínico foi 17,4 anos (649), semelhante à descrita por Merle et al. (2007), entretanto existem publicações, oriundas principalmente de serviços asiáticos, com pacientes mais jovens, exibindo idade média inferior a 16 anos (Taly et al., 2007; Tatsumi et al., 2010; Wang et al., 2011), contudo outros trabalhos demonstraram média acima de 23 anos (Svetel et al., 2009; Bem et al., 2011; Litwin et al., 2011). A faixa etária de início dos sintomas parece não seguir um padrão definido, possivelmente por influência de alguns fatores ambientais ou genéticos.

Os casos assintomáticos foram os mais jovens dessa pesquisa, com média de 15,2 anos, enquanto aqueles com quadro neurológico demonstraram maior idade na abertura dos sintomas e na época do diagnóstico, com idades de 19,3 e 21 anos, respectivamente, sendo significativa a diferença com os portadores da forma hepática. Esses resultados estão de acordo com as descrições da literatura e compatível com a progressão da doença (Vrabelova et al., 2005; Merle et al., 2007; Tatsumi et al., 2010), entretanto observamos no 
presente trabalho que 12 casos neurológicos não exibiam alteração hepática.

O tempo necessário para realização do diagnóstico em nossos pacientes foi 1,4 anos, porém houve decréscimo ao longo das décadas, sendo inferior a um ano, atualmente. Weiss et al. (2011) relataram também atraso de 1,0 ano, entretanto Litwin et al. (2011) na maior série registrada, com 627 portadores da DW, referiram uma demora de quase dois anos.

Apesar de manifestações hematológicas, renais ou osteoarticulares terem sido evidenciadas na abertura do quadro clínico, as apresentações mais freqüentes foram hepática $(36,2 \%)$ e neurológica $(34,7 \%)$, o que está de acordo com os principais órgãos envolvidos nesta doença (Brewer; YuzbasiyanGurkan, 1992; Ala et al., 2007). Essa classificação dentro de formas clínicas tem algumas dificuldades, pois durante a avaliação médica inicial $86,8 \%$ dos pacientes com quadro neurológico também exibiam anormalidade no fígado. Os trabalhos que mostram um predomínio significativo de um quadro sobre outro são provavelmente devido a especialidade do centro de referência (Gow et al., 2000; Taly et al., 2007, Merle et al., 2007, Abdel Ghaffar et al., 2011). Contudo há estudos que demonstram a influência de mutações do gene ATP7B na expressão fenotípica da doença (Wu et al., 2001; Liu et al., 2004; Stapelbroek et al., 2004).

Ao longo das seis décadas foram utilizados parâmetros diagnósticos propostos por Wilson (1912), Scheinberg e Sternlieb (1984), Ferenci et al. (2003), Roberts; Schilsky, (2008). Em nosso serviço, entretanto, outros achados também foram considerados importantes tais como hepatopatia de causa indeterminada associada a níveis reduzidos séricos de ceruloplasmina e história 
familiar de DW, ou hepatopatia de origem desconhecida apresentando anéis de KF e/ ou hemólise, ou alteração nos exames do metabolismo do cobre com resposta terapêutica favorável ao uso de quelantes ou zinco. A utilização dessas variantes proporcionou a inserção de 14 pacientes. Entretanto, a validação desses critérios deverá ser objeto de futuros estudos.

Os anéis de KF foram detectados em $78,3 \%$ dos indivíduos pesquisados, sendo observados em $100 \%$ dos casos hematológicos, seguida das formas neurológica $98,9 \%$ e neuro-psiquiátrica $95 \%$, todavia dois pacientes (casos 19 e 106) apresentavam sinais neurológicos e não exibiam essas estruturas, contrariando Scheinberg e Sternlieb (1984) que propuseram a exclusão do diagnóstico nessa situação. Outros trabalhos reportam a não obrigatoriedade absoluta dessa associação (Steindl et al., 1997, Gow et al., 2000; Bruha et al., 2010, Mehta et al., 2010). Um achado importante é que $86,8 \%$ dos portadores assintomáticos pesquisados não demonstravam essas estruturas, reforçando a necessidade de outros parâmetros diagnósticos nestes casos.

A dosagem de ceruloplasmina sérica foi o exame mais frequentemente alterado, encontrando-se reduzido em $98,7 \%$ dos pacientes, percentagem acima da relatada na literatura (Steindl et al., 1997; Medici et al., 2006; Merle et al., 2007). Por outro lado, Stremmel et al. (1991) encontraram valores aproximados ao nosso, e recentes trabalhos (Tatsumi et al., 2010; Lee et al., 2011) reportaram baixos níveis séricos da proteína em 100\% da casuística. Todos os casos hematológicos e neuro-psiquiátricos testados também exibiam hipoceruloplasminemia. 
Um estudo de Walshe (2005) mostrou indivíduos sem DW com sintomas neurológicos associados a baixos níveis de ceruloplasmina, os anéis de KF estavam ausentes, sendo hipotetizado 0 diagnóstico de aceruloplasminemia. Contudo para o sistema de escore de Ferenci et al. (2003) seriam dados suficientes para sugerir o diagnóstico de DW. Outro problema desse sistema diagnóstico de escore é a não consideração da hepatopatia como variável de pontuação, contemplando somente os casos neurológicos e hematológicos. Ocorre que não há forma hepática típica de DW, mas a identificação de doença hepática não colestáticas com presença de anéis de KF é altamente sugestiva ao diagnóstico de DW.

Aproximadamente $20 \%$ dos heterozigotos podem apresentar níveis reduzidos da proteína sem ter a doença (Scheinberg; Sternlieb, 1984; Brewer; Yuzbasiyan-Gurkan, 1992), porém observamos que $24,4 \%$ dos pacientes da nossa pesquisa foram oriundos de triagem familiar e apenas um mostrava nível acima de $20 \mathrm{mg} / \mathrm{dL}$ (caso 256). Com o advento da genotipagem é possível que alguns desses indivíduos deixem de ser considerados heterozigotos para serem portadores assintomáticos.

Em 10 indivíduos houve quantificação do cobre hepático, e todos estavam acima dos limites de normalidade, porém quatro mensurações foram inferiores a $250 \mu \mathrm{g} / \mathrm{g}$ de tecido seco, duas delas foram obtidas por necrópsia o que elimina o problema de erro amostral. Ferenci et al. (2005) não consideram o estudo do cobre hepático como padrão ouro para o diagnóstico da DW sob o argumento que uma quantificação inferior a $250 \mu \mathrm{g} / \mathrm{g}$ não devesse excluir a doença, pois a sensibilidade observada pelos autores foi $83,5 \%$. Em nosso 
estudo o exame foi decisivo para o diagnóstico nos casos 58 e 256, ambos eram heterozigotos simples, assintomáticos, os anéis de KF estavam ausentes, e os níveis de cuprúria basal eram normais.

Apesar das diretrizes da Associação Européia para os Estudos do Fígado (2012) reportarem que menos de $10 \%$ das colorações com rodanina e orceína são positivas na DW, encontramos reatividade para essa pigmentação em $54,5 \%$ das análises, semelhante a descrição de Jain et al. (1978). Há relato que na fase inicial da doença a sensibilidade do método diminui (Pilloni et al., 1998), o que está de acordo com os resultados do presente estudo pois $77,8 \%$ das análises positivas foram em pacientes cirróticos. Isso sugere que na carência da quantificação hepática do cátion o estudo histoquímico poderia corroborar o diagnóstico em indivíduos cirróticos.

O seqüenciamento do gene $A T P 7 B$ detectou mutação em ambos os cromossomos em $84,4 \%$ das análises, estando em concordância com a literatura (Stapelbroek et al., 2004; Vrabelova et al., 2005; Tatsumi et al., 2010; Lee et al., 2011). Não houve diferença significante entre as formas clínicas e o acometimento alélico.

Ferenci et al. (2003) e a AASLD (Roberts; Schilsky, 2008) recomendam o estudo genético para screening dos irmãos de portadores da DW. As diretrizes da EASL (2012) estenderam a utilização desse exame para os filhos dos pacientes. Em nossa pesquisa a análise genética contribui de maneira variável no diagnóstico definitivo em 25 dos casos (9,5\%). Desses 16 foram assintomáticos incluídos por triagem familiar, outros dois indivíduos que também não demonstravam sintomas foram descobertos durante investigação 
de elevação das aminotransferases. Em dois portadores a identificação foi realizada após transplante hepático (casos 65 e 161).

A cuprúria basal estava acima de $100 \mu \mathrm{g} / 24 \mathrm{~h}$ em $73 \%$ dos casos avaliados, sendo que $79 \%$ dos testes revelaram valores maiores que $40 \mu \mathrm{g} / \mathrm{dia}$. Gow et al. (2000) reportaram aumento em $65 \%$ dos exames de cobre urinário, Taly et al. (2007) evidenciaram resultados semelhantes ao nosso, porém utilizaram valor discriminante distinto. Outros trabalhos relataram maior sensibilidade (Lau et al., 1990; Steindl et al., 1997; Merle et al., 2007, Lee et al., 2011). As menores mensurações foram detectadas nos assintomáticos, conforme descrito por Ferenci et al. (2003). Um achado intrigante foi que os pacientes com quadro neurológico exibiam maiores níveis e número de exames alterados enquanto os com a forma neuropsiquiátrica demonstravam exatamente o inverso. Infelizmente apenas três portadores dessa apresentação fizeram o teste da DPA e somente um foi positivo, enquanto os casos neurológicos reproduziram os mesmos resultados. Uma possível justificativa é que $49 \%$ dos doentes com essa apresentação exibiam elevação do cobre sérico livre, em contrapartida somente dois indivíduos com apresentação neuropsiquiátrica registraram aumento.

O teste da DPA foi positivo em $50,8 \%$ dos 63 pacientes da presente casuística. Apesar do exame de cuprúria de $24 \mathrm{~h}$ demonstrar maior sensibilidade, o estímulo com a penicilamina promoveu a inclusão de dois pacientes (5 e 181) que demonstravam baixos níveis de cobre urinário de $24 \mathrm{~h}$. Ao considerarmos como teste positivo um incremento maior que cinco vezes ao encontrado na cuprúria basal (Ferenci et al., 2003) cinco pacientes foram 
inseridos (casos 28, 90, 196, 252, 256), entretanto Vieira et al. (2012) reportaram que a grande maioria dos pais de pacientes com DW, potenciais heterozigotos, apresentavam valores médios de incremento na cuprúria maiores do que 15 vezes após administração da DPA.

Semelhante aos resultados de Muller et al. (2007) nossos casos assintomáticos mostraram menor resposta após estímulo com DPA em relação as demais formas. Roberts e Schilsky (2008) recomendam esse exame para crianças sintomáticas com cuprúria menor que $100 \mu \mathrm{g} /$ dia e as diretrizes da EASL (2012) não sugerem seu uso em adultos.

O gênero masculino foi registrado em $68,1 \%$ (62/91) dos casos com a forma neurológica e em 59,1\% (13/22) daqueles com a apresentação neuropsiquiátrica. Um dos mecanismos propostos para explicar a relação entre sexo e manifestação neurológica seria que os homens têm maior concentração cerebral de ferro ligado à ferritina que as mulheres e a presença desse metal estaria associada a doenças neurodegenerativas (Bartzokis et al., 2007). No presente estudo evidenciamos maiores níveis de ferritina entre os indivíduos do sexo masculino, de acordo como descrito na literatura (Pfeiffenberger et al., 2012). Contudo, entre os 14 pacientes do sexo masculino que apresentavam esse exame alterado, cinco exibiam quadro neurológico, em contrapartida seis mulheres com hiperferritinemia três demonstravam essa manifestação clínica.

A ceruloplasmina é uma proteína com ação de ferroxidase, que catalisa a reação da forma ferrosa do ferro $\left(\mathrm{Fe}^{2^{+}}\right)$em férrica $\left(\mathrm{Fe}^{3^{+}}\right)$que é incorporada à transferrina. Dessa forma desempenha importante papel no transporte transmembrana desse metal (Pérez-Aguilar, 2002). Como a doença de Wilson 
cursa com hipoceruloplasminemia, há descrição de portadores apresentando acúmulo hepático do ferro (Shiono et al., 2001). Seis pacientes da casuística mostraram siderose na biópsia hepática. Nenhum deles submeteu-se a exames de imagem encefálica. Em todos eles os valores de ceruloplasmina eram inferiores a $10 \mathrm{mg} / \mathrm{dL}$. Apenas um (caso 66) apresentava quadro neurológico e faleceu após 11 dias de tratamento com DPA e não havia registro dos exames de ferritina ou saturação férrica. A análise por autópsia revelou discreta siderose, esteatose macro e microvesicular e cirrose hepática.

Um paciente (caso 7) não evoluiu com alteração no metabolismo do ferro. A sua primeira biópsia, aos 10 anos de idade, registrava cirrose hepática com rodanina presente e o segundo estudo histopatológico, efetuado 13 anos após o início da farmacoterapia (utilizou DPA, sais de zinco e trientina), mostrava discreta fibrose e siderose. Os lipídes não se encontravam alterados, embora tenha sido notificado sobrepeso. Apesar da possibilidade de erro na amostra histológica, esse caso não evoluiu com sinais de hipertensão portal, sugerindo que realmente possa ter ocorrido regressão da cirrose hepática.

O caso 214 efetuou a primeira biópsia aos 10 anos que evidenciou cirrose. Fez uso irregular de DPA e apresentou importante sobrecarga de ferro. Foi submetido a segunda biópsia aos 20 anos que mostrou persistência da cirrose e siderose, sendo realizadas flebotomias. Evoluiu satisfatoriamente com normalização das aminotransferases e dos testes laboratoriais do metabolismo do metal.

É descrito na literatura que a deficiência do cobre está relacionada à esteatose hepática e esteatohepatite não alcoólica (Aigner et al., 2010). Os 
portadores de DW submetidos a períodos prolongados de quelação do metal poderiam evoluir com essas enfermidades . Entretanto, dos três indivíduos com avaliação histopatológica compatível e sob tratamento quelante, apenas o caso 102 demonstrava níveis terapêuticos adequados do cátion, e os demais ainda exibiam sobrecarga de cobre. Na casuística, observaram-se achados dessas enfermidades em 18 estudos anatomopatológicos hepáticos, realizados ainda durante o período pré-tratamento. O conjunto dessas informações sugere que na etiopatogênese da doença hepática gordurosa não alcoólica nos portadores de DW há participação de outros mecanismos tais como disfunção mitocondrial, formação de radicais livres e oxidação lipídica (Yamamoto et al., 1999; Gu et al., 2000; Ferenci, 2004; Nagasaka et al., 2009).

A reatividade dos autoanticorpos hepáticos não é patognomônica dos processos auto-imunes. A evolução satisfatória dos casos, sem tratamento específico para hepatite auto-imune corroboram o diagnóstico único da DW, entretanto a associação é relatada na literatura (Milkiewicz et al., 2000; Yener et al., 2004). Uma paciente da casuística (caso 56) aos nove anos de idade, exibia adinamia, palidez, dor abdominal, náuseas e elevação das aminotransferases, não existia relato de consangüinidade ou familiar afetado, os anéis de KF estavam ausentes, o estudo histopatológico hepático era sugestivo de hepatite auto-imune (cirrose, esteatose macrogoticular, rosetas e atividade de interface). Os exames laboratoriais mostravam anticorpo antimúsculo liso $>1 / 320$, gamaglobulinas $1,5 \mathrm{~g} / \mathrm{dL}$, ceruloplasmina sérica $5 \mathrm{mg} / \mathrm{dL}$, cuprúria $10 \mu \mathrm{g} / 24 \mathrm{~h}$ que após o uso de DPA houve um incremento superior a 13 vezes. Não existiam registros de sorologia para hepatites virais. Foi submetida ao uso da 
penicilamina e piridoxina, com normalização das enzimas hepáticas e resolução da sintomatologia.

O caso 6 também apresentou reatividade para o anticorpo antimúsculo liso (1/160), com o padrão mais específico da hepatite auto-imune (reatividade em vasos, glomérulos e fibrilas dos túbulos renais), os marcadores virais mostravam cicatriz sorológica para hepatite $A$, não havia dosagem de imunoglobulinas, dados de biópsia hepática ou exame de imagem encefálica. Todavia esse paciente apresentava sintomas neurológicos da linha extrapiramidal, alteração do comportamento e reclusão social, anéis de KF, níveis séricos de ceruloplasmina indetectáveis, cuprúria $1235 \mu \mathrm{g} / 24 \mathrm{~h}$ e aminotransferases normais. Após instituição de farmacoterapia houve melhora clínica significativa, com independência para cuidados pessoais.

A DPA foi utilizada no tratamento da DW em nosso serviço desde 1963 , e foi a única medicação padronizada para tratamento da DW no Brasil por longo período. Essa é uma das razões pela qual foi a droga inicial em 93,5\% dos casos submetidos à fármacoterapia. Outra razão é indisponibilidade comercial da trientina em nosso meio. Os sais de zinco só foram introduzidos para tratamento da DW no início dos anos 80 e, a priori, foi utilizado em pacientes que apresentaram efeitos adversos à DPA (Barbosa et al.,1992). Só a partir de 1991 começou a ser prescrito, em alguns casos, como primeira escolha.

Apesar da limitação do nosso trabalho, por se tratar de estudo retrospectivo, a responsividade de 112 pacientes com boa aderência à farmacoterapia foi também avaliada e $23,2 \%, 44,5 \%$ e $31,3 \%$ obtiveram resposta completa, incompleta e ruim respectivamente. Quando considerado os 
demais níveis de adesão houve significativa piora dos resultados. Outros autores têm descrito a associação entre má aderência e pobre desfecho terapêutico (Walshe, 2007; Svetel et al., 2009). Entretanto, uma paciente (caso 184) investigada por triagem familiar, aos 51 anos apresentava reduzido nível de ceruloplasmina ( $3 \mathrm{mg} / \mathrm{dL}$ ), mas sem os demais parâmetros diagnósticos, foi acompanhada por seis anos sem tratamento, e recentemente apresentou discreta alteração nas aminotransferases e na textura ecogênica hepática, mas sem evidente sobrecarga de cobre. O exame anatomopatológico do fígado foi sugestivo de esteatohepatite sem coloração positiva pela rodanina e a genotipagem demonstrou ser heterozigota composta (p.A1135Qfs/p.M645R), a mesma encontrada em seu irmão (caso 31), que é cirrótico e iniciou sintomatologia aos 34 anos.

O portador (caso 29) mais idoso, à época do diagnóstico, abriu quadro extrapiramidal aos 49 anos, a despeito do laudo da biópsia hepática ter sido normal. Na literatura encontramos descrições similares (Ferenci et al., 2007). Czlonkowska et al. (2008) reportaram um caso de uma paciente diagnosticada aos 54 anos que recusou tratamento e os níveis das enzimas hepáticas somente se alteraram 20 anos após, e a paciente insistiu em permanecer sem fármacoterapia. Atualmente com 84 anos e asintomática, apesar de não ter sido realizada biópsia hepática, as provas de função hepática estão praticamente normais com apenas discreta redução dos níveis de albumina. Esses achados sugerem que doença de Wilson ocorre em qualquer idade e pode comportar-se de modo diferente, mais tênue naqueles com maior faixa etária. 
Ao se analisar a resposta clínica houve resolução em $77,3 \%$ dos 110 casos que manifestaram sintomas hepáticos. Registrando-se piora em 20,0\%. O estudo bioquímico hepático em 194 pacientes demonstrou melhora em 39,7\% dos exames, enquanto $17,0 \%$ deterioraram. Ficando evidente a distinção entre a melhora clínica e laboratorial, contudo o agravamento do quadro teve resultados semelhantes. Cope-Yokoyama et al. (2010) não encontraram correlação significante entre os achados laboratoriais de seis pacientes que tiveram aumento da fibrose hepática durante o tratamento com DPA ou zinco naqueles que não pioraram, sugerindo a realização de biópsia a cada três anos. Um trabalho de lorio et al. (2004) descreveu elevação persistente da TGP em $32 \%$ e $43 \%$ de 107 crianças tratadas com DPA e sais de zinco, respectivamente, que mantiveram quadro clínico estável a despeito dessa alteração bioquímica. Uma limitação dessa avaliação foi a falta de dados nos demais exames laboratoriais e de controle de função hepática. Os presentes achados nos remetem ao questionamento se a normalização das aminotransferases deveria ser um dos objetivos de sucesso terapêutico.

Dos 33 pacientes que persistiram com os anéis de KF, 21 (63,6\%) evoluíram com resultado clínico ruim, enquanto dos 29 pacientes em que essas estruturas desapareceram, $28(96,6 \%)$ apresentaram boa resposta hepática e neurológica. Nenhum demonstrava cobre sérico livre superior a $15 \mu \mathrm{g} / \mathrm{dL}$. Entretanto 11/26 que realizaram cuprúria (42,3\%) ainda exibiam níveis acima de $500 \mu \mathrm{g} / 24 \mathrm{~h}$ para os agentes quelantes ou $75 \mu \mathrm{g} / 24 \mathrm{~h}$ para os sais de zinco e as enzimas persistiam alteradas em 13/29 (44,8\%). Isso poderia ser indício de que a falha na normalização enzimática estaria associada à sobrecarga do metal, 
expressa pela elevação do cobre urinário, contudo observaram-se valores de aminotransferases normais em $50 \%$ daqueles com cobre urinário elevado.

Quando se avaliaram indivíduos com boa aderência e cuprúria dentro da faixa terapêutica observou-se que $43,3 \%$ exames bioquímicos mostravam ainda aumento dessas enzimas, entretanto $93,3 \%$ cursaram com boa resposta hepática e 90\% com melhora neurológica. Um fato intrigante do nosso estudo é que em 27 casos com excreção do cobre urinário superior a recomendada, 85,2\% e 88,8\% exibiram uma boa evolução neurológica e hepática respectivamente, e $50 \%$ obtiveram normalização laboratorial, todos estavam com cobre sérico livre menor que $15 \mu \mathrm{g} / \mathrm{dL}$ e $68,8 \%$ negativaram os anéis de KF. Talvez isso sugira que a cuprúria não seja adequada para controle terapêutico ou talvez seja uma evidência indireta que os pacientes estavam aderentes ao tratamento e por essa razão mantinham níveis elevados do metal na urina. Esse é um contrasenso, pois a cuprúria com valores não muito elevados (dentro da faixa de terapêutica adequada ou mesmo abaixo) poderia indicar boa aderência ou até mesmo excesso de medicação, porém poderia representar ingestão de dose menor do medicamento.

A respeito do cobre livre estimado, oito pacientes apresentaram valores dentro dos limites terapêuticos recomendados e todos cursaram com boa resposta clínica hepática e neurológica, quatro (50\%) exibiram elevação das aminotransferases e um de quatro indivíduos pesquisados mostrou persistência dos anéis de KF. Por outro lado 24 pacientes $(54,5 \%)$ daqueles com níveis abaixo do esperado obtiveram melhora hepática e 79,5\% neurológica. Os três pacientes em que foram registrados valores acima de $15 \mu \mathrm{g} / \mathrm{dL}$ não obtiveram 
melhora hepática, porém um deles evoluiu com boa resposta neurológica, sinalizando que a mensuração do cobre sérico livre poderia ser um exame eficaz, no controle terapêutico.

Em relação às manifestações neurológicas, 77,5\% dos 111 pacientes avaliados mostraram melhora importante, e em 16 casos $(14,4 \%)$ houve deterioração clínica. É interessante ressaltar que os resultados ruins foram registrados com as três drogas, e na maioria deveu-se à gravidade prévia ao tratamento. Dos 10 portadores com má resposta a DPA, dois $(21,21)$ exibiam graves sequelas antes do uso, um iniciou o tratamento com dose elevada com piora clínica importante (261) e quatro faleceram em até quatro meses de terapia $(51,81,194,249)$. Um indivíduo (37) foi a óbito devido à broncopneumonia aspirativa no segundo mês de seguimento, porém havia iniciado tratamento com quelante, por iniciativa própria, dois anos antes de chegar ao nosso serviço. Um paciente cometeu suicídio (253) e outro faleceu após três anos, e apresentava sinais de pouca resposta à terapia (caso 172). Uma paciente (121) foi refratária às três drogas, falecendo devido à insuficiência hepática em uso de sais de zinco. Outro portador (219) também submetido a essa droga foi a óbito com um mês de tratamento por broncopneumonia. Em relação a trientina, dois doentes $(17,137)$ já irresponsivos as outras drogas, substituíram-nas por esse fármaco, e sucumbiram por insuficiência hepática e complicação neurológica.

Dos 44 pacientes inicialmente assintomáticos, três demonstraram sintomas hepáticos durante o tratamento com a DPA, entretanto todos eram maus aderentes $(2,168,191)$. Uma doente (34) abriu quadro neurológico, 
porém foi medicada com dose inicial de $1,5 \mathrm{~g}$ de DPA, em outro serviço. Uma criança (234) diagnosticada por triagem familiar, também tratada com esse quelante, desenvolveu manifestações neurológicas, mas encontra-se bem atualmente com 47 anos e sem sequelas. Nenhum paciente assintomático com boa aderência demonstrou resultado terapêutico ruim, sinalizando a importância de orientar o paciente e seus familiares a seguir rigorosamente o tratamento proposto, mesmo que haja necessidade de suporte psicossocial.

$\mathrm{Na}$ presente pesquisa os portadores assintomáticos que usaram DPA apresentaram melhores resultados evolutivos em relação às formas hepática e neurológica, mas não houve diferença entre os medicamentos utilizados e os desfechos terapêuticos dentro de cada apresentação clínica. Esses achados sugerem que tanto os sais de zinco quanto os agentes quelantes poderiam ser utilizados como primeira linha na terapia da DW, o que está em discordância com as últimas publicações (Linn et al., 2009; Weiss et al., 2011; EASL, 2012) que propõem o uso de sais de zinco para os casos com manifestação neurológica e em assintomáticos. Contudo, Czlonkowska et al. (2005) não encontraram diferença significante na sobrevida dos pacientes tratados com sais de zinco ou DPA. Hoogenraad (2006) defende o uso do indutor de metalotioneína para todas as apresentações da DW. Entretanto, outras publicações recomendam o tratamento inicial com os sais somente na forma assintomática ou na fase de manuntenção (Brewer; Yuzbasiyan-Gurkan, 1992; Roberts; Schilsky, 2008; Huster 2010).

Contrapondo-se ao nosso resultado, Weiss et al. (2011) encontraram menor deterioração hepática e maior sobrevida sem transplante com uso de 
quelantes, a casuística desse trabalho era oriunda de dois centros de gastroenterologia e somente $34,4 \%$ apresentavam sintomas neurológicos, não refletindo a realidade do nosso estudo. Todavia, ao se analisar um subgrupo de 53 casos com cirrose hepática descompensada, submetidos ao uso da DPA, 34 (64,2\%) evoluíram com importante melhora da função hepática, 11 (20,7\%) foram a óbito em até seis meses de terapia, sete $(13,2 \%)$ faleceram entre sete meses a quatro anos, e um caso (11) não respondeu satisfatoriamente, cursando com síndrome portopulmonar e encefalopatia por shunt portosistêmico. Esses achados são condizentes com as recomendações do uso de DPA na forma hepática feitas por Wiggelinkhuizen et al. (2009). Nenhum dos 53 pacientes fez uso inicial dos sais de zinco, dois casos $(49,254)$ usaram essa droga como manutenção com melhora da função hepática, porém dois outros portadores $(236,257)$ exibiram aumento das aminotransferases e um caso (170) demonstrou deterioração clínica e faleceu. Desse modo, evidenciamos que apesar da boa resposta ao quelante, uma parte não obteve sucesso, sugerindo que o transplante hepático é uma alternativa plausível naqueles não respondedores, conforme descrito na literatura (Roberts; Schilsky, 2008; EASL, 2012). O uso dos sais de zinco como terapia de manuntenção dessa grave forma de apresentação hepática aparentemente não demonstrou segurança.

Oito dos nove portadores submetidos a transplante hepático sobreviveram, atualmente estão com média 6 anos (1-14) de seguimento após o procedimento. O único óbito (caso 109) foi devido à asfixia por alimento, depois de três anos do enxerto, complicação secundária a disfagia que ficou como sequela neurológica da doença. Duas crianças com insuficiência hepática 
aguda grave morreram antes da disponibilidade desse tratamento. Todas as cirurgias foram indicadas por falência hepática. Uma paciente (161) apresentou sepse e disfunção do enxerto sendo retransplantada duas vezes no período de um mês, mas atualmente encontra-se bem. Dois pacientes transplantados evoluíram com tremores (casos 65, 77) nas primeiras semanas do pósoperatório. Há relato na literatura de abertura do quadro neurológico após transplante hepático (Litwin et al., 2008). Entretanto Duarte-Rojo et al.(2009) reportaram dois casos de resolução dos sintomas neurológicos após este procedimento. Outro estudo Japonês (Yoshitoshi et al., 2009) também evidenciou resolução clínica em um indivíduo que apresentava leve disartria e dificuldade para andar, e estabilização das manifestações em outro. Um trabalho com irmãos gêmeos homozigotos mostrou resultados neurológicos discordantes após transplante, porém o paciente com pior desfecho estava séptico (Senzolo et al., 2007). No momento, não há evidências suficientes para a indicação desse recurso no tratamento de casos neurológicos não responsivos à farmacoterapia. Somos da opinião que se houver melhora neurológica pós-transplante hepático é porque havia ainda excesso de cobre e o tratamento clínico deveria ser continuado.

Houve perda de seguimento em 55 casos, o que corresponde a $20,1 \%$ de toda a casuística. A maioria desses pacientes $(58,2 \%)$ residia em outros estados, e considerando as dimensões do país, a dificuldade para o deslocamento é uma razão concreta a ser considerada para justificar o abandono do serviço e quatro prontuários exibiam notificações a esse respeito. Outra possibilidade é que esses casos faleceram apesar das tentativas de 
contato telefônico terem sido infrutíferas. Cinco portadores receberam alta do Instituto da Criança da FMUSP, ao completar 18 anos e foram seguidos em suas cidades. Dening e Berrios (1990) em artigo sobre sintomas psiquiátricos em 195 pacientes com DW reportaram uma perda de 44 casos $(22,2 \%)$, não decorrente de óbitos, atribuindo à questão geográfica a desistência no acompanhamento de 15 pacientes $(34,1 \%)$.

Enquanto a resposta terapêutica não diferiu entre as três drogas, o tratamento com DPA demonstrou reação adversa em 53,0\% dos 236 usuários, $21,0 \%$ deles apresentaram reações importantes exigindo substituição da droga e um paciente faleceu por nefrotoxicidade. Efeitos colaterais também foram relatados em $36,6 \%$ dos 55 pacientes tratados com sais de zinco e em 16,7\% dos 30 dos medicados com trientina.

A DW pode cursar com manifestações renais (Ala et al., 2007; Zhuang et al., 2008), contudo existem diversas publicações relatando a nefrotoxicidade causada pela DPA (Siafakas et al., 1998; Nanke et al., 2000; Habib et al., 2006; Merle et al., 2007; Bruha et al., 2010). O mecanismo da lesão renal na degeneração hepatolenticular é desconhecido, ao contrário da artrite reumatóide em que essa droga induz a formação de imunocomplexos (Scheinberg e Sternlieb, 1984; Sharma et al., 2012).

Proteinúria foi o efeito adverso mais comum da DPA e foi relatada em 51 $(21,6 \%)$ dos pacientes, ocorrendo a partir do sexto mês de terapia. Em 19 casos a perda protéica foi transitória, entretanto em 27 exames houve persistência e cinco pacientes $(85,141,180,185,189)$ apresentaram síndrome nefrótica. A paciente 185 faleceu por insuficiência renal após nove anos de 
tratamento, entretanto referia histórico de nefrectomia devido a cisto e nefrocalcinose, anteriormente à instituição da DPA. A sua avaliação histopatológica evidenciou glomerulonefrite proliferativa mensangial.

As reações de hipersensibilidade, tais como febre, urticária, exantema e linfadenopatia foram mencionadas em 9,7\% dos usuários da DPA. O surgimento dessas alterações variou entre o terceiro e trigésimo dia de tratamento, em concordância com a literatura (Brewer; Yuzbasiyan-Gurkan, 1992; Ala et al., 2007).

As anormalidades hematológicas, leucopenia ou plaquetopenia, também foram observadas em $9,7 \%$ dos submetidos a essa medicação, porém no período compreendido entre o primeiro e o segundo mês. Os mecanismos dessas alterações podem ser por reação imunológica ou depressão medular (Walshe, 2011).

Em nosso trabalho houve relato de leucopenia em uma usuária do zinco (caso 85), apesar desse efeito ser justificado na literatura pela hipocupremia resultante do uso prolongado do indutor de metalotioneína (Porea et al., 2000; Igic et al., 2002; Willis 2005), houve mudança da terapia para trientina, que também reduz os níveis do cobre, com reversão do quadro hematológico o que nos leva a hipotetizar que existam outros fatores envolvidos tais como toxicidade direta na medula óssea pelo zinco.

$\mathrm{Na}$ literatura, Brewer (1999) cita que metade dos portadores da forma neurológica pode evoluir com deterioração quando submetidos ao uso da DPA, todavia nosso trabalho evidenciou piora em $11,7 \%$ dos 128 pacientes que apresentavam alguma sintomatologia neurológica e nos $9,7 \%$ de todos os 
usuários dessa medicação. O caso 155 demostrou melhora neurológica importante, porém devido à leucopenia houve substituição do quelante por sais de zinco durante oito meses, e posteriormente associação com a DPA. Evoluiu com grave comprometimento motor com dificuldade de deambulação e disfagia, que melhoraram após a retirada dos sais de zinco e permanência da DPA.

Em dois casos $(151,261)$ esse evento deveu-se a introdução da medicação com dosagem elevada. Outra paciente era assintomática e três meses após iniciar a terapia com 1,5 g/dia abriu o quadro de disartria, disfagia e tremores. Uma portadora (51) que iniciou a terapia com $0,25 \mathrm{~g}$ ao dia, na segunda semana apresentou movimentos involuntários e bicitopenia. Em geral a piora foi constatada entre duas semanas a dois anos de tratamento. Sete casos melhoraram ao reduzir a dose, outros cinco indivíduos necessitaram trocar de fármacos.

Os mecanismos da neurotoxicidade da DPA ainda não estão bem elucidados, Walshe (2011) não acredita na mobilização do cobre pela droga, pois o metal ligado a DPA não é lesivo, e hipotetiza que a quebra molecular do quelante poderia formar radicais que bloqueariam enzimas envolvidas no ciclo de Krebs, com prejuízo na formação de glicose, com perda do substrato energético neuronal. Chen et al. (2012) em estudo usando DPA em modelo animal da DW observaram aumento no cobre livre no sangue, córtex cerebral e nos gânglios da base, enquanto o ligado a proteína mostrou-se reduzido nessas últimas duas estruturas encefálicas. Houve redução dos níveis de glutationa e elevação da malondialdeído, um biomarcador da peroxidação lipídica, o que faz 
crer que a piora neurológica possa ser atribuída ao estresse oxidativo produzido pelo excesso do metal no parênquima.

Quatro pacientes que utilizaram zinco apresentaram deterioração neurológica (casos 106, 107, 158, 216). Apesar das várias descrições a respeito da segurança dessa droga (Hoogenraad et al., 1987; Brewer et al., 1998; Linn et al., 2009; Shimizu et al., 2010), Weiss et al. (2011) em uma série com 288 pacientes germânicos e austríacos descreveram piora do quadro neurológico nos portadores de DW tratados com DPA, trientina e zinco, porém observou-se nessa casuística menor aderência a esse medicamento em relação aos quelantes do cobre e o estudo não detalhou se os casos de falha terapêutica eram pouco aderentes.

Recente pesquisa em roedores sugere que o acúmulo do zinco depleta glutationa e ativa a enzima nicotinamida adenina dinucleotídeo fosfato oxidase, que é implicada na produção de radicais livres e no estresse oxidativo, resultando assim no desencadeamento do processo de apoptose celular e neurodegeneração dopaminérgica, similar à evidenciada na doença de Parkinson (Kumar et al., 2012). Outro trabalho, utilizando cultura de células do hipocampo, e expondo-as ao zinco, observou que ocorre aumento da ubiquitinação, que é dependente da dose e tempo de exposição, e consequentemente na degradação proteossomal (Zhu et al., 2012).

Contrapondo ao excesso de zinco, a sua deficiência também reduz a glutationa e resulta na morte celular (Nakatani et al., 2000), justificando que a homeostase desse metal é importante para integridade celular. Uma portadora (caso 228) evoluiu com alteração sensorial após 14 anos de tratamento, sendo 
diagnosticado mieloneuropatia (da Silva-Júnior et al., 2011 a). O valor mensurado do cobre sérico, na ocasião, era 0,04 vezes o do limite inferior de normalidade, enquanto o zinco exibia 2,7 vezes acima da valor superior. A cuprúria registrada foi $7 \mu \mathrm{g} / 24 \mathrm{~h}$, estava dentro da faixa laboratorial, entretanto abaixo da recomendada pelas diretrizes de Roberts e Schilsky (2008). Quatro meses após a suspensão dessa droga o cobre sérico aumentou quase 10 vezes em relação àquele valor enquanto os níveis de zinco encontravam-se discretamente elevados. Entre os mecanismos hipotetizados para justificar a mieloneuropatia, estão a toxicidade direta do zinco e a hipocupremia (da SilvaJúnior et al., 2011b).

Três portadores medicados com sais de zinco evoluíram com convulsão $(158,164,208)$, entre três a sete anos após início da terapia. A associação não está bem esclarecida, com relatos contraditórios entre os níveis desse elemento e o evento neurológico (Moreno et al., 2006).

Apenas dois pacientes (casos 17, 137) que usaram trientina tiveram piora neurológica, um desses exibia grave comprometimento e faleceu. Estudos demonstraram deterioração na fase inicial do tratamento, atribuindo à mobilização do cobre depositado nos tecidos para a circulação (Saito et al., 1991; Brewer et al., 2009).

Intolerância gástrica foi mencionada em 20 (8,5\%) usuários da DPA, uma criança (caso 57) modificou tratamento para sais de zinco associado à trientina devido à dor abdominal e vômitos. Bruha et al. também reportaram necessidade de troca de medicação pelo mesmo motivo em dois pacientes submetidos ao uso desse quelante. 
Houve queixas digestivas em 14 (25\%) dos 56 indivíduos submetidos ao tratamento com zinco e essa foi a principal reação adversa dessa droga, achado similar ao observado pelo estudo de Merle et al.(2007). Uma portadora (caso 160) apresentou vômitos persistentes e necessitou substituí-lo pela DPA, na segunda semana do tratamento. A formulação em acetato minimizou essas reações em duas pacientes $(85,252)$, contudo o caso 180 não melhorou da epigastralgia e trocou os sais de zinco por DPA. A intolerância gastrointestinal foi relatada em $13,3 \%$ dos usuários da trientina e esse foi o efeito colateral mais freqüente, porém não houve registro de mudança para outros fármacos, sugerindo que esses eventos não foram significantes e que a trientina é uma medicação segura, como reportado por Walshe (1982).

Seis indivíduos (casos 7, 47, 107, 117, 202 e 235) evoluíram com elastosis perforans serpiginosa (EPS), entre o quarto e décimo ano do tratamento com a DPA. Essa reação adversa é descrita na literatura (Lutz, 1953; Deguti et al., 2002; Bécuwe et al., 2005), e é atribuída a ação direta da DPA nas fibras de colágeno, o que resulta na deposição transepidérmica anormal das fibras elásticas, ou na quelação do cobre inibindo uma enzima cobre dependente, a lisil oxidase, que é requerida para o cruzamento das fibras de elastina (Pass; Sternlieb, 1973). Entretanto, observamos que um paciente (caso 7) teve melhora das lesões com trientina, que também é quelante do cobre. Em contrapartida, o caso 117 piorou a EPS em uso dessa medicação e Walshe (1982) descreveu um paciente com EPS, secundária a DPA, em que a mudança para trientina não provocou regressão das alterações cutâneas. Dahlman et al. (1995) reportaram dois casos que melhoraram após troca do 
quelante, e em um doente houve registro de desaparecimento das lesões após a administração de suplemento com sais de zinco. Essas observações nos levam a hipotetizar que a fisiopatologia da EPS está associada a outro mecanismo tal como a inibição direta das fibras de colágeno pela DPA.

Um paciente após 10 anos de tratamento com DPA queixou-se de alteração na visão e foi suspeitado de evolução com retinose pigmentar (caso 221). Similarmente, o surgimento dessa afecção após o mesmo período de uso já foi descrito na literatura (Scheinberg; Sternlieb, 1984).

A paciente (caso 204), que estava em tratamento com DPA desde o último trimestre de gestação, relatou que seu filho apresentou lesões papulares disseminadas aos quatro meses de idade. Outras duas portadoras fizeram uso de sais de zinco na gravidez e não houve menção de reações, sugerindo que esse medicamento seja seguro na gestação. No entanto, microcefalia e defeito cardíaco já foram relatados (Brewer et al., 2000). Houve notificação de dois abortos em uma paciente que estava sendo tratada com sais de zinco (caso 245) e outra com $1 \mathrm{~g}$ de DPA (caso 73), dose acima da atualmente recomendada por Roberts e Schilsky (2008).

Um dos principais achados desse estudo é a frequência de mortalidade de $31,3 \%$, durante o período de 64 anos. Uma série recentemente publicada com 28 pacientes admitidos no Instituto da Criança do HC-FMUSP (Kleine et al., 2012) registrou somente um óbito durante seis anos (média) de seguimento. Contrapondo-se a esses dados, nosso trabalho com maior período de inclusão e follow-up, incluiu 143 casos (4-18 anos) dos 262 pertencentes à casuística, e 
21 mortes foram registradas $(14,7 \%)$ na faixa limite de 18 anos, durante a média de 10,5 anos de acompanhamento.

Bruha et al. (2010) relataram que a sobrevida dos pacientes com DW, não diferiu da população geral na república Theca. Entretanto, Czlonkowska et al. (2005) encontraram taxa de sobrevida dos portadores da degeneração hepatolenticular inferior à registrada pela população polonesa.

A mortalidade pode ser atribuída ao retardo no diagnóstico. O estudo evidenciou diferença significante entre o atraso no diagnóstico dos casos que sobreviveram daqueles com pior desfecho. Contudo como discutimos anteriormente, a média de atraso no serviço foi inferior a de outras publicações. A maioria dos pacientes vem ao nosso serviço com doença avançada (Tabela 4.2). Nove portadores faleceram durante a investigação clínica e 15 casos sucumbiram com até seis meses de tratamento. Contudo, apesar da adequada aderência terapêutica, seis indivíduos que não apresentavam inicialmente grave comprometimento clínico (42, 76, 121, 172, 247 e 253) evoluíram com piora e faleceram durante o seguimento. Os níveis de cuprúria ou do cobre livre não evidenciavam sobrecarga de cobre nos exames de controle de cinco desses casos e em um não havia dados registrados a respeito. Svetel et al. (2009) acompanharam 142 pacientes com DW e também observaram deterioração clínica em 15 casos que foram prontamente tratados, porém nove relataram interrupção temporária do tratamento. Foram registrados 30 óbitos nessa série.

A expectativa de vida dos pacientes não tratados para a DW é de aproximadamente cinco anos (Svetel et al., 2009; Barbosa et al., 2009), porém 
observamos nesse estudo uma evolução mais rápida, com média inferior a dois anos em 12 casos, destes 11 faleceram antes do exame de seqüenciamento genético estar disponível em nosso serviço. Seis mensuraram cobre sérico e nenhum exibiu níveis abaixo do limite inferior de referência, entretanto nove casos submeteram-se à aferição da ceruloplasmina e sete $(77,7 \%)$ apresentavam valores de até $5 \mathrm{mg} / \mathrm{dL}$, e os dois outros exames encontravam-se na faixa de até $10 \mathrm{mg} / \mathrm{dL}$. Por se tratar de longo estudo retrospectivo é difícil explicarmos com exatidão o que teria colaborado para esse desfecho. Gromadzka et al (2005) descreveram que mutações frameshift e nonsense no gene $A T P 7 B$ são associadas com início mais precoce do quadro clínico, baixos níveis de ceruloplasmina e de cobre sérico, atribuindo uma expressão fenotípica mais severa. Uma série com 163 portadores de DW (Merle et al., 2007) registraram-se níveis inferiores a $5 \mathrm{mg} / \mathrm{dL}$ em somente $29,5 \%$ dos examinados, sendo reportado três óbitos, bem menos que o apresentado pelo nosso trabalho. Bruha et al. (2010) ao analisar 117 portadores da degeneração hepatolenticular também relataram reduzida mortalidade (três casos), e a menor média de ceruloplasmina reportada foi de $10 \mathrm{mg} / \mathrm{dL}$, em portadores da forma neurológica associada à hepática. Contudo, na série do serviço de pediatria (Kleine et al., 2012) o valor médio da ceruloplasmina não foi relatado, e sim a mediana de 3,0 mg/dL (1-11 mg/dL) e houve apenas uma perda. Considerando essa mesma faixa etária, foram registrados 127 pacientes na presente casuística, com mediana de ceruloplasmina de 3,0 mg/dL e média de 4,6 mg/dL (0,0-26), com 21 óbitos documentados, como mencionado anteriormente. 
Outro aspecto a ser considerado é a gravidade clínica desses casos, pois onze indivíduos, com idade entre 9 a 28 anos, sucumbiram ainda na fase propedêutica. Contudo, pode-se questionar se a doença tem um comportamento mais agressivo em nossos pacientes ou se a dificuldade de acesso aos serviços de saúde foi fator decisivo para esse resultado. Possivelmente a questão seja multifatorial.

Em estudo indiano, Richard et al. (2000) descreveram que pacientes com a forma hepática apresentavam risco de mortalidade cinco vezes maior quando comparados aqueles com quadro neurológico. Nosso trabalho mostrou que a forma hepática não foi associada a piores resultados e a duração do seguimento dos pacientes indianos (entre 4 a 6 anos) foi inferior ao da nossa pesquisa. Contudo, a descompensação hepática foi a causa mais frequente de óbito da presente casuística, ocorrendo em $41,5 \%$. Outras séries também apontaram para esse motivo (Gow et al., 2000; Gheorghe et al., 2004; Czlonkowska et al., 2005; Svetel et al., 2009). Entretanto, Czlonkowska et al (2004) informaram que dez pacientes diagnosticados eram terminais, fato considerado de maior relevância para o desfecho.

Walshe (2007) em estudo sobre causas de morte em 67 portadores de DW concluiu que o principal responsável pelo resultado ruim foi retardo do diagnóstico, mas outros fatores, tais como má aderência ao tratamento e o desenvolvimento de neoplasias malignas após dez anos de seguimento, também foram importantes. Alguns desses achados estão em concordância com nosso trabalho em que a média de atraso no diagnóstico dos pacientes 
que faleceram foi 2,3 anos (0-22), sendo superior a média de 1,4 anos (0-22) encontrada na casuística geral.

No presente estudo registrou-se a aderência terapêutica de 61 casos que sucumbiram e a mesma foi considerada boa em $49,2 \%$, irregular $13,1 \%$, e ruim $37,7 \%$. Todavia dos 30 portadores com aderência satisfatória dois faleceram por causa externa e doze com até seis meses do início da farmacoterapia. Quatro pacientes que abandonaram o tratamento evoluíram a óbito no mesmo ano, e dois em período acima de três anos.

Em nossos pacientes que não receberam tratamento específico, pneumonia foi a causa mais comum de óbito, principalmente naqueles imobilizados por grave comprometimento neurológico.

Durante 0 seguimento, 95 pacientes expressaram alguma sintomatologia psiquiátrica e dez casos $(6,13,47,100,121,151,201,219,229)$ necessitaram de internação hospitalar especializada. $O$ caso 47 submeteu-se a várias hospitalizações por agressividade (incendiário). Foram obtidos registros de dependência química por drogas ilícitas em seis indivíduos (103, 140, 141, $231,237,258)$ e outros seis referiram alcoolismo $(2,24,40,41,49,74,248)$.

Sete pacientes da casuística relataram idealização suicida, cinco desses tentaram suicídio e três foram a óbito $(17,213,253)$. A taxa evidenciada é bem maior que a média de 4,5 casos $/ 100.000$ habitantes encontrada na população brasileira (portal.saude.gov.br). Outros estudos também registram essa grave complicação psiquiátrica nos portadores de DW (Czlonkowska et al., 2005; Svetel et al., 2009; Tatsumi et al., 2010). O uso da DPA pode resultar em depressão (Mcdonald; Lake, 1995), contudo a própria doença cursa com 
alterações psiquiátricas. Assim como o tratamento preconizado para 0 tratamento, a atenção psicológica também deverá ser efetuada para identificação precoce de sinais depressivos ou de outros transtornos mentais.

Washe et al. (2003) relataram que $15 \%$ dos pacientes com DW manifestaram alguma neoplasia maligna ao longo de 30-39 anos de follow up. Um portador (200) desenvolveu câncer prostático aos 55 anos, com 31 anos de seguimento da DW, evoluindo satisfatoriamente até o presente momento. Outro caso (232) referiu câncer de colo uterino, e encontra-se clinicamente bem no vigésimo ano de acompanhamento. Um dado interessante é que apesar de 133 casos apresentarem evidência de cirrose, não houve registro de carcinoma hepatocelular e nenhum paciente da casuística foi a óbito devido a neoplasias. Outras pesquisas oriundas da Europa reportaram resultados menos favoráveis (Czlonkowska et al., 2005; Merle et al., 2007 Walshe, 2007; Svetel et al., 2009). Uma série de 36 pacientes da região sul do Brasil (Bem et al., 2011) noticiou três perdas, uma delas decorrente de leucemia. Nesse trabalho a ascendência européia foi documentada em $74,5 \%$ dos casos. 
CONCLUSÕES/ CONSTATACÕES MAIS RELEVANTES 


\section{CONCLUSÕES/CONSTATAÇÕES MAIS RELEVANTES}

1) A doença de Wilson ocorre em ampla faixa etária, mas ocorreu principalmente na faixa etária dos 15 aos 19 anos.

2) Houve redução no tempo de atraso diagnóstico nas últimas décadas.

3) A apresentação hepática foi a forma clínica mais frequente, manifestando-se a partir dos sete anos.

4) Disartria, tremor, alteração da marcha e distonia, constituem os principais achados clínicos iniciais dos casos neurológicos.

5) Os anéis de Kayser-Fleischer estiveram presentes em quase todos os casos com apresentação neurológica, porém são menos observados nas formas hepática e assintomática.

6) Outros parâmetros diagnósticos tais como história familiar da doença, hepatopatia de causa ignorada associada a anormalidades no estudo do metabolismo do cobre ou a presença dos anéis de Kayser-Fleischer, ou a redução dos níveis de ceruloplasmina deveriam ser mais considerados nos critérios diagnósticos.

7) A dosagem de ceruloplasmina foi o exame que mais frequentemente se mostrou alterado no nosso estudo.

8) A triagem familiar viabilizou a inclusão de casos ainda em fase assintomática.

9) Nos indivíduos identificados por rastreamento familiar, que ainda não apresentaram o quadro clínico e/ou laboratorial clássico da doença, assim como naqueles com diagnóstico duvidoso, o estudo de 
genotipagem ATP7B é um relevante instrumento propedêutico.

10) Os casos assintomáticos com boa aderência terapêutica apresentaram desfecho clínico mais favorável.

11) Penicilamina, zinco e trientina apresentaram padrões semelhantes de resposta terapêutica, entretanto outros estudos são necessários para definir qual a melhor droga.

12) Penicilamina foi a medicação mais utilizada, porém pela frequência de efeitos adversos, seu uso como primeira escolha de tratamento deve ser revisto.

13) A mensuração do cobre sérico livre e a pesquisa dos anéis de KF mostraram-se eficazes para os fins de controle terapêutico.

14) A piora dos exames bioquímicos correspondeu a deterioração clínica hepática, contudo as aminotransferases persistiram alteradas na maioria dos pacientes com boa resposta clínica.

15) O transplante hepático foi eficaz para os casos de insuficiência hepática aguda grave e de cirrose hepática descompensada, não responsiva ao uso de farmacoterapia.

16) As complicações da insuficiência hepática e da hipertensão portal e pneumonia foram as principais causas de morte em DW.

17) A ocorrência de suicídio sugere que os pacientes com doença de Wilson deveriam ser monitorados quanto ao surgimento de sinais de depressão ou de alterações de comportamento. 


\section{ANEXO A}

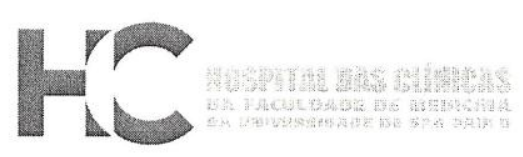

\section{APROVAÇÃO}

A Comissão de Ética para Análise de Projetos de Pesquisa CAPPesa da Diretoria Clínica do Hospital das Clínicas e da Faculdade de Medicina da Universidade de São Paulo, em sessão de 05/08/2009, APROVOU O Protocolo de Pesquisa n 0667/09, intitulado: "DOENÇA DE WILSON: A EXPERIÊNCIA DE SEIS DÉCADAS NO HC-FMUSP" apresentado pelo Departamento de GASTROENTEROLOGIA.

Cabe ao pesquisador elaborar e apresentar à CAPPesq, os relatórios parciais e final sobre a pesquisa (Resolução do Conselho Nacional de Saúde n 196, de 10/10/1996, inciso IX.2, letra "c").

Pesquisador (a) Responsável: Dra. Marta Mitiko Deguti

Pesquisadoŕ (a) Executante: Dra. Fabiana Cordeiro de Araújo

CAPPesq, 05 de Agosto de 2009

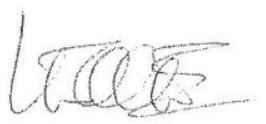

PROF. DR. CLAUDIO LEONE

Vice-Presidente da Comissão Ética para Análise

de Projetos de Pesquisa

\footnotetext{
Comissão de Ética para Análise de Projetos de Pesquisa do HCFMUSP e da FMUSP Diretoria Clínica do Hospital das Clinicas da Faculdade de Medicina da Universidade de São Paulo Rua Ovídio Pires de Campos,

225, $5^{\circ}$ andar - CEP 05403010 - São Paulo - SP Fone: 01130696442 Fax: 01130696492 e-mail: cappesq@hcnet.usp.br / secretariacappesq2@hcnet.usp.br 


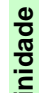

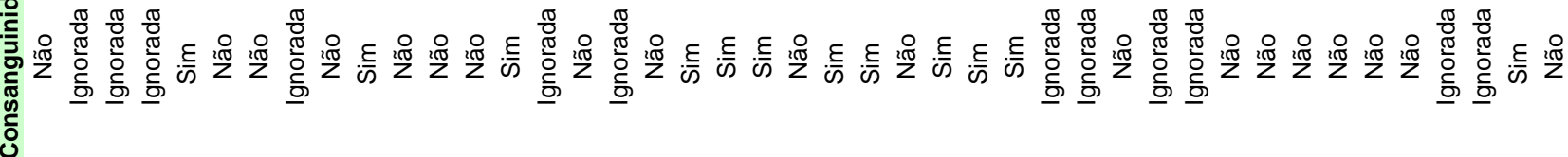

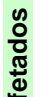

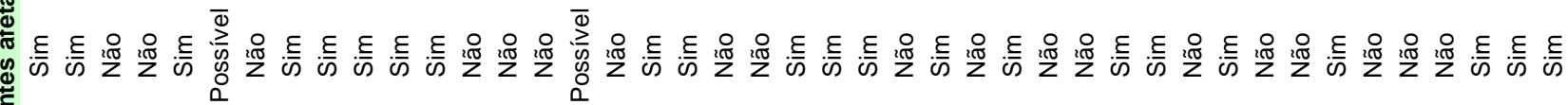

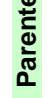

$\stackrel{Ð 0}{\frac{\Xi}{0}}$

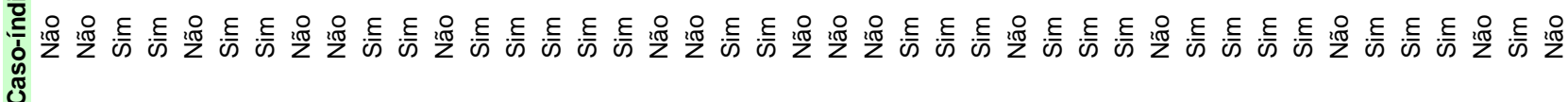

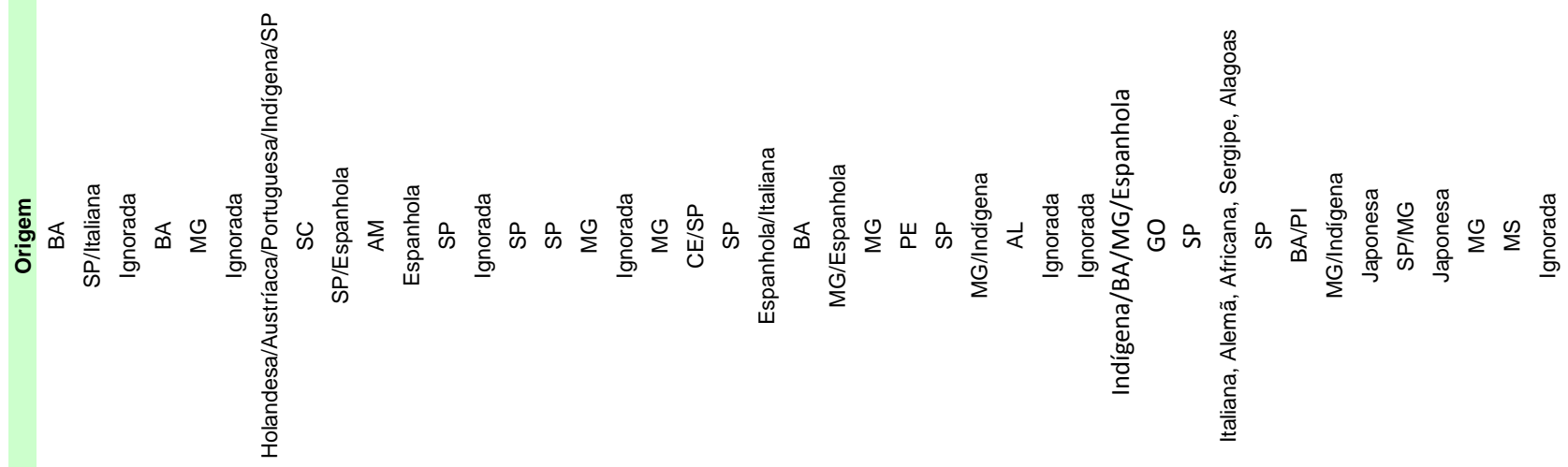

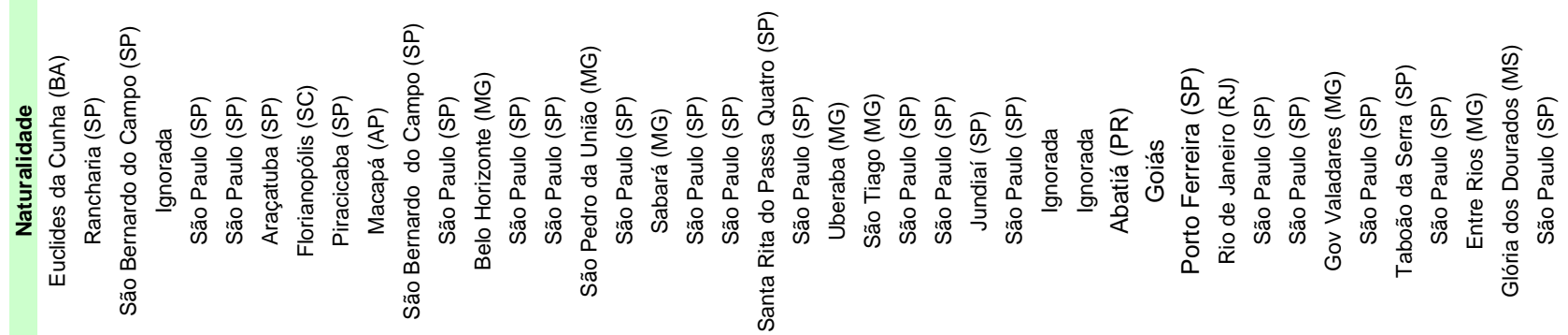

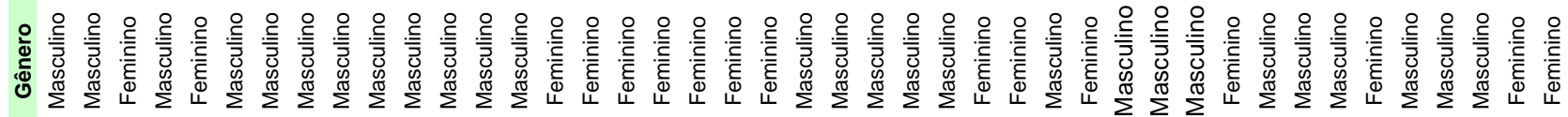

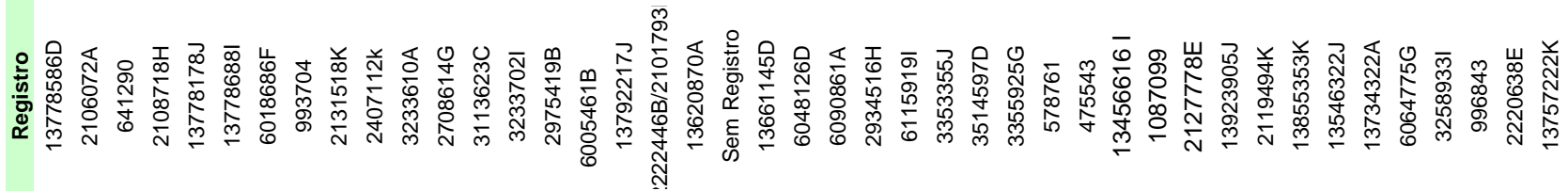

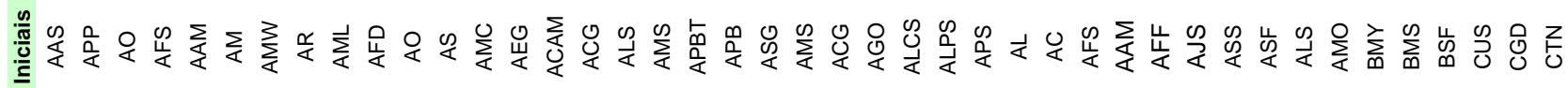




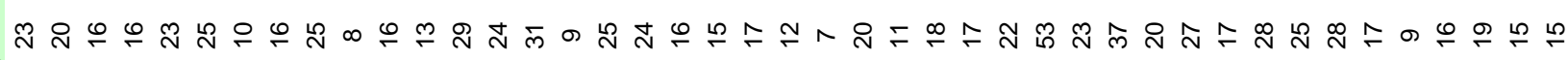
离

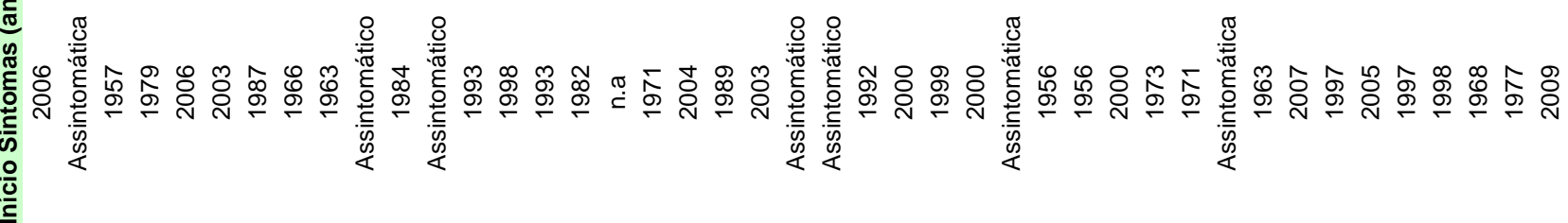

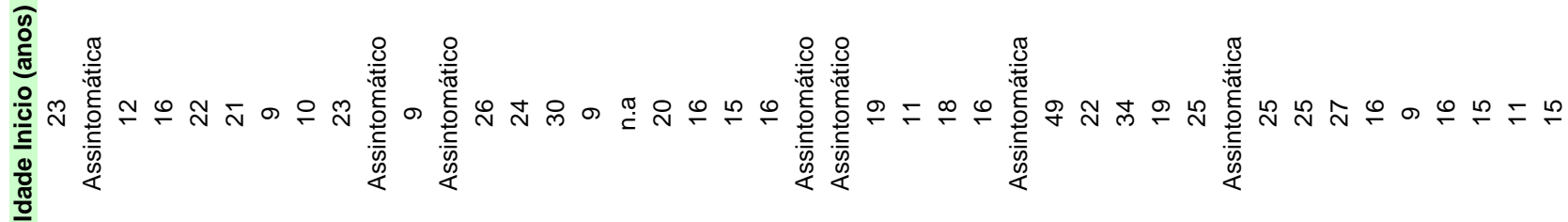
$\frac{0}{2}$

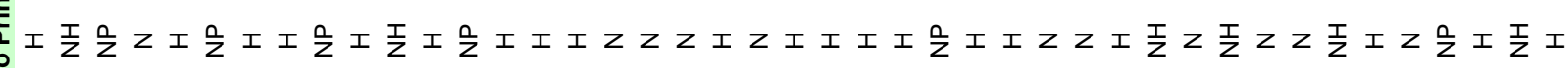
产

:

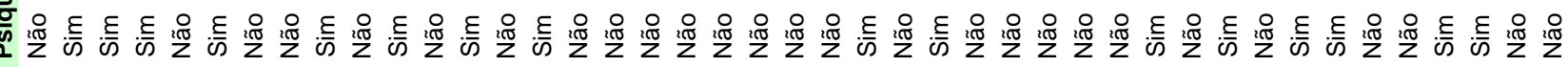
竞

항

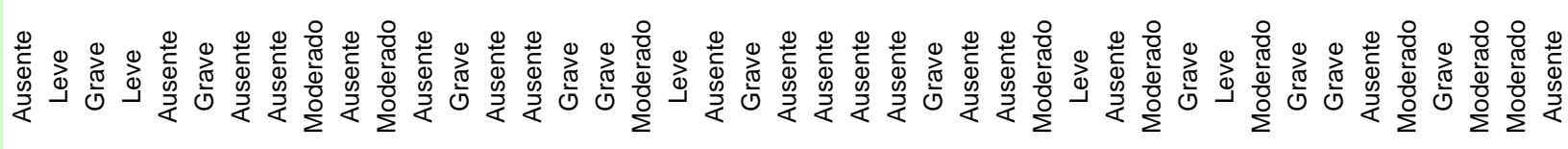

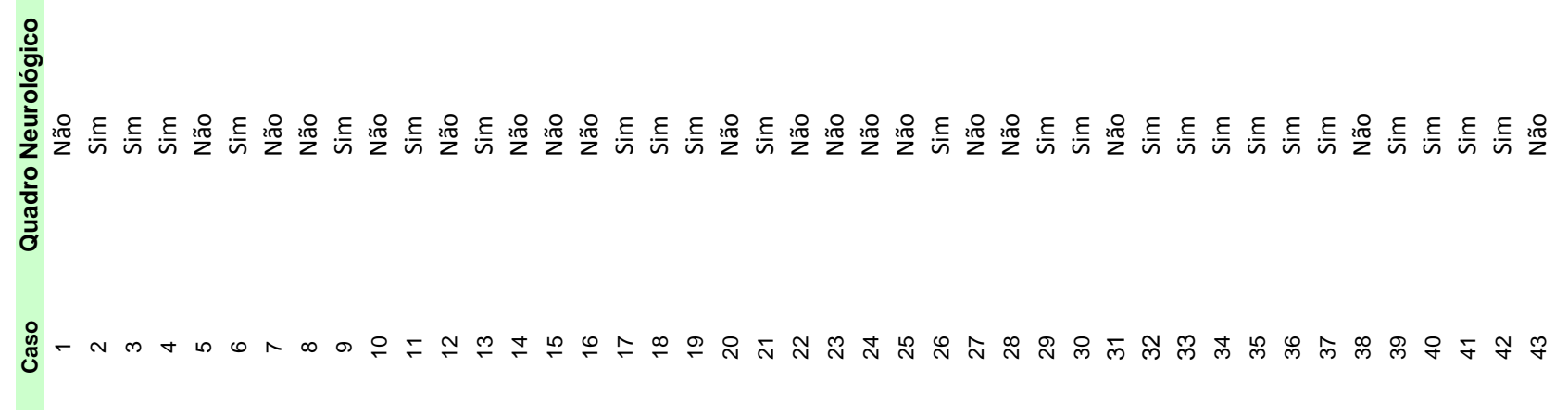




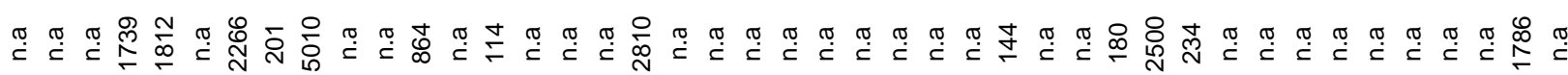
8

ํㅗㅇ

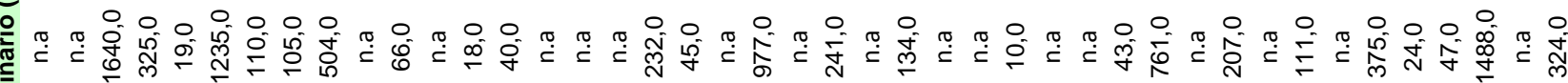

융

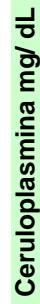

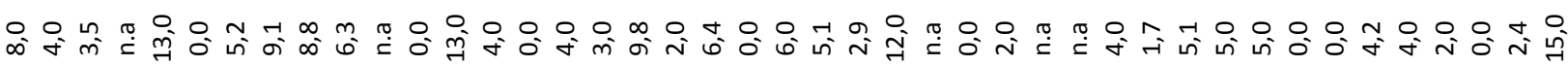

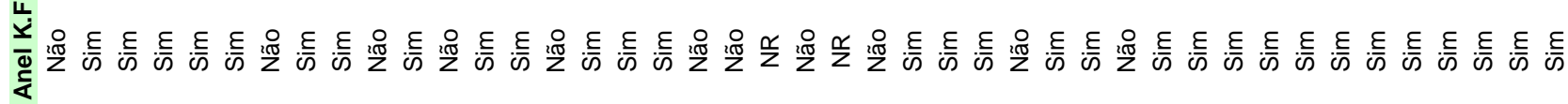

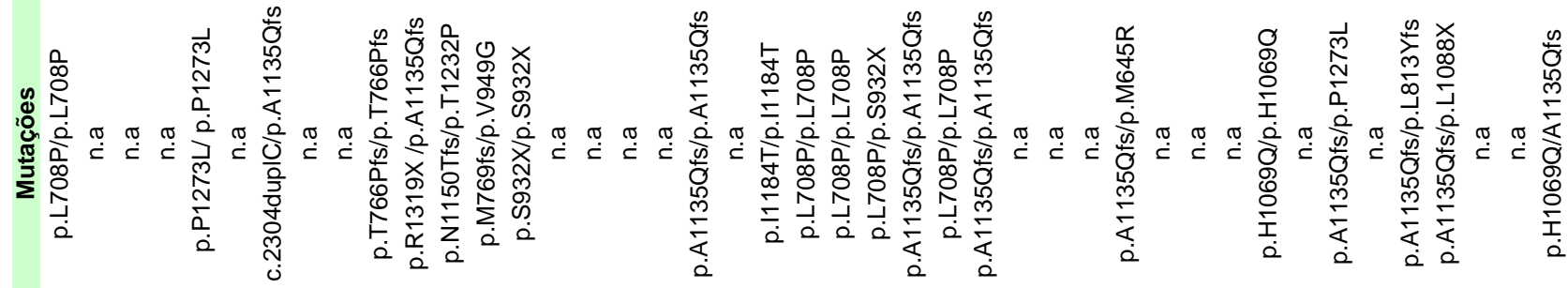
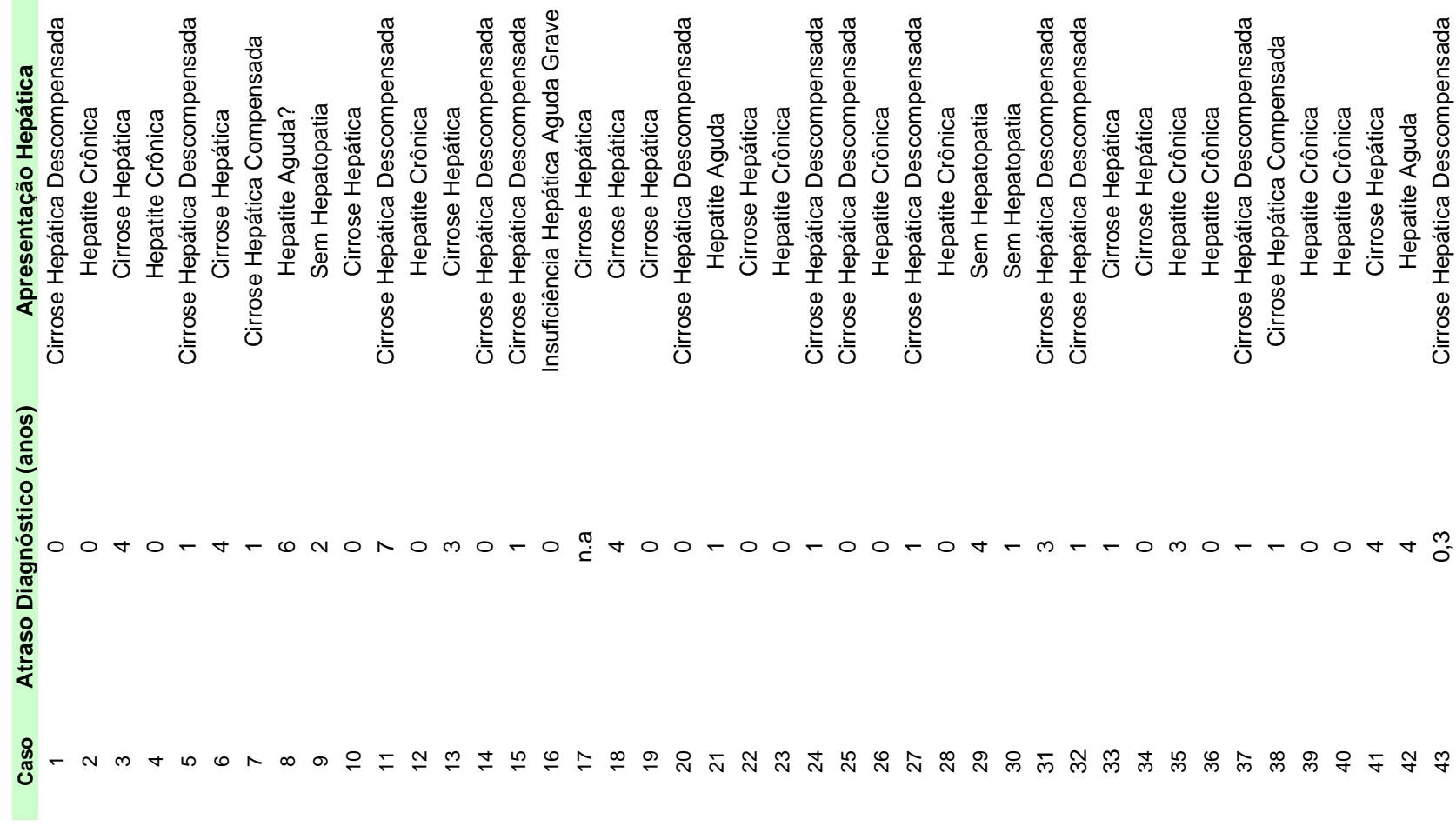


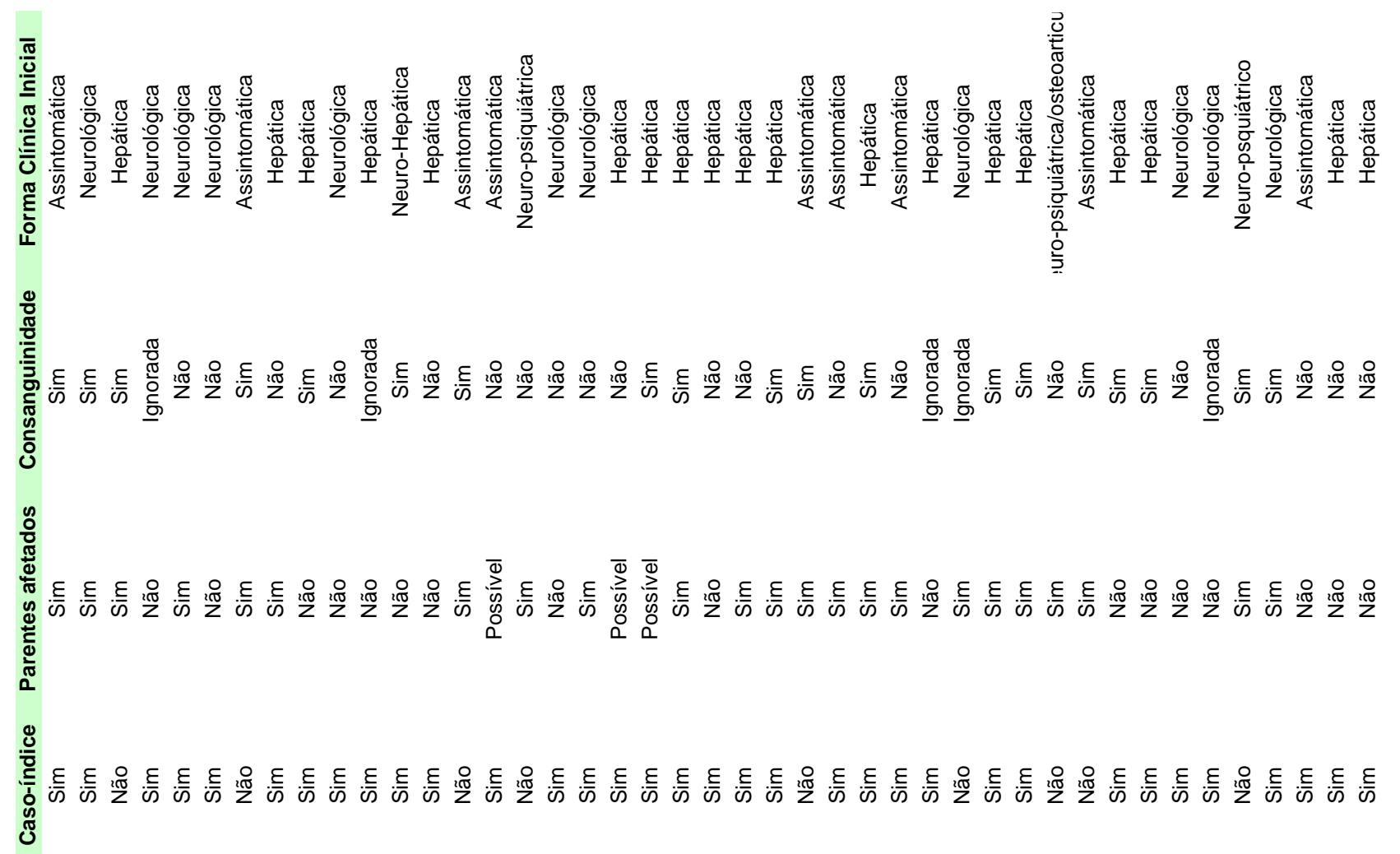

110

. 


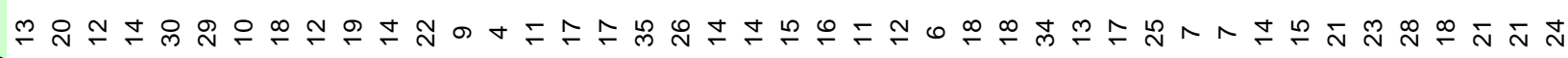

횽

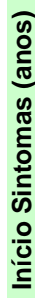

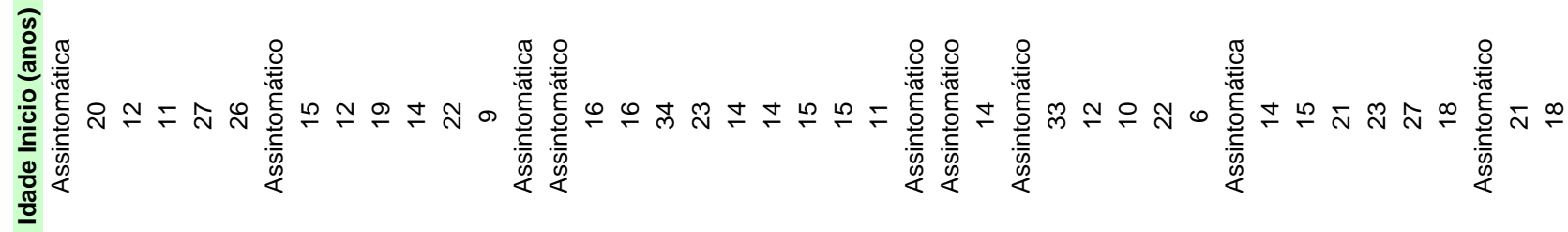

$\frac{1}{0}$

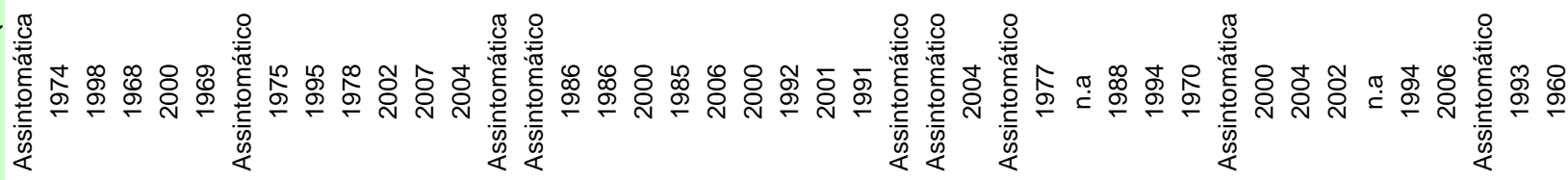
.

$\frac{0}{3}$

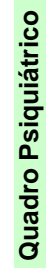

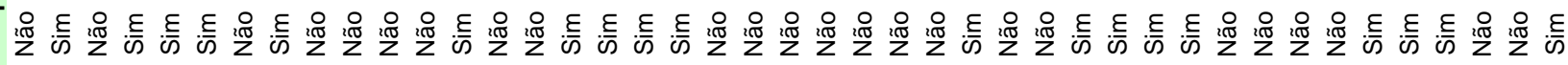

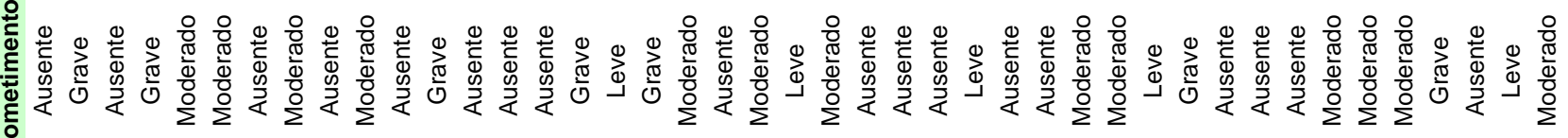

ठั

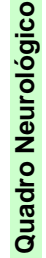

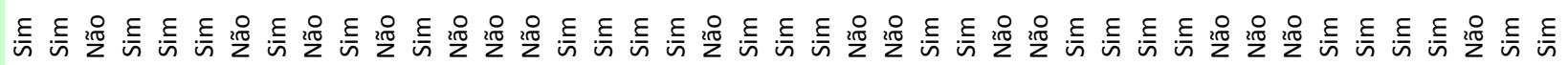

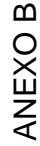

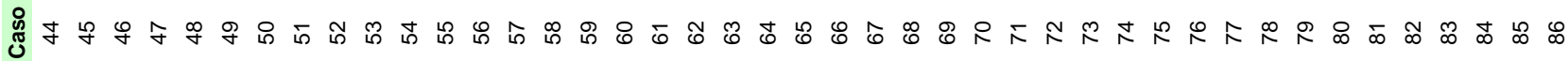




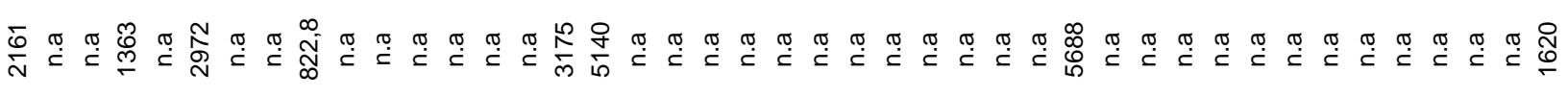

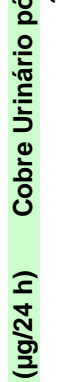

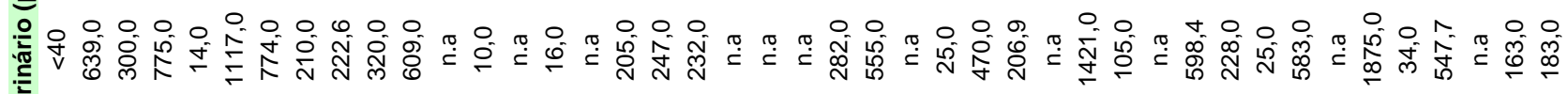

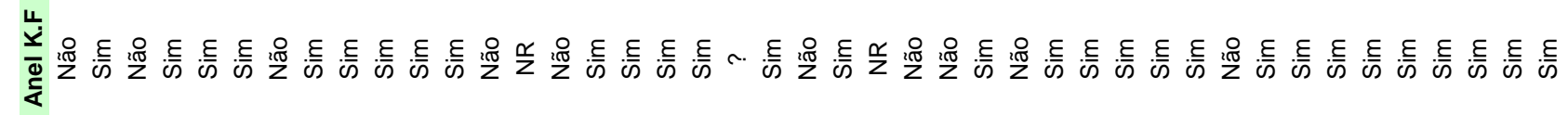

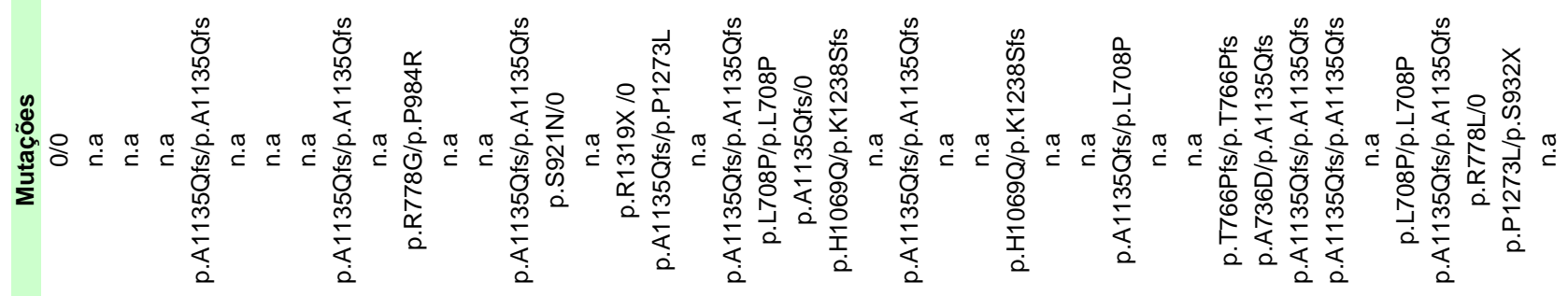

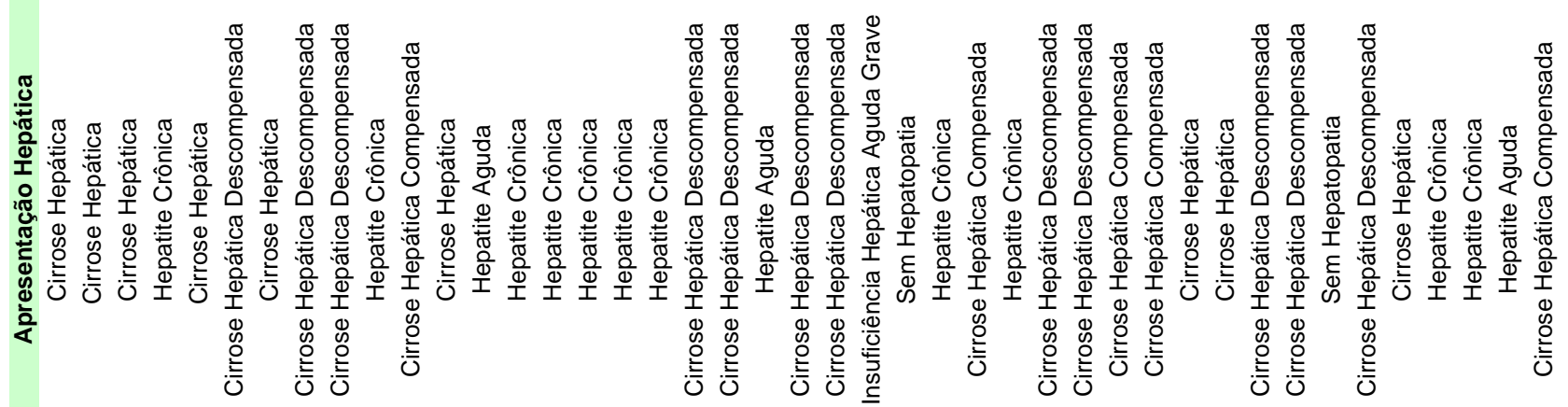

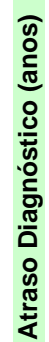


$\frac{\bar{\pi}}{\stackrel{\frac{\pi}{L}}{\underline{5}}}$

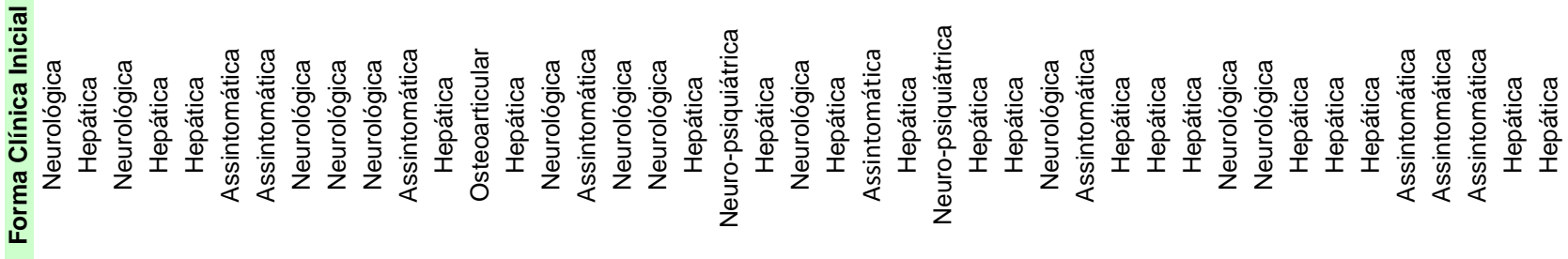
113

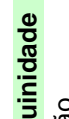

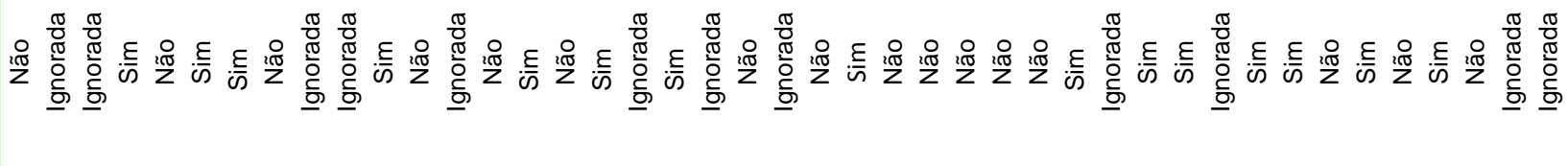

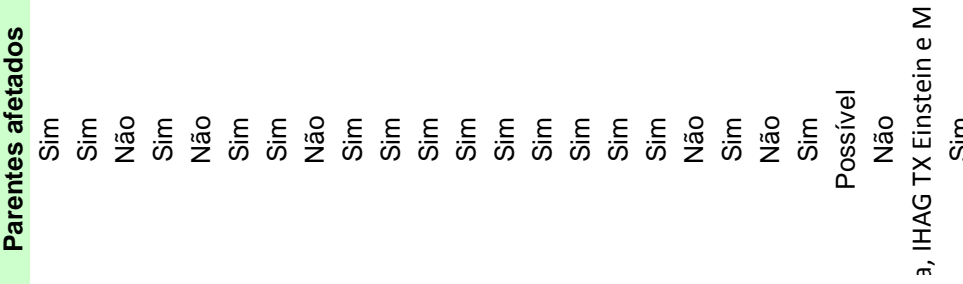

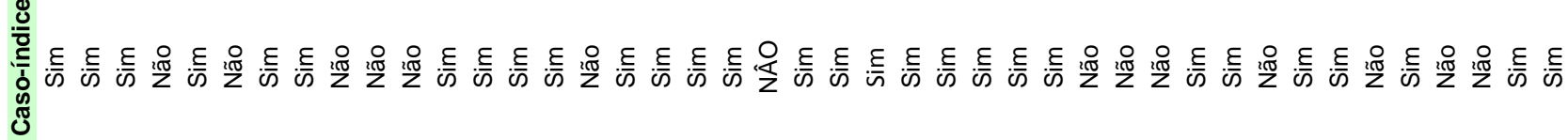

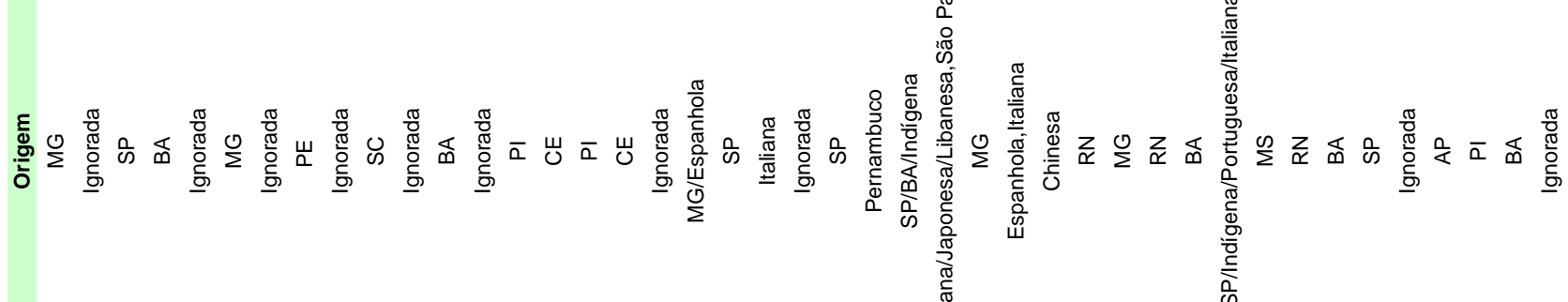

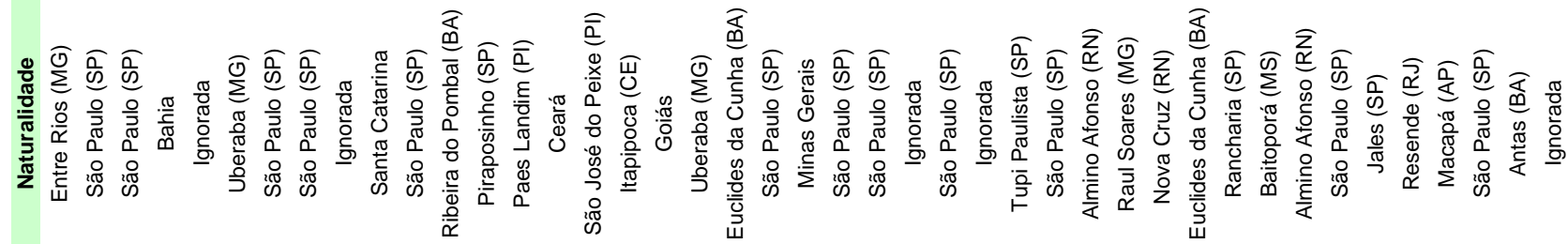
funmminm

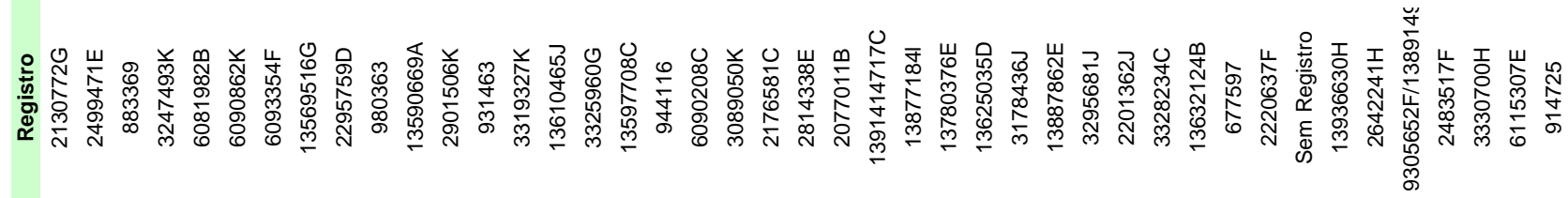

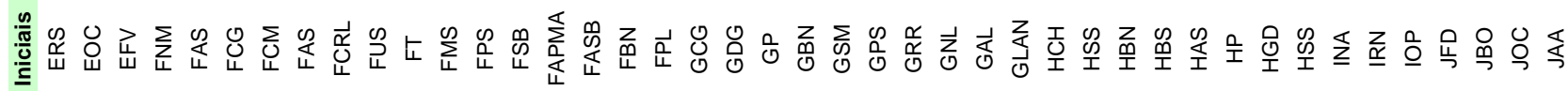

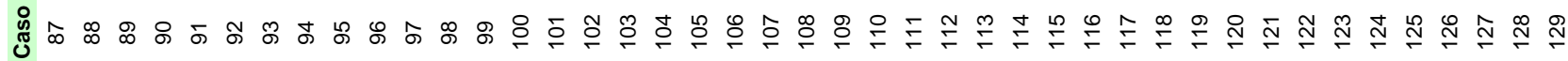




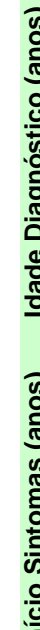

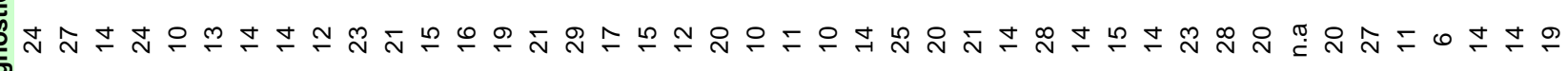

क्ष

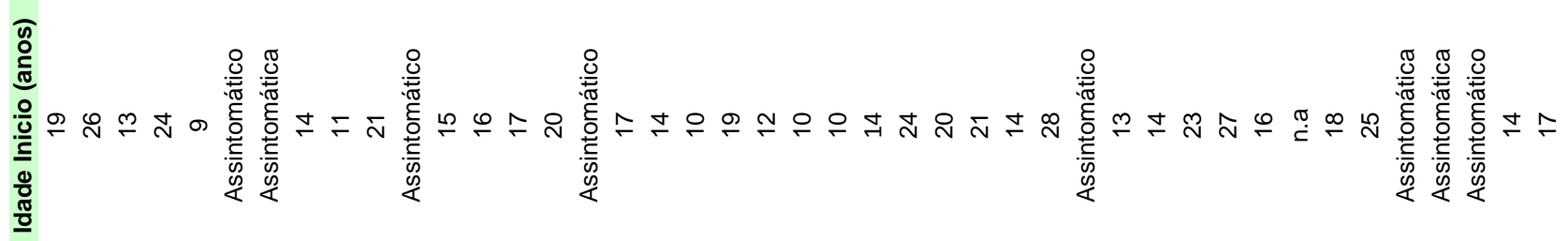

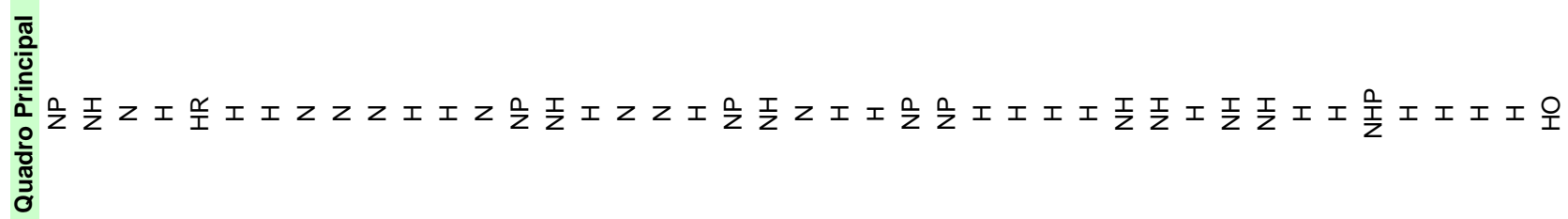

蓄

वेँ

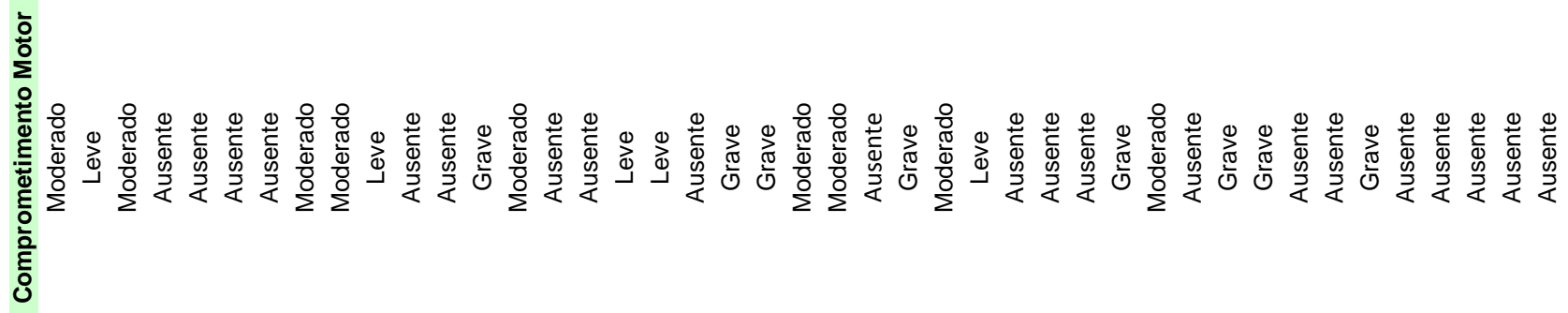

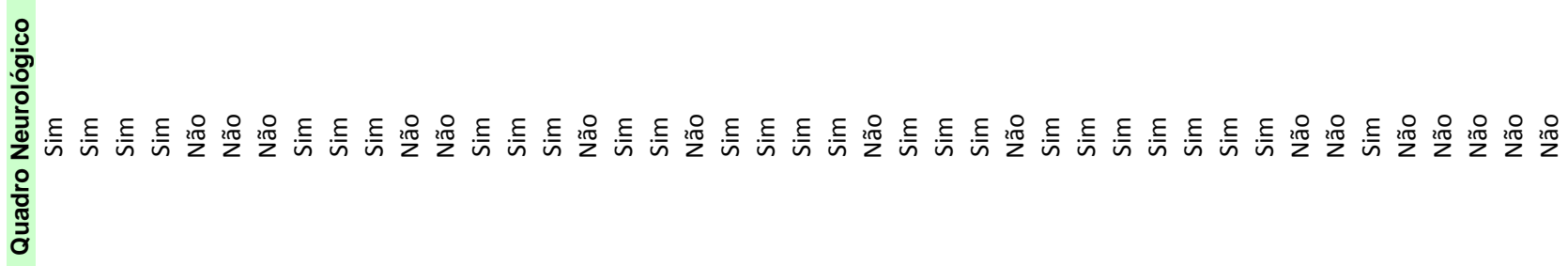

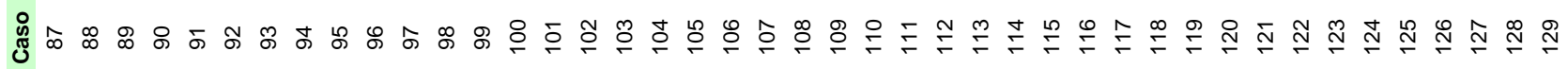




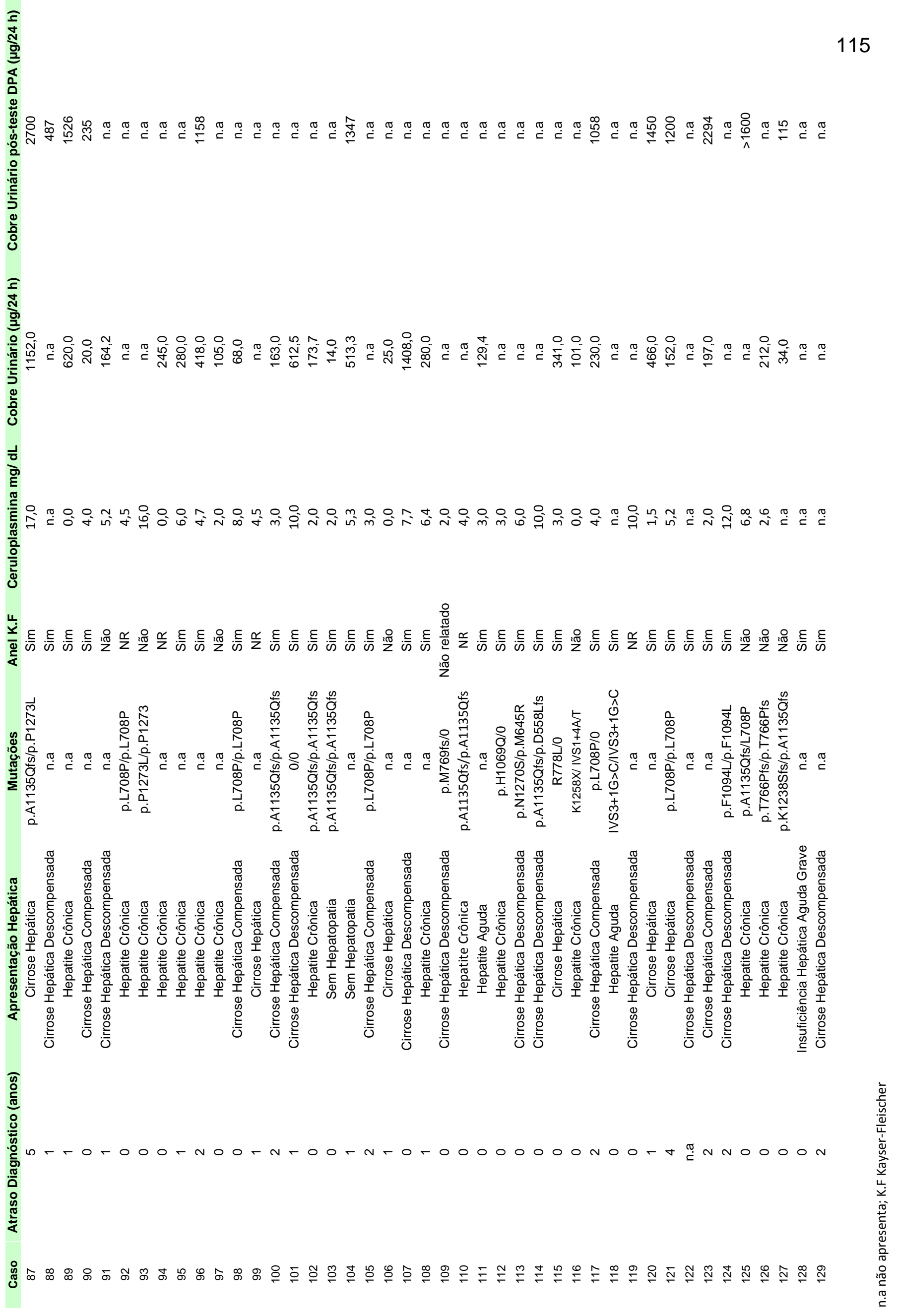




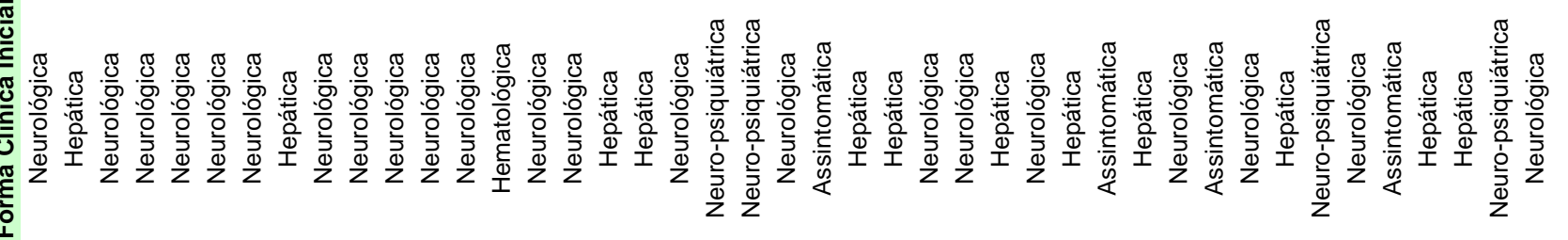
116

$\frac{\mathbb{8}}{\frac{\pi}{0}}$

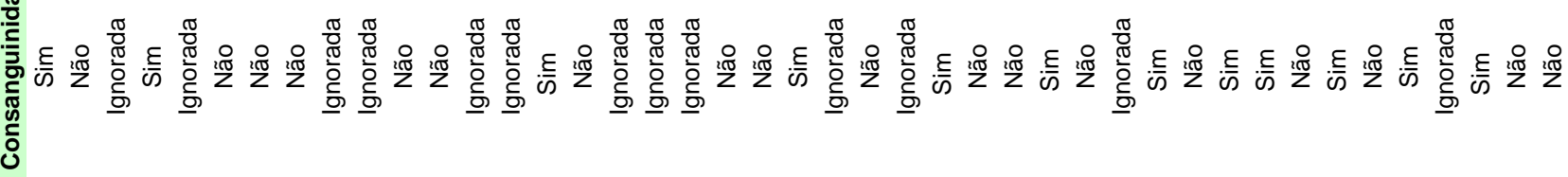

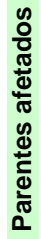

$\stackrel{\Perp}{ \pm}$

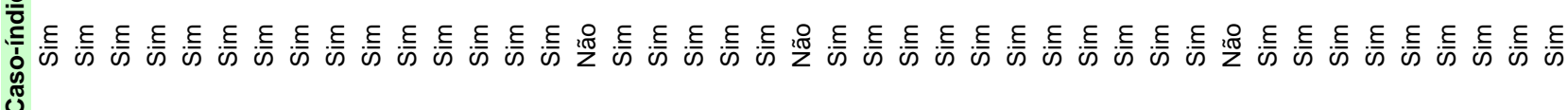

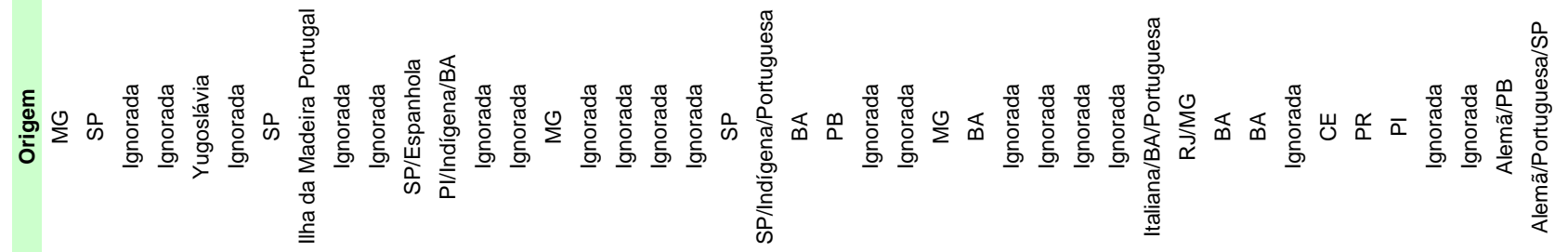

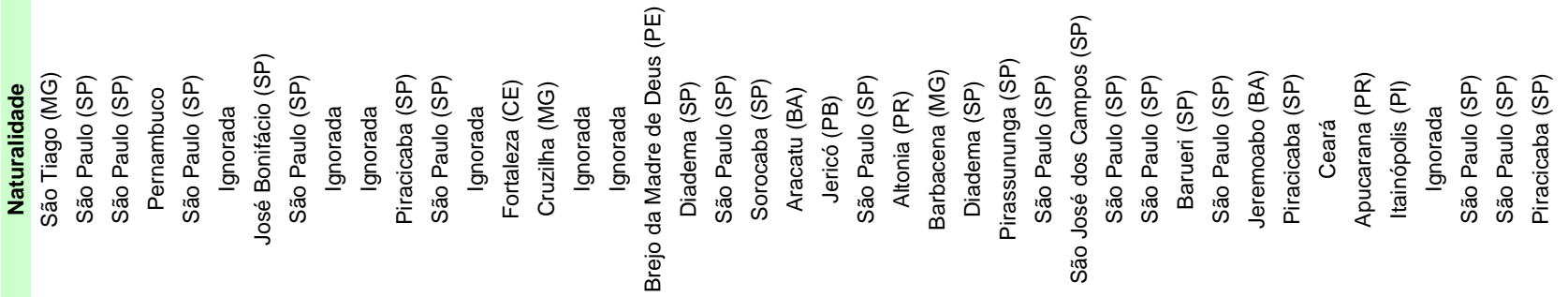

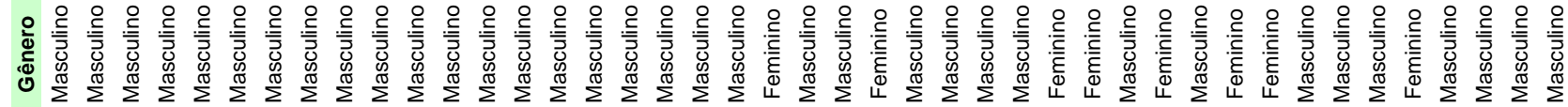

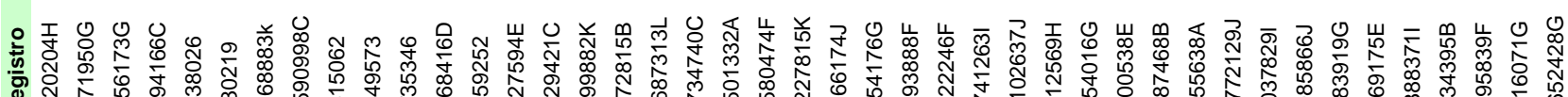

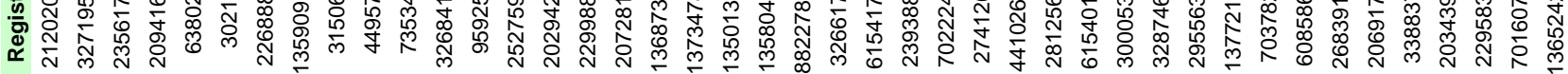

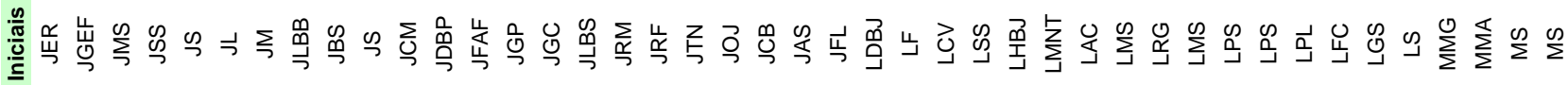




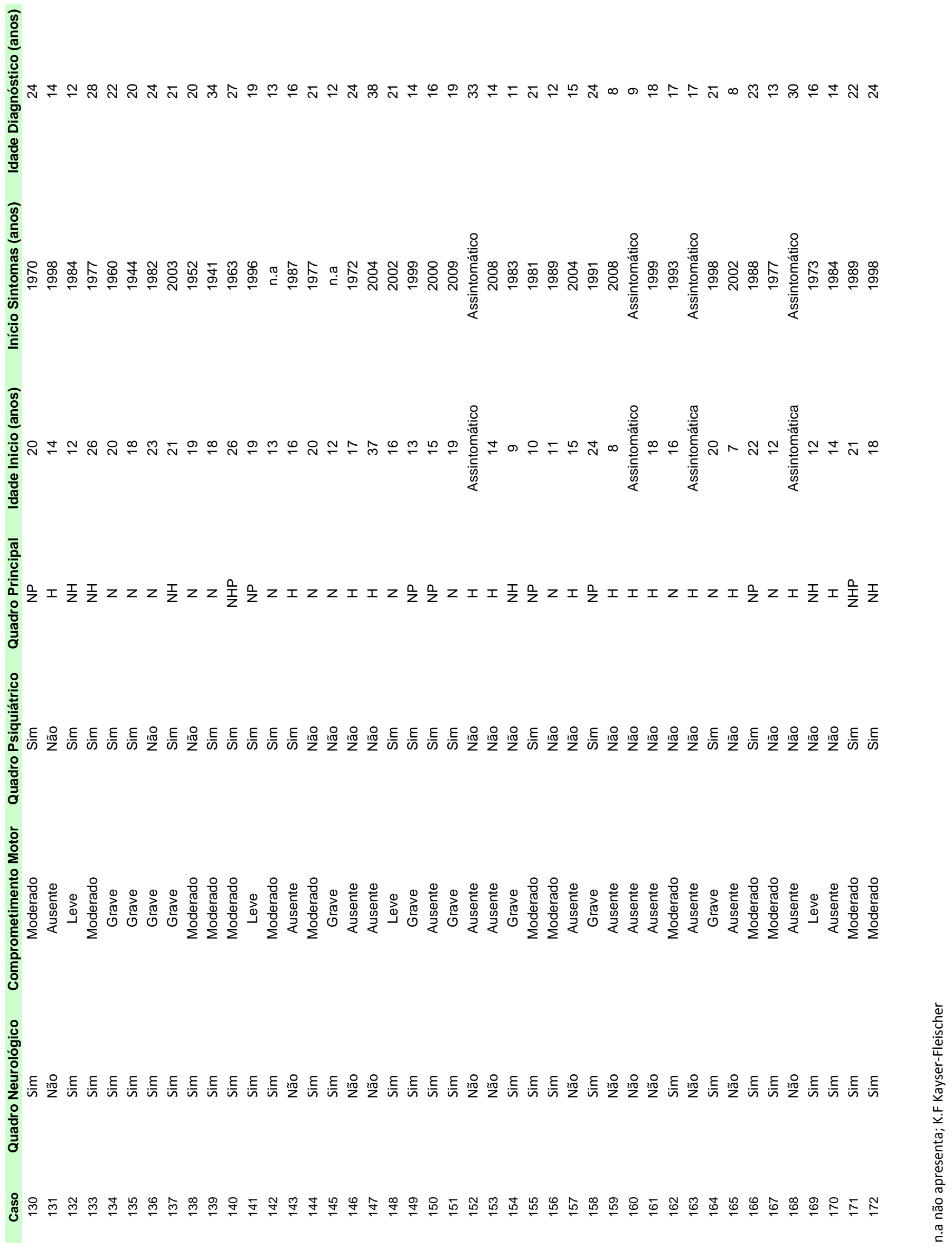




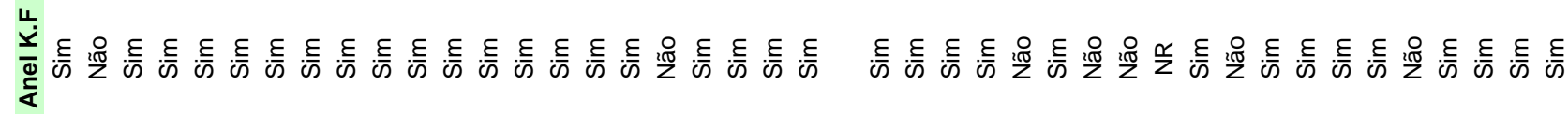

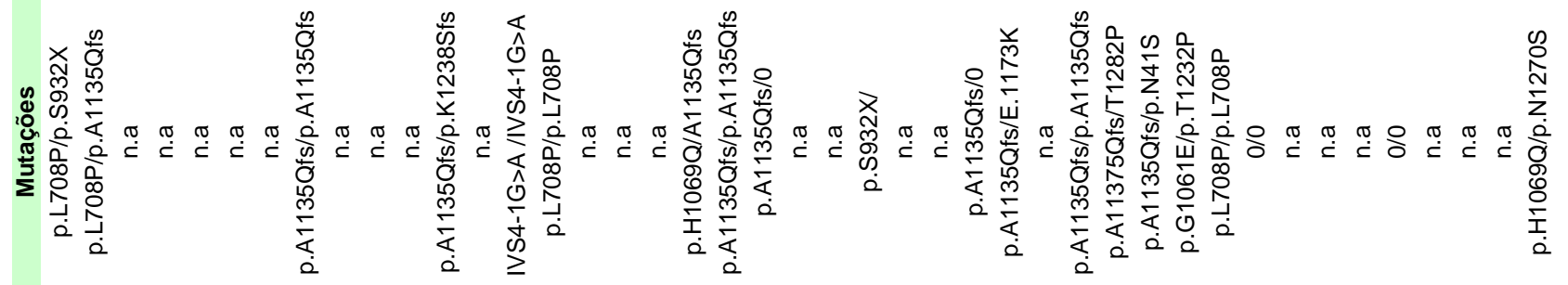

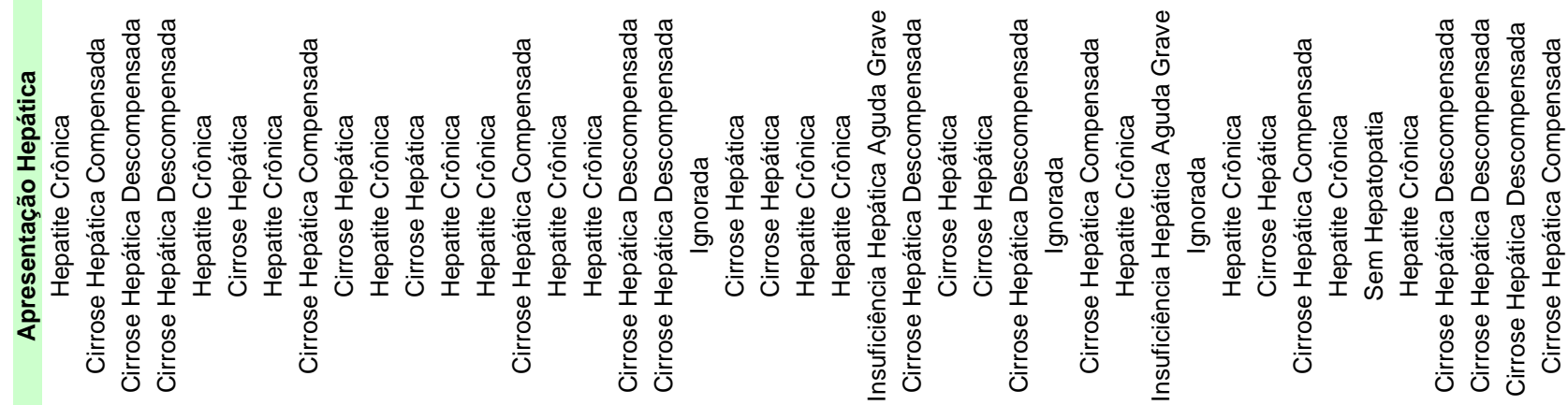

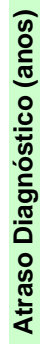

엉에 $\frac{0}{\frac{2}{2}}$ 


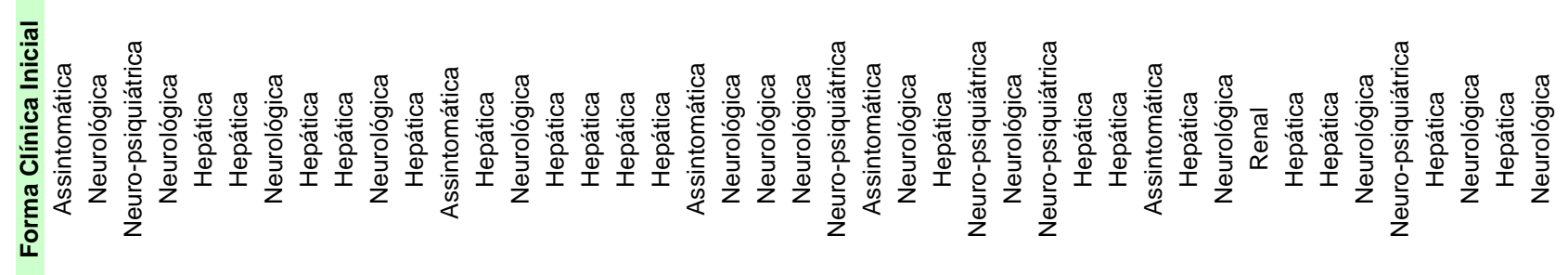

:

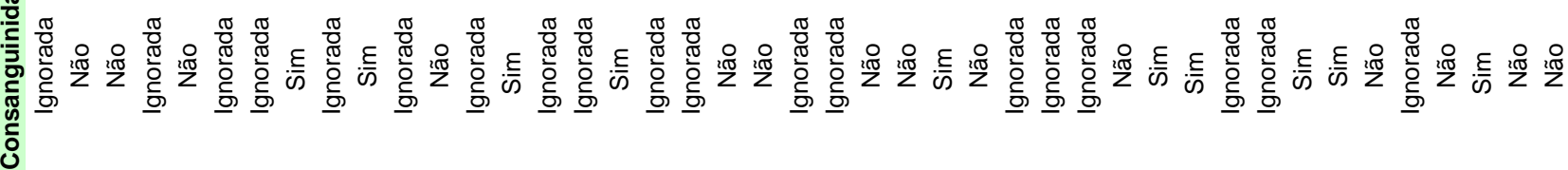

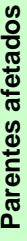

$\stackrel{Ð}{\frac{0}{9}}$

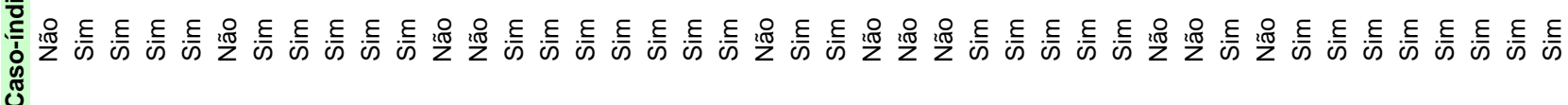

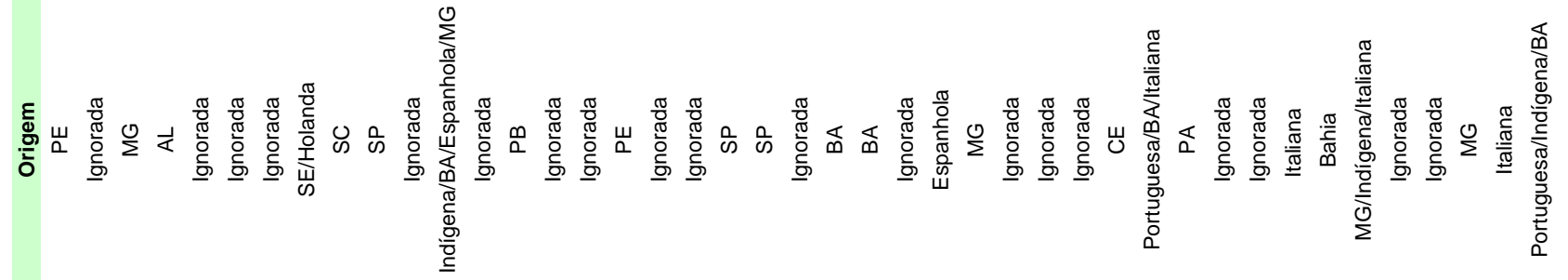

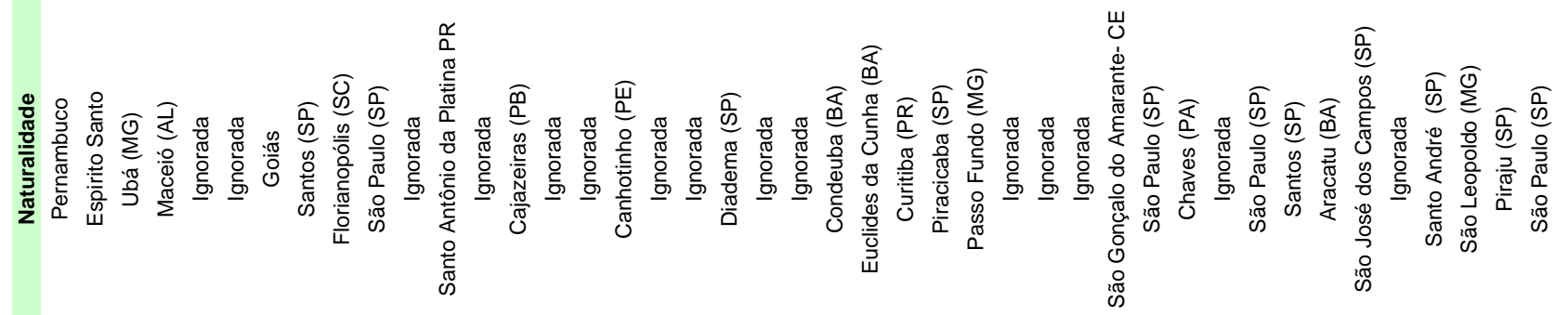

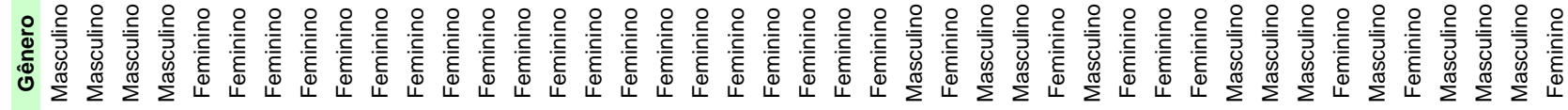

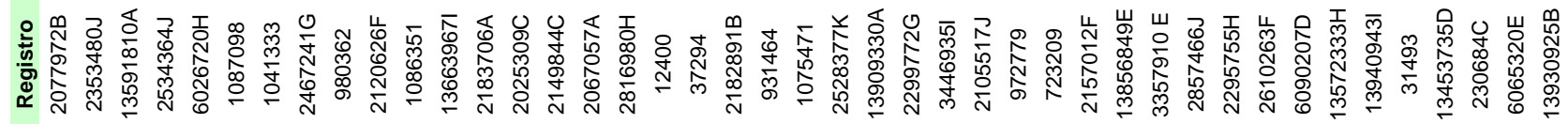

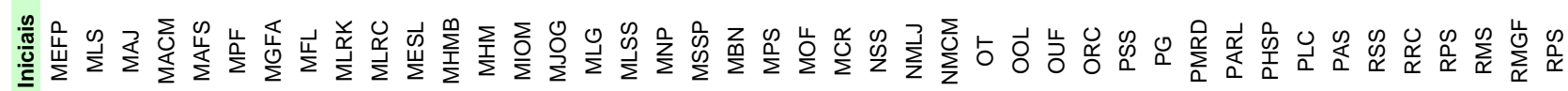




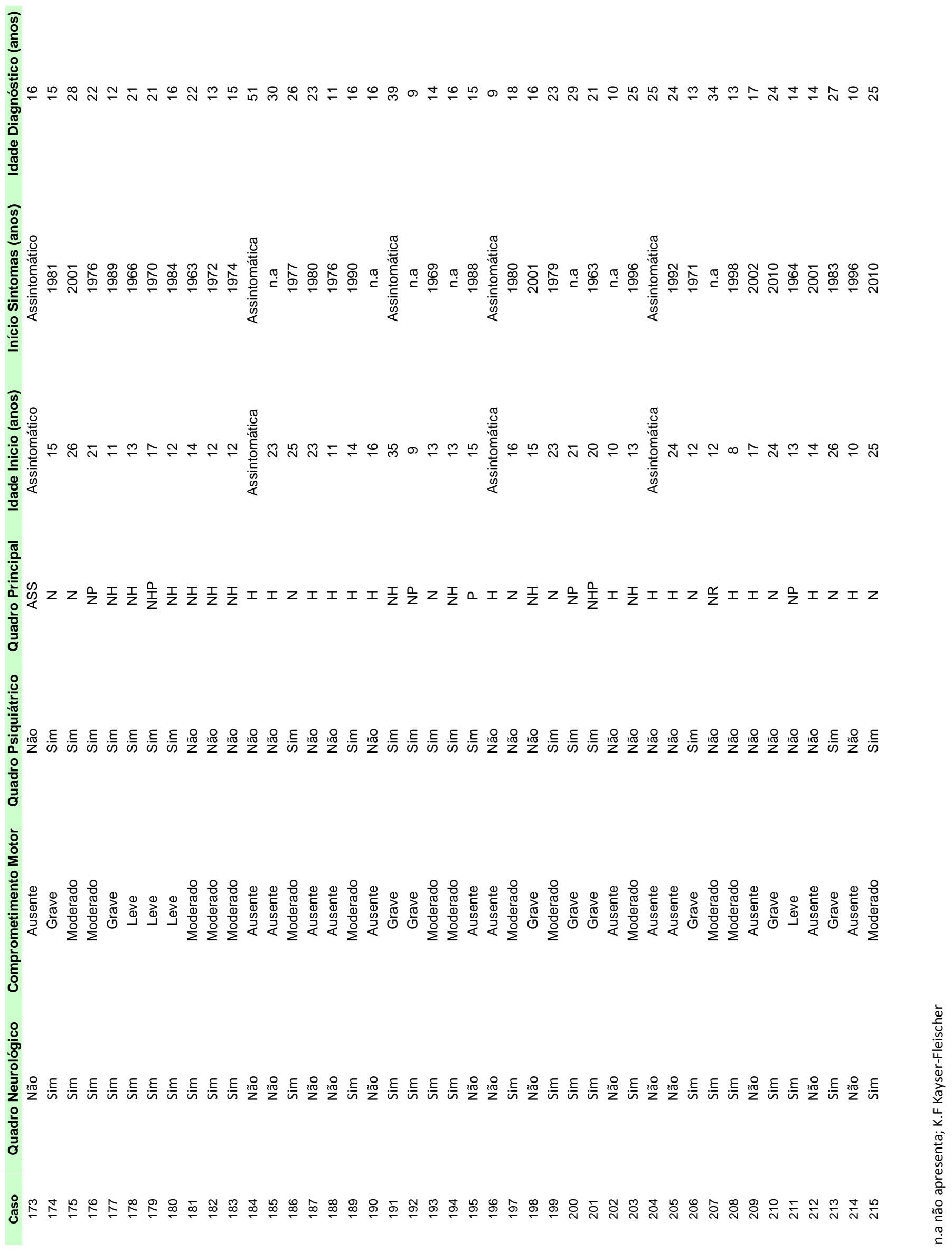




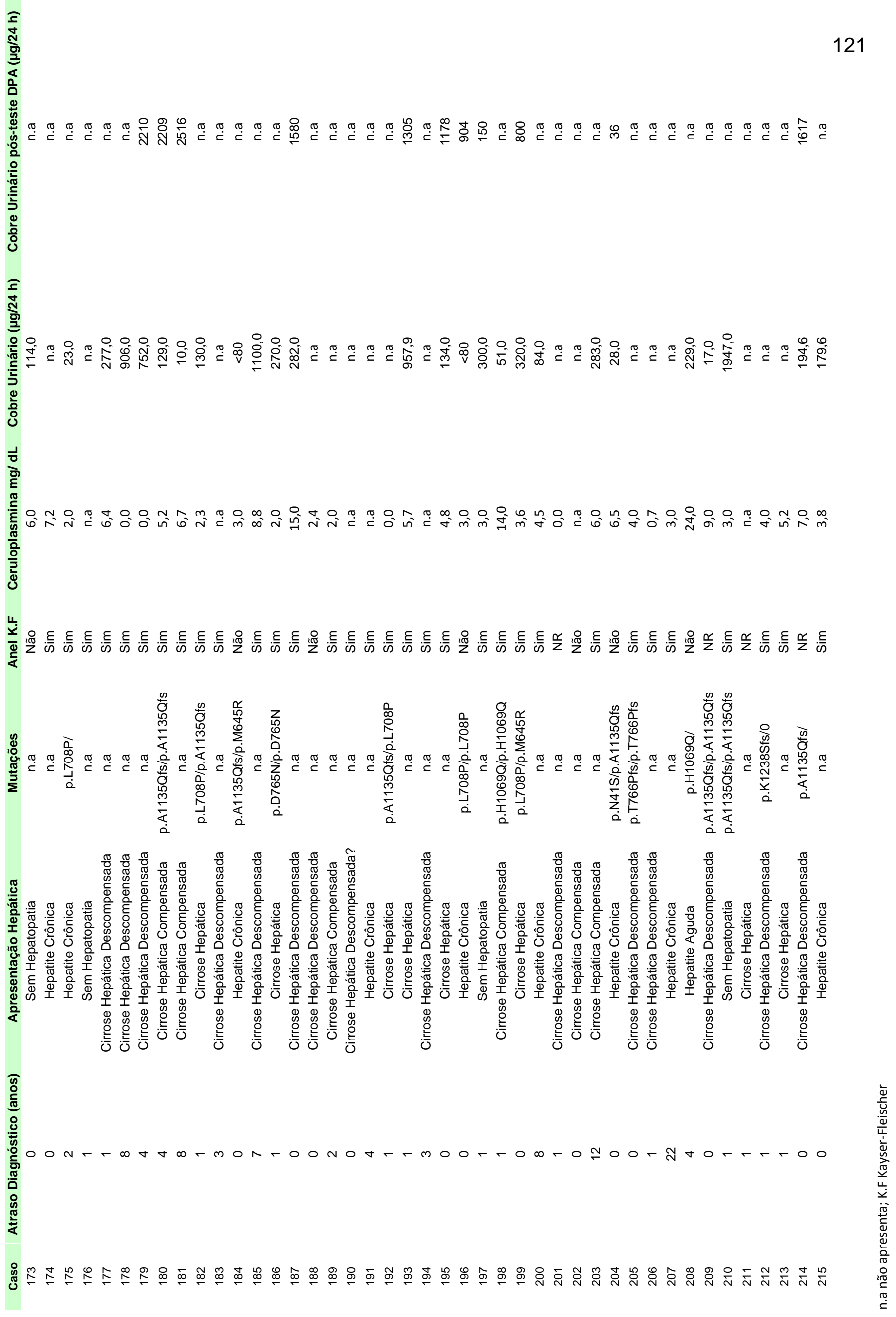




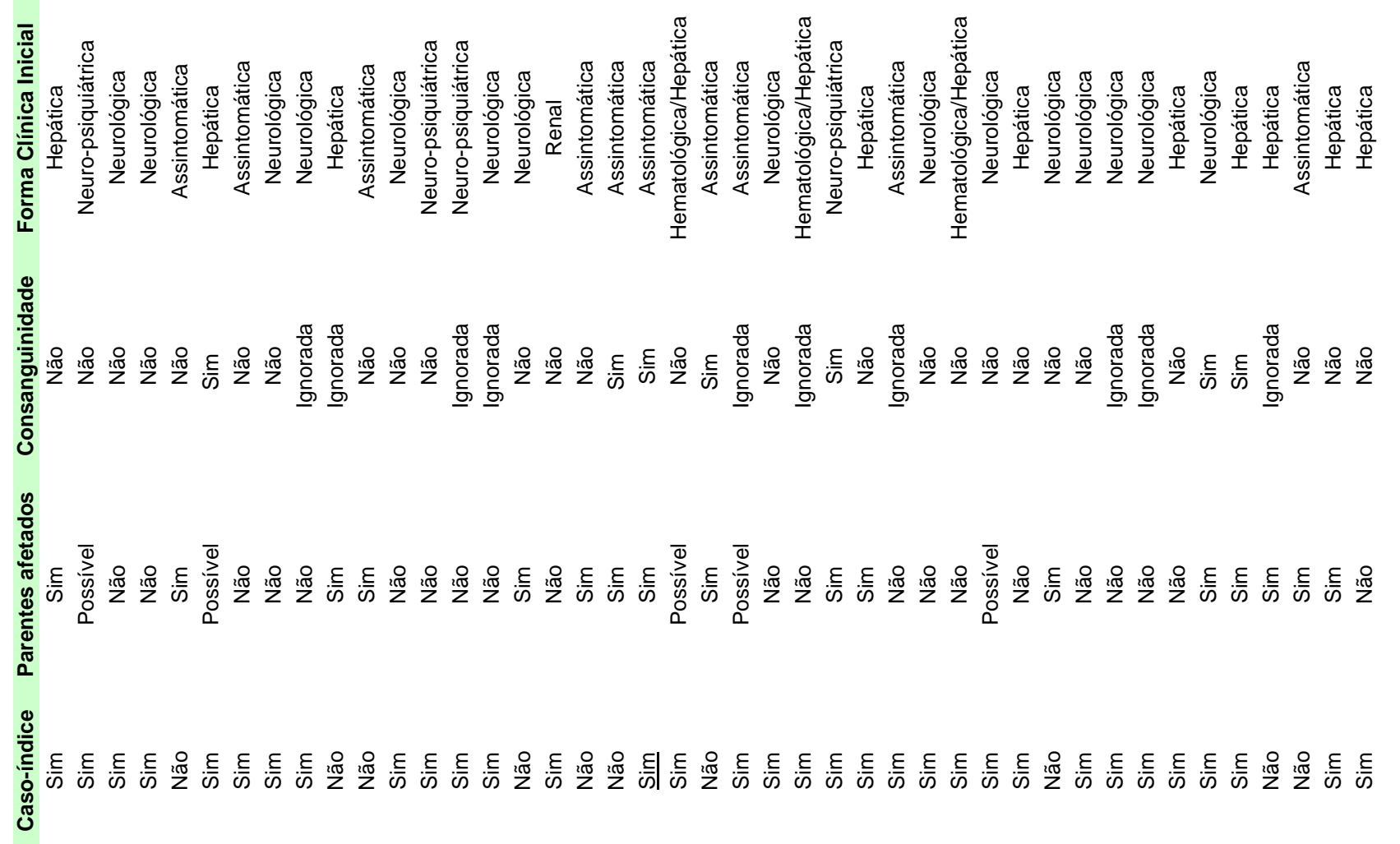




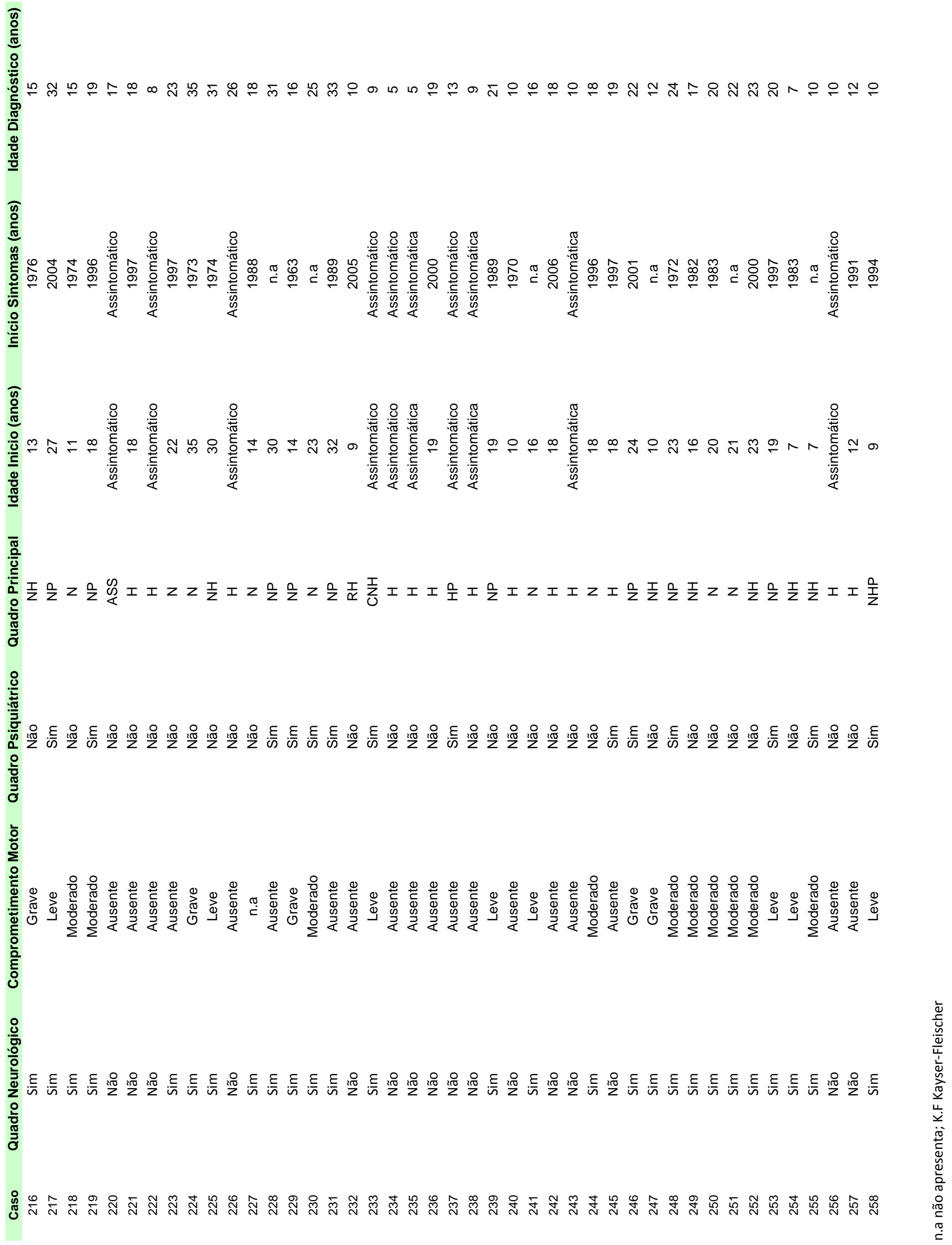




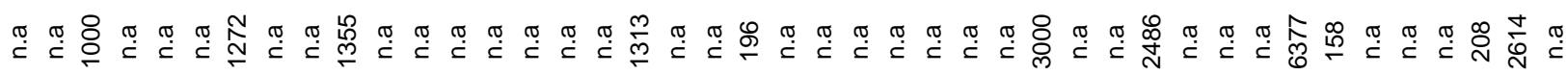

을

ํํำ

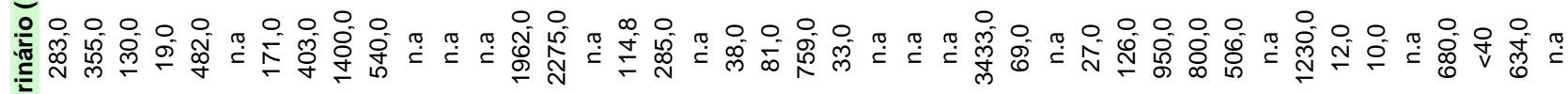
今ั

훙

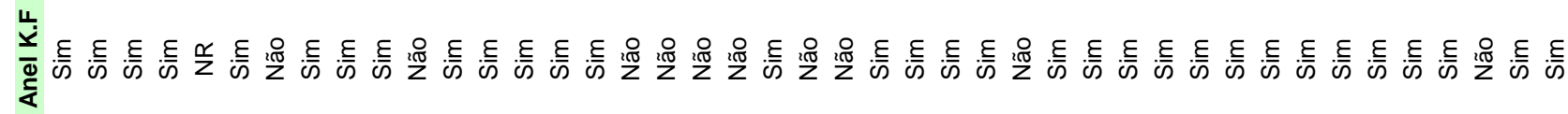
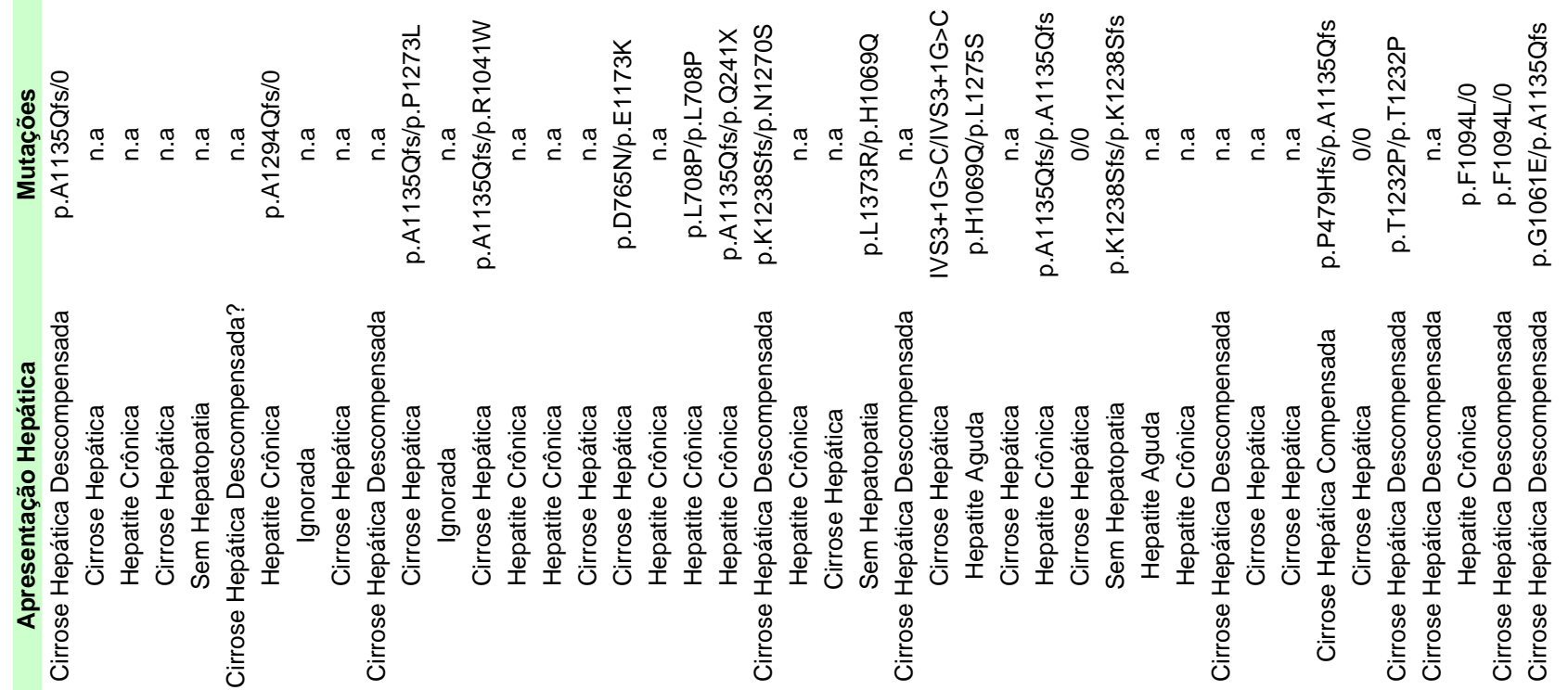

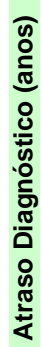



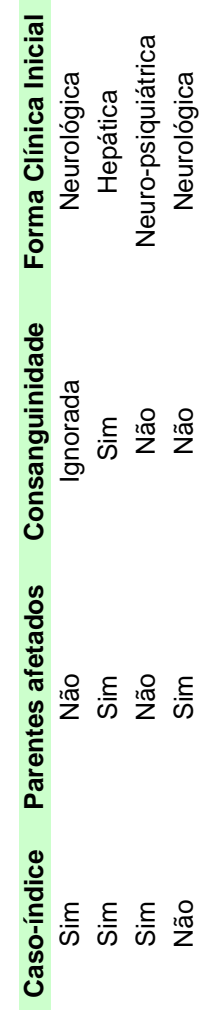

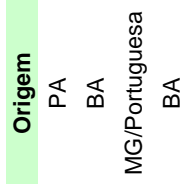

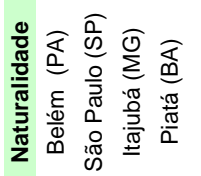

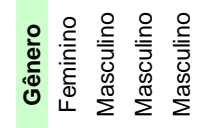

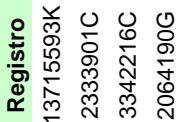

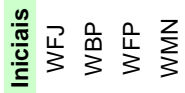

感 

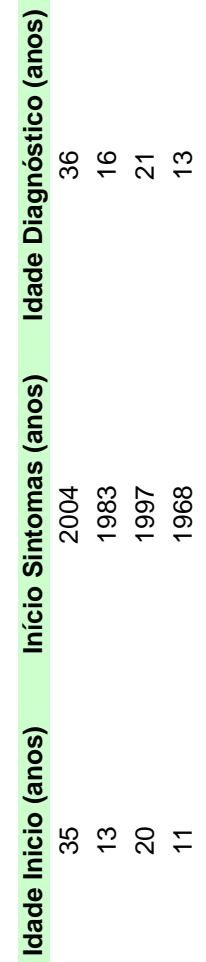

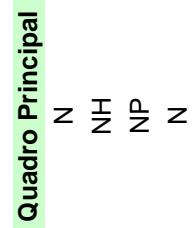
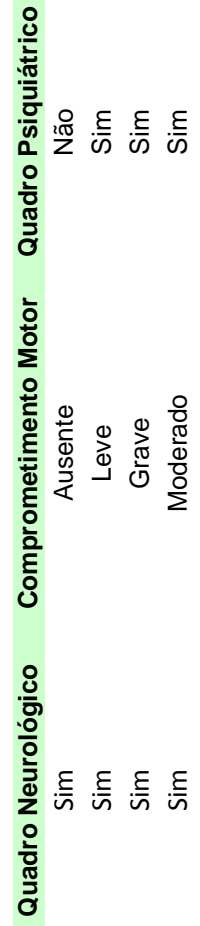

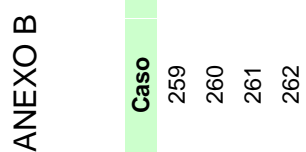



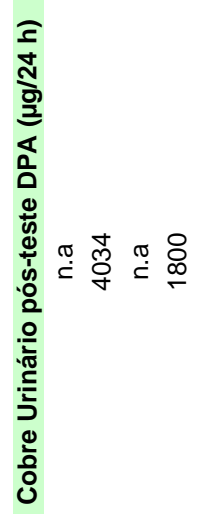

ปั่

을

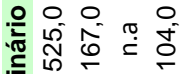

ป

ठัँ

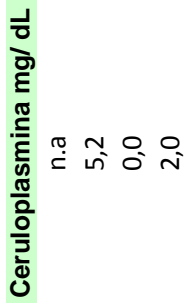

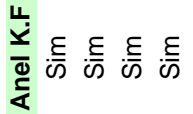
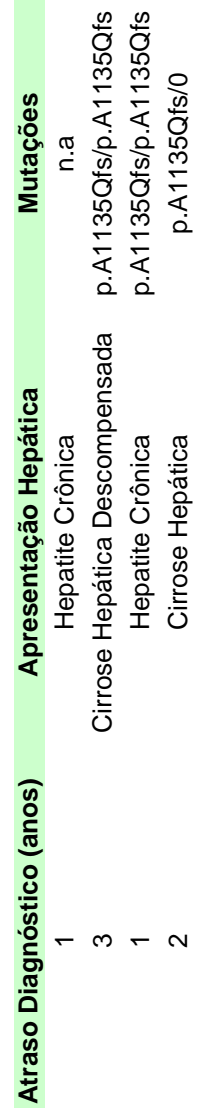

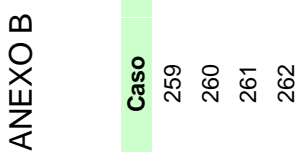




\section{REFERÊNCIAS BIBLIOGRÁFICAS*}

1. Abdel Ghaffar TY, Elsayed SM, Elnaghy S, Shadeed A, Elsobky ES, Schmidt H. Phenotypic and genetic characterization of a cohort of pediatric Wilson disease patients. BMC Pediatr. 2011; 11:56.

2. Aigner E, Strasser M, Haufe H, Sonnweber T, Hohla F, Stadlmayr A, Solioz M, Tilg H, Patsch W, Weiss G, Stickel F, Datz C. A role for low hepatic copper concentrations in nonalcoholic Fatty liver disease. Am J Gastroenterol. 2010;105:1978-85.

3. Ala A, Borjigin J, Rochwarger A, Schilsky M. Wilson disease in septuagenarian siblings: Raising the bar for diagnosis. Hepatology. $2005 ; 41: 668-70$.

4. Ala A, Schilsky ML. Wilson disease: pathophysiology, diagnosis, treatment, and screening. Clin Liver Dis. 2004;8:787-805.

5. Ala A, Walker AP, Ashkan K, Dooley JS, Schilsky ML. Wilson's disease. Lancet. 2007;3:397-408.

\footnotetext{
* De acordo com:

Adaptado de International Committee of Medical Journals Editors (Vancouver). Universidade de São Paulo. Faculdade de Medicina. Serviço de Biblioteca e Documentação. Guia de apresentação de dissertações, teses e monografias da FMUSP. Elaborado por Anneliese Carneiro da Cunha, Maria Julia A.L. Freddi, Maria F. Crestana, Marinalva de S. Aragão, Suely C. Cardoso, Valéria Vilhena. 3a ed. São Paulo: Divisão de Biblioteca e Documentação; 2011.

Abreviaturas dos títulos dos periódicos de acordo com List of Journals Indexed in Index Medicus.
} 
6. Araujo FC, Evangelista AS, Cançado ELR. Doenças Metabólicas do Fígado. In: Zaterka S, Eisig, JN. editores. Tratado de Gastroenterologia da graduação à pós-graduação. São Paulo. Atheneu; 2011. p 981-91.

7. Barbosa ER, Burdmann Ede A, Cançado ER, Haddad MS, Scaff M, Canelas HM. Zinc in the treatment of hepatolenticular degeneration: report of 3 cases. Arq Neuropsiquiatr. 1992;50:99103.

8. Barbosa ER, Culchebachi MD, Navarro JM, Scaff M, Canelas HM. Hypoattenuating lesions of the basal ganglia associated with pyramido-extrapyramidal features:report of two cases in brothers. Arq Neuropsiquiatr. 1986;44:55-9.

9. Barbosa ER, Machado AA, Cançado EL, Deguti MM, Scaff M. Wilson's disease: a case report and a historical review. Arq Neuropsiquiatr. 2009;67:539-43.

10. Barbosa ER, Scaff M, Comerlatti LR, Canelas HM. Hepatolenticular degeneration: critical evaluation of the diagnostic criteria in 95 cases. Arq Neuropsiquiatr. 1985;43:234-42.

11. Barbosa ER, Scaff M, Canelas HM. Hepatolenticular degeneration: analysis of neurological manifestations under treatment in 76 patients. Arq Neuropsiquiatr. 1991;49:399-404.

12. Bartzokis G, Tishler TA, Lu PH, Villablanca P, Altshuler LL, Carter M, Huang D, Edwards N, Mintz J. Brain ferritin iron may influence age- and gender-related risks of neurodegeneration. Neurobiol Aging. 2007;28:414-23. 
13. Bécuwe C, Dalle S, Ronger-Savlé S, Skowron F, Balme B, Kanitakis J, Thomas L. Elastosis perforans serpiginosa associated with pseudo-pseudoxanthoma elasticum during treatment of Wilson's disease with penicillamine. Dermatology. 2005;210:60-3.

14. Bem RS, Muzzillo DA, Deguti MM, Barbosa ER, Werneck LC, Teive HA. Wilson's disease in southern Brazil: a 40-year follow-up study. Clinics. 2011;66:411-6.

15. Bennett J, Hahn SH. Clinical molecular diagnosis of Wilson disease. Semin Liver Dis. 2011;31:233-8.

16. Beyersdorff A, Findeisen A. Morbus Wilson: Case report of a twoyear-old child as first manifestation. Scand $J$ Gastroenterol. 2006;41:496-7.

17. Brewer GJ. Penicillamine should not be used as initial therapy in Wilson's disease. Mov Disord. 1999;14:551-4.

18. Brewer GJ, Askari F, Dick RB, Sitterly J, Fink JK, Carlson M, Kluin KJ, Lorincz MT. Treatment of Wilson's disease with tetrathiomolybdate: V. Control of free copper by tetrathiomolybdate and a comparison with trientine. Trans/ Res. 2009;154:70-7.

19. Brewer GJ, Dick RD, Johnson VD, Brunberg JA, Kluin KJ, Fink JK. Treatment of Wilson's disease with zinc: XV long-term follow-up studies. J Lab Clin Med. 1998;132:264-78.

20. Brewer GJ, Johnson VD, Dick RD, Hedera P, Fink JK, Kluin KJ. Treatment of Wilson's disease with zinc. XVII: treatment during pregnancy. Hepatology. 2000; 31:364-70. 
21. Brewer GJ, Yuzbasiyan-Gurkan V. Wilson disease. Medicine. $1992 ; 71: 139-64$.

22. Bruha R, Marecek Z, Pospisilova L, Nevsimalova S, Vitek L, Martasek P, Nevoral J, Petrtyl J, Urbanek P, Jiraskova A, Ferenci P. Long-term follow-up of Wilson disease: natural history, treatment, mutations analysis and phenotypic correlation. Liver Int. 2010; 3:83-91.

23. Bull PC, Thomas GR, Rommens JM, Forbes JR, Cox DW. The Wilson disease gene is a putative copper transporting P-type ATPase similar to the Menkes gene. Nat Genet. 1993;5: 327-37.

24. Cançado EL, Rocha Mde S, Barbosa ER, Scaff M, Cerri GG, Magalhães A, Canelas HM. Abdominal ultrasonography in hepatolenticular degeneration. A study of 33 patients. Arq Neuropsiquiatr. 1987;45:131-6.

25. Canelas HM. Hepatolenticular degeneration. Apropos of 102 cases. Arq Neuropsiquiatr. 1987;45:197-212.

26. Canelas HM, De Jorge FB. Contribuição ao estudo da ceruloplasmina. I: Valores normais no soro sangüíneo. Arq Neuropsiquiatr. 1964; 22: 271-76.

27. Canelas HM, De Jorge FB, Costa-Silva. Contribuição ao estudo do metabolismo do cobre.I: Metodologia da determinação do cobre em materiais biológicos. Rev Paul Med. 1962; 61:350-55. 
28. Canelas HM, De Jorge FB, Escalante OD, Rocha-Quintão, EC. Hepatolenticular degeneration: clinical and biochemical study of three cases. Arq Neuropsiquiatr. 1963a; 21: 229-50.

29. Canelas HM, De Jorge FB, Spina-França. Contribuição ao estudo do metabolismo do cobre. II: Valores normais do cobre no sangue, líquido cefalorraqueano e urina. Rev Paul Med. 1963b; 62: 125128.

30. Cartwright GE, Hodges RE, Gubler CJ, Mahoney JP, Daum K, Wintrobe MM, Bean WB. Studies on copper metabolism. XIII. Hepatolenticular degeneration. J Clin Invest. 1954;33:1487-501.

31. Catana AM, Medici V. Liver transplantation for Wilson disease. World J Hepatol. 2012;4:5-10.

32. Chen $\mathrm{DB}$, Feng $\mathrm{L}$, Lin $\mathrm{XP}$, Zhang $\mathrm{W}$, Li FR, Liang $\mathrm{XL}$, Li XH. Penicillamine increases free copper and enhances oxidative stress in the brain of toxic milk mice. PLOS One. 2012;7(5):e37709.

33. Cope-Yokoyama S, Finegold MJ, Sturniolo GC, Kim K, Mescoli C, Rugge M, Medici V. Wilson disease: histopathological correlations with treatment on follow-up liver biopsies. World J Gastroenterol. 2010 28;16:1487-94.

34. Cumings, JN.The copper and iron contend of brain and liver in the normal and in hepatolenticular degeneration. Brain. 1948;71:41015.

35. Cumings JN. The effects of BAL. in hepatolenticular degeneration. Brain. 1951;74:10-22. 
36. Curtis D, Durkie M, Balac (Morris) P, Sheard D, Goodeve A, Peake I, Quarrell O, Tanner S. A study of Wilson disease mutations in Britain. Hum Mutat. 1999;14:304-11.

37. Członkowska A, Rodo M, Gromadzka G. Late onset Wilson's disease: therapeutic implications. Mov Disord. 2008;23:896-8.

38. Członkowska A, Tarnacka B, Litwin T, Gajda J, Rodo M. Wilson's disease-cause of mortality in 164 patients during 1992-2003 observation period. J Neurol. 2005 ;252:698-703.

39. Dahlman T, Hartvig $\mathrm{P}$, Löfholm $\mathrm{M}$, Nordlinder $\mathrm{H}$, Lööf $\mathrm{L}$, Westermark K. Long-term treatment of Wilson's disease with triethylene tetramine dihydrochloride (trientine). Q J Med. 1995;88: $609-16$.

40. da Silva-Júnior FP, Machado AA, Lucato LT, Cançado EL, Barbosa ER. Copper deficiency myeloneuropathy in a patient with Wilson disease. Neurology. 2011 a May 10;76(19):1673-4.

41. da Silva-Júnior FP, Lucato LT, Machado AA, Barbosa ER. Copper deficiency in Wilson's disease: an avoidable complication of treatment. Mov Disord. 2011 b Nov;26:2448-9; author reply 244950.

42. de Bie P, van de Sluis B, Burstein E, van de Berghe PV, Muller P, Berger R, Gitlin JD, Wijmenga C, Klomp LW. Distinct Wilson's disease mutations in ATP7B are associated with enhanced binding to COMMD1 and reduced stability of ATP7B. Gastroenterology. 2007;133:1316-26. 
43. Denny-Brown D, Porter H. The effect of BAL (2,3dimercaptopropanol) on hepatolenticular degeneration (Wilson's disease). N Engl J Med. 1951;245:917-25.

44. Deguti MM, Genschel J, Cancado EL, Barbosa ER, Bochow B, Mucenic $\mathrm{M}$, et al. Wilson disease: novel mutations in the ATP7B gene and clinical correlation in Brazilian patients. Hum Mutat. 2004;23:398.

45. Deguti MM, Mucenic M, Cançado EL, Tietge UJ. Elastosis perforans serpiginosa secondary to D-penicillamine treatment in a Wilson's disease patient. Am J Gastroenterol 2002;97:2153-4.

46. Dening TR, Berrios GE. Wilson's disease: a longitudinal study of psychiatric symptoms. Biol Psychiatry. 1990;28:255-65.

47. Duarte-Rojo A, Zepeda-Gómez S, García-Leiva J, Remes-Troche JM, Angeles-Ángeles A, Torre-Delgadillo A, Olivera-Martínez MA. Liver transplantation for neurologic Wilson's disease: reflections on two cases within a mexican cohort. Rev Gastroenterol Mex. $2009 ; 74: 218-23$.

48. DuBois RS, Rodgerson DO, Martineau G, Shroter G, Giles G, Lilly J, Halgrimson CG, StarzI TE, Sternlieb I, Scheinberg IH. Orthotopic liver transplantation for Wilson's disease. Lancet. 1971;1:505-8.

49. European Association for the Study of the Liver. EASL clinical practice guidelines: Wilson's disease. J Hepatol. 2012;56:671-85.

50. Ferenci P. Pathophysiology and clinical features of Wilson disease. Metab Brain Dis. 2004; 19: 229-39. 
51. Ferenci P, Caca K, Loudianos G, Mieli-Vergani G, Tanner S, Sternlieb I, Schilsky $M$ et al. Diagnosis and phenotypic classification of Wilson disease. Liver Int. 2003;23: 139-42.

52. Ferenci P, Członkowska A, Merle U, Ferenc S, Gromadzka G, Yurdaydin C, Vogel W, Bruha R, Schmidt HT, Stremmel W. Lateonset Wilson's disease. Gastroenterology. 2007;132:1294-8.

53. Ferenci $P$, Steindl-Munda $P$, Vogel W, Jessner W, Gschwantler M, Stauber R, Datz C, Hackl F, Wrba F, Bauer P, Lorenz O. Diagnostic value of quantitative hepatic copper determination in patients with Wilson's Disease. Clin Gastroenterol Hepatol. 2005;3:811-8.

54. Figus A, Angius A, Loudianos G, Bertini C, Dessi V, Loi A, Deiana M, Lovicu M, Olla N, Sole G, et al. Molecular pathology and haplotype analysis of Wilson disease in Mediterranean populations. Am J Hum Genet. 1995 Dec;57(6):1318-24.

55. Frommer DJ. Defective biliary excretion of copper in Wilson's disease.Gut. 1974;15:125-29.

56. Gheorghe L, Popescu I, lacob S, Gheorghe C, Vaidan R, Constantinescu A, lacob R, Becheanu G, Angelescu C, Diculescu M. Wilson's Disease: a challenge of diagnosis. The 5-year experience of a tertiary centre. Rom J Gastroenterol. 2004;13:17985. 
57. Gow PJ, Smallwood RA, Angus PW, Smith AL, Wall AJ, Sewell RB. Diagnosis of Wilson's disease: an experience over three decades. Gut. 2000;46:415- 19.

58. Gromadzka G, Rudnicka M, Chabik G, Przybyłkowski A, Członkowska A. Genetic variability in the methylenetetrahydrofolate reductase gene (MTHFR) affects clinical expression of Wilson's disease. J Hepatol. 2011;55:913-9.

59. Gromadzka G, Schmidt HH, Genschel J, Bochow B, Rodo M, Tarnacka B, Litwin T, Chabik G, Czlonkowska A: Frameshift and nonsense mutations in the gene for ATPase7B are associated with severe impairment of copper metabolism and with an early clinical manifestation of Wilson's disease. Clin Genet. 2005; 68:524-32.

60. Gu M, Cooper JM, Butler P, Walker AP, Mistry PK, Dooley JS, Schapira AH. Oxidative-phosphorylation defects in liver of patients with Wilson's disease. Lancet. 2000;356:469-74.

61. Gupta A, Chattopadhyay I, Dey S, Nasipuri P, Das SK, Gangopadhyay PK, Ray K. Molecular pathogenesis of Wilson disease among Indians: a perspective on mutation spectrum in ATP7B gene, prevalent defects, clinical heterogeneity and implication towards diagnosis. Cell Mol Neurobiol. 2007;27:102333.

62. Habib GS, Saliba W, Nashashibi M, Armali Z. Penicillamine and nephrotic syndrome. Eur J Intern Med. 2006;17:343-8. 
63. Hahn SH, Lee SY, Jang YJ, Kim SN, Shin HC, Park SY, Han HS, Yu ES, Yoo HW, Lee JS, Chung CS, Lee SY, Lee DH. Pilot study of mass screening for Wilson's disease in Korea. Mol Genet Metab. $2002 ; 76: 133-6$.

64. Harris ED. Cellular copper transport and metabolism. Annu Rev Nutr. 2000;20:291-310.

65. Hoogenraad TU. Paradigm shift in treatment of Wilson's disease: zinc therapy now treatment of choice. Brain Dev. 2006;28:141-6.

66. Hoogenraad TU, Van den Hamer CJ, Koevoet R, Korver EG. Oral zinc in Wilson's disease. Lancet. 1978;2:1262.

67. Hoogenraad TU, Van Hattum J, Van den Hamer CJ. Management of Wilson's disease with zinc sulphate. Experience in a series of 27 patients. J Neurol Sci. 1987;77:137-46.

68. Huster D, Finegold MJ, Morgan CT, Burkhead JL, Nixon R, Vanderwerf SM, Gilliam CT, Lutsenko S. Consequences of copper accumulation in the livers of the Atp7b-/- (Wilson disease gene) knockout mice. Am J Pathol. 2006;168:423-34.

69. Huster D. Wilson disease. Best Pract Res Clin Gastroenterol. 2010;24:531-9.

70. Igic PG, Lee E, Harper W, Roach KW. Toxic effects associated with consumption of zinc. Mayo Clin Proc. 20021;77:713-6.

71. Iorio R, D'Ambrosi M, Marcellini M, Barbera C, Maggiore G, Zancan L, Giacchino R, Vajro P, Marazzi MG, Francavilla R, Michielutti F, Resti M, Frediani $T$, Pastore M, Vegnente A. 
Persistence of elevated aminotransferases in Wilson's disease despite adequate therapy. Hepatology. 2004;39:1173-4.

72. Jain S, Scheuer PJ, Archer B, Newman SP, Sherlock S. Histological demonstration of copper and copper-associated protein in chronic liver diseases. J Clin Pathol. 1978;31:784-90.

73. Johncilla M, Mitchell KA. Pathology of the liver in copper overload. SeminLiver Dis. 2011;31:239-44.

74. Johnson PE, Milne DB, Lykken Gl. Effects of age and sex on copper absorption, biological half-life, and status in humans. Am J Clin Nutr. 1992;56:917-25.

75. Kleine RT, Mendes R, Pugliese R, Miura I, Danesi V, Porta G. Wilson's disease: an analysis of 28 Brazilian children. Clinics. 2012;67:231-5.

76. Kroll CA, Ferber MJ, Dawson BD, Jacobson RM, Mensink KA, Lorey F, Sherwin J, Cunningham G, Rinaldo P, Matern D, Hahn $\mathrm{SH}$. Retrospective determination of ceruloplasmin in newborn screening blood spots of patients with Wilson disease. Mol Genet Metab. 2006;89:134-8.

77. Kumar A, Singh BK, Ahmad I, Shukla S, Patel DK, Srivastava G, Kumar V, Pandey HP, Singh C. Involvement of NADPH oxidase and glutathione in zinc-induced dopaminergic neurodegeneration in rats: similarity with paraquat neurotoxicity. Brain Res. 2012;1438:48-64. 
78. Lang PA, Schenck M, Nicolay JP, Becker JU, Kempe DS, Lupescu A, Koka S, Eisele K, Klarl BA, Rübben H, Schmid KW, Mann K, Hildenbrand S, Hefter H, Huber SM, Wieder T, Erhardt A, Häussinger D, Gulbins E, Lang F. Liver cell death and anemia in Wilson disease involve acid sphingomyelinase and ceramide. Nat Med. 2007;13:164-70.

79. Lau JY, Lai CL, Wu PC, Pan HY, Lin HJ, Todd D. Wilson's disease: 35 years' experience. Q J Med. 1990;75:597-605.

80. Lee BH, Kim JH, Lee SY, Jin HY, Kim KJ, Lee JJ, Park JY, Kim GH, Choi JH, Kim KM, Yoo HW. Distinct clinical courses according to presenting phenotypes and their correlations to ATP7B mutations in a large Wilson's disease cohort. Liver Int. $2011 ; 31: 831-9$.

81. Linn FH, Houwen $\mathrm{RH}$, van Hattum J, van der Kleij S, van Erpecum KJ. Long-term exclusive zinc monotherapy in symptomatic Wilson disease: experience in 17 patients. Hepatology. 2009;50:1442-52.

82. Litwin T, Gromadzka G, Członkowska A. Neurological presentation of Wilson's disease in a patient after liver transplantation. Mov Disord. 2008;23:743-6.

83. Litwin T, Gromadzka G, Członkowska A. Apolipoprotein E gene (APOE) genotype in Wilson's disease: Impact on clinical presentation. Parkinsonism Relat Disord. 2012;3: 1-3.

84. Litwin T, Gromadzka G, Członkowska A. Gender differences in Wilson's disease. J Neurol Sci. 2012;312:31-5. 
85. Liu XQ, Zhang YF, Liu TT, Hsiao KJ, Zhang JM, Gu XF, Bao KR, Yu LH, Wang MX. Correlation of ATP7B genotype with phenotype in Chinese patients with Wilson disease. World $J$ Gastroenterol. 2004;10:590-3.

86. Lutz W. Keratosis follicularis serpiginosa. Dermatologica 1953;106:318-20.

87. Machado AA, Deguti MM, Genschel J, Cançado EL, Bochow B, Schmidt H, Barbosa ER. Neurological manifestations and ATP7B mutations in Wilson's disease. Parkinsonism Relat Disord. 2008;14:246-9.

88. Mak CM, Lam CW, Tam S. Diagnostic accuracy of serum ceruloplasmin in Wilson disease: determination of sensitivity and specificity by ROC curve analysis among ATP7B-genotyped subjects. Clin Chem. 2008;54:1356-62.

89. McDonald LV, Lake CR. Psychosis in an adolescent patient with Wilson'sdisease: effects of chelation therapy. Psychosom Med. $1995 ; 57: 202-4$.

90. Medici V, Rossaro L, Sturniolo GC. Wilson disease--a practical approach to diagnosis, treatment and follow-up. Dig Liver Dis. 2007 ;39:601-9.

91. Mehta SH, Parekh SM, Prakash R, Morgan JC, Miyajima H, Sethi KD. Predominant ataxia, low ceruloplasmin, and absent K-F rings: hypoceruloplasminemia or Wilson's disease. Mov Disord. 2010 ;25:2260-1. 
92. Merle U, Schaefer M, Ferenci P, Stremmel W. Clinical presentation, diagnosis and long-term outcome of Wilson's disease: a cohort study. Gut. 2007;56:115-20.

93. Merle U, Stremmel W, Gessner R. Influence of homozygosity for methionine at codon 129 of the human prion gene on the onset of neurological and hepatic symptoms in Wilson disease. Arch Neurol. 2006;63:982-5.

94. Milkiewicz P, Saksena S, Hubscher SG, Elias E. Wilson's disease with superimposed autoimmune features: report of two cases and review. J Gastroenterol Hepatol. 2000;15:570-4.

95. Moreno CB, Gutiérrez-Alvarez AM, González-Reyes RE. [Zinc and epilepsy: is there a causal relation between them?]. Rev Neurol. $2006 ; 42: 754-9$.

96. Mufti AR, Burstein E, Csomos RA, Graf PC, Wilkinson JC, Dick RD, Challa M, Son JK, Bratton SB, Su GL, Brewer GJ, Jakob U, Duckett CS. XIAP Is a copper binding protein deregulated in Wilson's disease and other copper toxicosis disorders. MolCell. $2006 ; 21: 775-85$.

97. Muller $\mathrm{P}$, van Bakel $\mathrm{H}$, van de Sluis $\mathrm{B}$, Holstege $\mathrm{F}$, Wijmenga $\mathrm{C}$, Klomp LW. Gene expression profiling of liver cells after copper overload in vivo and in vitro reveals new copper-regulated genes. $J$ Biol Inorg Chem. 2007;12:495-507.

98. Müller T, Koppikar S, Taylor RM, Carragher F, Schlenck B, HeinzErian P, Kronenberg F, Ferenci P, Tanner S, Siebert U, Staudinger 
R, Mieli-Vergani G, Dhawan A. Re-evaluation of the penicillamine challenge test in the diagnosis of Wilson's disease in children. $J$ Hepatol. 2007;47:270-6.

99. Nagasaka H, Takayanagi M, Tsukahara H. Children's toxicology from bench to bed--Liver Injury (3): Oxidative stress and antioxidant systems in liver of patients with Wilson disease. J Toxicol Sci. 2009;34:229-36.

100. Nakatani T, Tawaramoto M, Opare Kennedy D, Kojima A, MatsuiYuasa I. Apoptosis induced by chelation of intracellular zinc is associated with depletion of cellular reduced glutathione level in rat hepatocytes. Chem Biol Interact. 2000;125:151-63.

101. Nanke Y, Akama H, Terai C, Kamatani N. Rapidly progressive glomerulonephritis with D-penicillamine. Am J Med Sci. 2000 ;320:398-402.

102. Nathan BP, Chang KC, Bellosta S, Brisch E, Ge N, Mahley RW, Pitas RE. The inhibitory effect of apolipoprotein E4 on neurite outgrowth is associated withmicrotubule depolymerization. $\mathrm{J}$ Biol Chem. 1995 ;270:19791-9.

103. Nazer H, Ede RJ, Mowat AP, Williams R. Wilson's disease: clinical presentation and use of prognostic index. Gut. 1986;27:1377-81.

104. Ohura T, Abukawa D, Shiraishi H, Yamaguchi A, Arashima S, Hiyamuta S, Tada K, linuma K. Pilot study of screening for Wilson disease using dried blood spots obtained from children seen at outpatient clinics. J Inherit Metab Dis. 1999;22:74-80. 
105. Panagiotakaki E, Tzetis M, Manolaki N, Loudianos G, Papatheodorou A, Manesis E, Nousia-Arvanitakis S, Syriopoulou V, Kanavakis E. Genotype-phenotype correlations for a wide spectrum of mutations in the Wilson disease gene (ATP7B). Am J Med Genet A. 2004;131:168-73.

106. Pass F, Sternlieb I. Elastosis perforans serpiginosa during penicillamine therapy for Wilson disease. Arch Dermatol 1973;108:713-15.

107. Payne AS, Kelly EJ, Gitlin JD. Functional expression of the Wilson disease protein reveals mislocalization and impaired copperdependent trafficking of the common $\mathrm{H} 1069 \mathrm{Q}$ mutation. Proc Natl Acad Sci U S A. 1998;95:10854-9.

108. Pérez-Aguilar F. Ceruloplasmine and iron metabolism: their implications in hemochromatosis, Wilson's disease and aceruloplasminemia. Rev Clin Esp. 2002;202:649-51.

109. Petrukhin K, Lutsenko S, Chernov I, Ross BM, Kaplan JH, Gilliam TC. Characterization of the Wilson disease gene encoding a P-type copper transporting ATPase: genomic organization, alternative splicing, and structure/function predictions. Hum Mol Genet. 1994;3:1647-56.

110. Pfeiffenberger J, Gotthardt DN, Herrmann T, Seessle J, Merle U, Schirmacher $\mathrm{P}$, et al. Iron metabolism and the role of HFE gene polymorphisms in Wilson disease. Liver Int. 2012;32:165-70. 
111. Pilloni L, Lecca S, Van Eyken P, Flore C, Demelia L, Pilleri G, Nurchi AM, Farci AM, Ambu R, Callea F, Faa G. Value of histochemical stains for copper in the diagnosis of Wilson's disease. Histopathology. 1998;33:28-33.

112. Porea TJ, Belmont JW, Mahoney DH Jr. Zinc-induced anemia and neutropenia in an adolescent. $J$ Pediatr. 2000;136:688-90.

113. Porter $\mathrm{H}$. Copper excretion in the urine of normal individuals and of patients with hepatolenticular degeneration (Wilson's disease). Arch Biochem Biophys. 1951;31:262-5.

114. Prashanth LK, Sinha S, Taly AB, Vasudev MK. Do MRI features distinguish Wilson's disease from other early onset extrapyramidal disorders? An analysis of 100 cases. Mov Disord. 2010;25:672-8.

115. Prusiner SB. Prions. Proc Natl Acad Sci U S A. 1998;95:13363-83.

116. Richard VS, Harris VK, Shankar V, Loganathan G, Chandy GM. Clinical manifestations and survival pattern of Wilson's disease. Natl Med J India. 2000; 13:301-3.

117. Roberts EA, Sarkar B. Liver as a key organ in the supply, storage, and excretion of copper. Am J Clin Nutr. 2008;88:851S-4S.

118. Roberts EA, Schilsky ML. A practice guideline on Wilson disease. Hepatology. 2003;37:1475-92.

119. Roberts, EA, Schilsky ML. Diagnosis and treatment of Wilson disease:An update. Hepatology. 2008; 47: 2089-2111. 
120. Rosencrantz R, Schilsky M. Wilson disease: pathogenesis and clinical considerations in diagnosis and treatment. Semin Liver Dis. $2011 ; 31: 245-59$.

121. Rumpel A. Ueber das wesen und die bedeutung der leberveranderungen und der pigmentierunen bie den damitverbundenen fallen von pseudosklerose, zugleich ein beitrag zur lehre von der pseudosklerose (Westphal-Strumpell). Dtsch Z Nervenheilk. 1913;49:54-73.

122. Saito H, Watanabe K, Sahara M, Mochizuki R, Edo K, Ohyama Y. Triethylene-tetramine (trien) therapy for Wilson's disease. Tohoku $\mathrm{J}$ Exp Med. 1991;164:29-35.

123. Schaefer $M$, Roelofsen $H$, Wolters $H$, Hofmann WJ, Müller M, Kuipers F, Stremmel W, Vonk RJ. Localization of the Wilson's disease protein in human liver. Gastroenterology. 1999;117:13805.

124. Scheinberg IH, Gitlin D. Deficiency of ceruloplasmin in patients with hepatolenticular degeneration (Wilson's disease). Science. 1952;116:484-5.

125. Scheinberg, IH. Sternlieb I. Wilson`s disease. Major problems in internal medicine., ed. L. Smith. 1984, Philadelphia: WB Saunders.

126. Schiefermeier M, Kollegger H, Madl C, Polli C, Oder W, Kühn H, et al. Impact of apolipoprotein E genotypes on age at onset of symptoms and phenotypic expression in Wilson's disease. Brain. 2000;123:585-90 
127. Schmidt, HHJ. Role genotyping in Wilson's diseases. J Hepatol. $2009 ; 50: 449-52$

128. Senzolo M, Loreno M, Fagiuoli S, Zanus G, Canova D, Masier A, Russo FP, Sturniolo GC, Burra P. Different neurological outcome of liver transplantation for Wilson's disease in two homozygotic twins. Clin Neurol Neurosurg. 2007;109:71-5.

129. Shah AB, Chernov I, Zhang HT, Ross BM, Das K, Lutsenko S, et al. Identification and analysis of mutations in the Wilson disease gene (ATP7B):population frequencies, genotype-phenotype correlation, and functional analyses. Am $J$ Hum Genet. 1997;61:317-28.

130. Sharma R, Jain S, Kher V. ANCA-associated Goodpasture's syndrome in a patient with rheumatoid arthritis on penicillamine. Indian J Nephrol. 2012;22:45-7.

131. Shim H, Harris ZL. Genetic defects in copper metabolism. J Nutr. 2003;133:1527S-31S.

132. Shiono Y, Wakusawa S, Hayashi H, Takikawa T, Yano M, Okada $\mathrm{T}$, Mabuchi $\mathrm{H}$, Kono $\mathrm{S}$, Miyajima $\mathrm{H}$. Iron accumulation in the liver of male patients with Wilson's disease. Am $J$ Gastroenterol. 2001;96:3147-51.

133. Shimizu N, Fujiwara J, Ohnishi S, Sato M, Kodama H, Kohsaka T, Inui A, Fujisawa T, Tamai H, Ida S, Itoh S, Ito M, Horiike N, Harada M, Yoshino M, Aoki T. Effects of long-term zinc treatment in 
Japanese patients with Wilson disease: efficacy, stability, and copper metabolism. Trans/ Res. 2010;156:350-7.

134. Siafakas CG, Jonas MM, Alexander S, Herrin J, Furuta GT. Early onset of nephrotic syndrome after treatment with D-penicillamine in a patient with Wilson's disease. Am J Gastroenterol. 1998;93:25446.

135. Spillane JD, Keyser JW, Parker RA. Amino-aciduria and copper metabolism in hepatolenticular degeneration. J Clin Pathol. 1952 ;5:16-24

136. Stapelbroek JM, Bollen CW, van Amstel JK, van Erpecum KJ, van Hattum J, van den Berg LH, Klomp LW, Houwen RH. The H1069Q mutation in ATP7B is associated withlate and neurologic presentation in Wilson disease: results of a meta-analysis. $J$ Hepatol. 2004;41:758-63.

137. Starzl TE, Giles G, Lilly JR, Takagi H, Martineau G, Schroter G,et al. Indications for orthotopic liver transplantation: with particular reference to hepatomas, biliary atresia, cirrhosis, Wilson's disease and serum hepatitis. Transplant Proc. 1971;3:308-12.

138. Steindl P, Ferenci P, Dienes HP, Grimm G, Pabinger I, Madl C, et al. A. Wilson's disease in patients presenting with liver disease: a diagnostic challenge. Gastroenterology. 1997;113:212-8.

139. Stremmel W, Meyerrose KW, Niederau C, Hefter H, Kreuzpaintner G, Strohmeyer G. Wilson disease: clinical presentation, treatment, and survival. Ann Intern Med. 1991;115:720-6. 
140. Suvarna JC. Kayser-Fleischer ring. J Postgrad Med. 2008;54:23840.

141. Svetel M, Pekmezović T, Petrović I, Tomić A, Kresojević N, Jesić R, Kazić S, Raicević R, Stefanović D, Delibasić N, Zivanović D, Dordević M, Kostić VS. Long-term outcome in Serbian patients with Wilson disease. Eur J Neurol. 2009;16:852-7.

142. Taly AB, Meenakshi-Sundaram S, Sinha S, Swamy HS, Arunodaya GR. Wilson disease: description of 282 patients evaluated over 3 decades. Medicine. 2007;86:112-21.

143. Tanzi RE, Petrukhin K, Chernov I, Pellequer JL, Wasco W, Ross B, et al. The Wilson disease gene is a copper transporting ATPase with homology to the Menkes disease gene. Nat Genet. 1993;5:344-50.

144. Tao TY, Gitlin JD. Hepatic copper metabolism: insights from genetic disease. Hepatology. 2003;37:1241-7.

145. Tatsumi $Y$, Hattori $A$, Hayashi $H$, Ikoma J, Kaito M, Imoto $M$, Wakusawa S, Yano M, Hayashi K, Katano Y, Goto H, Okada T, Kaneko S. Current state of Wilson disease patients in central Japan. Intern Med 2010; 49:809-15.

146. Thomas GR, Forbes JR, Roberts EA, Walshe JM, Cox DW. The Wilson disease gene: spectrum of mutations and their consequences. Nat Genet. 1995;9:210-7. 
147. van den Berghe PV, Klomp LW. New developments in the regulation of intestinal copper absorption. Nutr Rev. 2009;67:65872.

148. van den Berghe PV, Stapelbroek JM, Krieger E, de Bie P, van de Graaf SF, de Groot RE, van Beurden E, Spijker E, Houwen RH, Berger R, Klomp LW. Reduced expression of ATP7B affected by Wilson disease-causing mutations is rescued by pharmacological folding chaperones 4-phenylbutyrate and curcumin. Hepatology. 2009;50:1783-95.

149. Verghese PB, Castellano JM, Holtzman DM. Apolipoprotein E in Alzheimer's disease and other neurological disorders. Lancet Neurol. 2011;10:241-52.

150. Vieira J, Oliveira PV, Juliano Y, Warde KR, Deguti MM, Barbosa ER, Carrilho FJ, Cancado EL. Urinary copper excretion before and after oral intake of d-penicillamine in parents of patients with Wilson's disease. Dig Liver Dis. 2012;44:323-7.

151. Vrabelova S, Letocha O, Borsky M, Kozak L. Mutation analysis of the ATP7B gene and genotype/phenotype correlation in 227 patients with Wilson disease. Mol Genet Metab. 2005;86:277-85.

152. Walshe JM. Cause of death in Wilson disease. Mov Disord. 2007;22:2216-20.

153. Walshe JM. Diagnostic significance of reduced serum caeruloplasmin concentration in neurological disease. Mov Disord. 2005;20:1658-61. 
154. Walshe JM, Cox DW. Effect of treatment of Wilson's disease on natural history of haemochromatosis. Lancet. 1998;352:112-3.

155. Walshe JM, Waldestron E, Sams V, Nordlinder H, Westermark K. Abdominal malignancies in patients with Wilson's disease. $Q \mathrm{~J}$ Med 2003; 96:657-662.

156. Walshe JM; Clinical Investigations Standing Committee of the Association of Clinical Biochemists. Wilson's disease: the importance of measuring serum caeruloplasmin nonimmunologically. Ann Clin Biochem. 2003;40:115-21.

157. Walshe JM. History of Wilson's disease: 1912 to 2000. Mov Disord. 2006;21:142-7.

158. Walshe JM. Management of penicillamine nephropathy in Wilson's disease: a new chelating agent. Lancet. 1969;2:1401-2.

159. Walshe JM. Penicillamine, a new oral therapy for Wilson's disease. Am J Med. 1956;21:487-95.

160. Walshe JM. Penicillamine neurotoxicity: an hypothesis. ISRN Neurol. 2011;2011:464572.

161. Walshe JM. The conquest of Wilson's disease. Brain. 2009 ;132:2289-95.

162. Walshe JM. Treatment of Wilson's disease: the historical background. QJM. 1996;89:553-5.

163. Walshe JM. Treatment of Wilson's disease with trientine (triethylene tetramine) dihydrochloride. Lancet. 1982;1:643-7. 
164. Wang LH, Huang YQ, Shang X, Su QX, Xiong F, Yu QY, Lin HP, Wei ZS, Hong MF, Xu XM. Mutation analysis of 73 southern Chinese Wilson's disease patients: identification of 10 novel mutations and its clinical correlation. J Hum Genet. 2011;56:660-5.

165. Weiss KH, Gotthardt DN, Klemm D, Merle U, Ferenci-Foerster D, Schaefer M, Ferenci P, Stremmel W. Zinc monotherapy is not as effective as chelating agents in treatment of Wilson disease. Gastroenterology. 2011;140:1189-1198.

166. Weiss KH, Wurz J, Gotthardt D, Merle U, Stremmel W, Füllekrug J. Localization of the Wilson disease protein in murine intestine. $J$ Anat. 2008;213:232-40.

167. Werlin SL, Grand RJ, Perman JA, Watkins JB. Diagnostic dilemmas of Wilson's disease: diagnosis and treatment. Pediatrics. 1978;62:47-51.

168. Willis MS, Monaghan SA, Miller ML, McKenna RW, Perkins WD, Levinson BS, Bhushan V, Kroft SH. Zinc-induced copper deficiency: a report of three cases initially recognized on bone marrow examination. Am J Clin Pathol. 2005;123:125-31.

169. Wilson, SAK. Progressive lenticular degeneration: a familial nervous disease associated with cirrhosis of the liver. Brain. 1912;34:295-504.

170. Wu ZY, Wang N, Lin MT, Fang L, Murong SX, Yu L. Mutation analysis and the correlation between genotype and phenotype of 
Arg778Leu mutation in chinese patients with Wilson disease. Arch Neurol. 2001;58:971-6.

171. Yamaguchi Y, Heiny ME, Gitlin JD. Isolation and characterization of a human liver cDNA as a candidate gene for Wilson disease. Biochem Biophys Res Commun. 1993;197:271-7.

172. Yamamoto H, Hirose K, Hayasaki Y, Masuda M, Kazusaka A, Fujita S. Mechanism of enhanced lipid peroxidation in the liver of Long-Evans cinnamon (LEC) rats. Arch Toxicol. 1999;73:457-64.

173. Yener S, Akarsu M, Karacanci C, Sengul B, Topalak O, Biberoglu $\mathrm{K}$, Akpinar $\mathrm{H}$. Wilson's disease with coexisting autoimmune hepatitis. J Gastroenterol Hepatol. 2004;19:114-6.

174. Zhu L, Ji XJ, Wang HD, Pan H, Chen M, Lu TJ. Zinc neurotoxicity to hippocampal neurons in vitro induces ubiquitin conjugation that requires p38 activation. Brain Res. 2012;1438:1-7.

175. Zhuang $\mathrm{XH}$, Mo $\mathrm{Y}$, Jiang $\mathrm{XY}$, Chen SM. Analysis of renal impairment in children with Wilson's disease. World $J$ Pediatr. $2008 ; 4: 102-5$. 